UNIVERSIDADE DE SÃO PAULO

FACULDADE DE MEDICINA DE RIBEIRÃO PRETO

DAVID DA ROCHA LUCENA

Estudo comparativo da vitrectomia posterior via pars plana associada à cirurgia de facoemulsificação, imediata ou postergada, para tratamento de membrana epirretiniana e buraco macular - Análise das alterações do segmento anterior 


\title{
Estudo comparativo da vitrectomia posterior via pars plana associada à cirurgia de facoemulsificação, imediata ou postergada, para tratamento de membrana epirretiniana e buraco macular - Análise das alterações do segmento anterior
}

\author{
Versão Corrigida \\ Versão original encontra-se na unidade que aloja o Programa de Pós-Graduação
}

Tese apresentada à Faculdade de Medicina de Ribeirão Preto da Universidade de São Paulo para obtenção do Título de Doutor em Ciências.

Área de Concentração: Mecanismos Fisiopatológicos dos Sistemas Visual e ÁudioVestibular.

Orientador: Prof. Dr. Rodrigo Jorge 
AUTORIZO A REPRODUÇÃO E DIVULGAÇÃO TOTAL OU PARCIAL DESTE TRABALHO, POR QUALQUER MEIO CONVENCIONAL OU ELETRÔNICO, PARA FINS DE ESTUDO E PESQUISA, DESDE QUE CITADA A FONTE.

FICHA CATALOGRÁFICA

Lucena, David da Rocha

Estudo comparativo da vitrectomia posterior via pars plana associada à cirurgia de facoemulsificação, imediata ou postergada, para tratamento de membrana epirretiniana e buraco macular - Análise das alterações do segmento anterior. / David da Rocha Lucena; Orientador, Rodrigo Jorge. Ribeirão Preto. - 2020.

160p.: 39il.; $30 \mathrm{~cm}$

Tese (Doutorado) - Programa de Oftalmologia, Otorrinolaringologia e Cirurgia de Cabeça e Pescoço. Área de Concentração: Mecanismos Fisiopatológicos dos Sistemas Visual e Áudio-Vestibular. Faculdade de Medicina de Ribeirão Preto da Universidade de São Paulo, Ribeirão Preto, 2020.

1. Endotélio corneano. 2. Cirurgia de catarata. 3. Vitrectomia via pars plana. 4. Facoemulsificação. 5. Densidade de células endoteliais. 6. Espessura corneana. 


\section{FOLHA DE APROVAÇÃO}

Aluno: David da Rocha Lucena

Título: Estudo comparativo da vitrectomia posterior via pars plana associada à cirurgia de facoemulsificação, imediata ou postergada, para tratamento de membrana epirretiniana e buraco macular - Análise das alterações do segmento anterior.

Tese apresentada à Faculdade de Medicina de Ribeirão Preto da Universidade de São Paulo para obtenção do Título de Doutor em Ciências.

Área de Concentração: Mecanismos Fisiopatológicos dos Sistemas Visual e ÁudioVestibular.

Aprovado em:

Prof. Dr.

Instituição:

Assinatura:

Prof. Dr.

Instituição:

Assinatura:

Prof. Dr.

Instituição:

Assinatura:

Prof. Dr.

Instituição:

Assinatura: 


\section{Dedicatóría}

AOS MEUS PAIS,

José Lucena (in memorian), que será eternamente minha fonte inspiradora e o maior modelo para minha vida; e Euridice, por sua serenidade, compreensão e incontestável força interior. Vocês são os mais belos exemplos de pais que um fitho poderia ter.

À MINHA ESPOSA,

Socorro, constante companheira, colega e estimuladora, a quem Deus me dew a graça de encontrar e com quem pretendo estar todos os dias de minha vida.

Todo $\sigma$ esforço envolvido neste estudo representa, também, $\sigma$ sew esforço para que eu conchisse mew objetivo.

AOS MEUS FILHOS,

David Fitho e Sarah, que trazem tanta luz e gosto para minha vida.

Agradeço a Deus por ter me abençoado com vocês.

AOS MEUS IRMÃOS,

Pelo incentivo e pelos bons exemplos que me passam, valorizando a educação como necessidade de vida. Profissionais exemplares e amigos constantes, pelos quais cultivo grande admiração.

Muito Obrigado! 


\section{Agradecimentos}

A Deus, por conceder-me a vida e os elementos (dons, oportunidades e saíde) necessários para alcançar mais este estágio.

Ao Prof Dr. André Márcio Vieira Messias, pela fundamental colaboração no tratamento estatistico dos dados.

Ao mew irmão Daniel, por suas orientações, ricas sugestões e permanente solicitude, que muito me ajudaram na fase final da tese, dosando as criticas com comentários de incentivo.

Ao Centro Avançado de Retina e Catarata, especialmente meus funcionários Cleilson e Tamara, pelo apoí eficiente e por entenderem e contornarem da melhor forma possivel minhas eventuais ausências nas atividades do consultório.

Ao men sobrinho Moisés, que me recebeu com carinho e amizade durante minhas constantes viagens para Ríbeirão Preto.

À Maria Cecília Onofre, por sua prestimosa e indispensável ajuda durante toda a pós-graduação e por sua zelosa atenção para que eu não perdesse os prazos. 


\section{Agradecimento Especial}

Ao Professor Doutor Rodrigo Jorge por ter sido, além de orientador seguro e eficiente, mestre e amigo em todos os momentos que necessiter.

Com oprofessor Rodrigo aprendi, entre outras coisas, que onde existe a vontade, existem os meios. Obrigado pelo constante estimulo e apoio durante todas as fases deste trabatho e na minha vida profissional. 


\section{Apoio Financeiro}

Agradeço à CAPES (Coordenação de Aperfeiçoamento de Pessoal de Nível Superior) pelo apoio financeiro. 
LUCENA, D. R. Estudo comparativo da vitrectomia posterior via pars plana associada à cirurgia de facoemulsificação, imediata ou postergada, para tratamento de membrana epirretiniana e buraco macular - Análise das alterações do segmento anterior. 2020. 160f. Tese (Doutorado) - Faculdade de Medicina de Ribeirão Preto, Universidade de São Paulo. Ribeirão Preto. 2020.

Objetivo: Dois planejamentos cirúrgicos (vitrectomia posterior via pars plana -VPP associada ou não à facoemulsificação - Faco, imediata ou postergada) foram comparados neste estudo clínico prospectivo para avaliar as diferenças na preservação da integridade do segmento anterior do olho após a cirurgia de catarata por facoemulsificação. Casuística e Métodos: Oitenta e dois pacientes (84 olhos) com buraco macular ou membrana epirretiniana sintomáticos submetidos à VPP foram randomizados para a cirurgia associada à Faco em mesmo tempo cirúrgico (Grupo cirurgia combinada: VPP + Faco) $(n=42)$, ou em tempo cirúrgico diferente (Grupo cirurgia sequencial: VPP + Faco sequencial) $(n=42)$. Os pacientes se submeteram a avaliações oftalmológicas no pré-operatório e no $1^{\circ} \stackrel{\circ}{3} 3^{\circ}, 6^{\circ}$, $9^{\circ}$ e $12^{\circ}$ meses de pós-operatório. A avaliação incluiu a melhor acuidade visual corrigida (MAVC) pela tabela de ETDRS (Early Treatment Diabetic Retinopathy Study), biomicroscopia de segmento anterior e posterior, mapeamento de retina, microscopia especular, paquimetria corneana, Tomografia de Coerência Óptica (OCT) e microperimetria. O desfecho primário foi a avaliação comparativamente das alterações do segmento anterior ao final de 12 meses de acompanhamento entre os dois grupos. Os desfechos secundários incluíram a análise comparativa em relação a densidade de células endoteliais (DCE), obtido pelo microscópio especular, a espessura central da córnea (ECC), obtida pela paquimetria, e o coeficiente de variabilidade do tamanho das células endoteliais (CV), obtido pela microscopia especular; análise comparativa da MAVC entre os dois grupos ao final de 12 meses; análise comparativa com relação ao erro refratométrico final; avaliar a incidência de complicações cirúrgicas do segmento anterior e posterior do globo ocular (traumas de íris, sinéquias posteriores, rotura de cápsula posterior ou endoftalmite) em ambos os grupos; análise comparativa das variações da pressão intraocular entre os dois grupos e avaliar a ocorrência e progressão da catarata no grupo de cirurgia sequencial após 12 meses de seguimento. Os pacientes do grupo sequencial poderiam realizar a facoemulsificação até 12 meses após a vitrectomia, caso catarata significativa fosse detectada. Resultados: Setenta e oito pacientes (80 olhos) (40-Grupo cirurgia combinada e 40-Grupo cirurgia sequencial) completaram a visita de 12 meses. A média da DCE no pré-operatório e aos 12 meses foi de $2408.70 \pm 56,60$ e $2117.10 \pm 77.74$, respectivamente, no grupo combinado e $2472.85 \pm 56,60$ e $2105.67 \pm 77.74$, respectivamente, no grupo sequencial. Houve diminuição significativa na média da DCE em todas as visitas do estudo no grupo combinado $(p<0.05)$ e após seis meses no grupo sequencial $(p<0.05)$, sem diferença significativa entre os grupos em qualquer visita do estudo $(p=0,707)$. A média da paquimetria (ECC) no pré-operatório e aos 12 meses foi de $533.93 \pm 6.55$ e $533.3 \pm$ 6.51 , respectivamente, no grupo combinado e $530.2 \pm 6.55$ e $522.23 \pm 6.51$, respectivamente, no grupo sequencial. E a média do CV no pré-operatório foi de $36.1 \pm 1.49 \%$ no grupo combinado e $34.6 \pm 1.49 \%$ no grupo sequencial, e no mês 12 foi de $32.18 \pm 1.22 \%$ no grupo combinado e $31.1 \pm 1.22 \%$ no grupo sequencial. Não houve diferenças significativas na ECC e CV entre os grupos ao final de 12 
meses de seguimento. A média da acuidade visual ( \pm SEM LogMAR BCVA) foi de $0,92 \pm 0,04$ e $0,90 \pm 0,04$ no início e melhorou significativamente para 0,60 $\pm 0,05$ e $0,58 \pm 0,05$ no mês 12 ( $p<0,0001)$ nos grupos combinado e sequencial, respectivamente. Não houve diferença significativa entre os grupos na média de MAVC. Conclusões: O grupo VPP + facoemulsificação combinada apresentou taxas de redução de DCE, ECC e CV, valores de MAVC, equivalente esférico final, complicações no segmento anterior e variações da pressão intraocular em um ano semelhantes às do grupo VPP e Faco sequencial em pacientes com membrana epirretiniana e buraco macular.

Palavras-chave: Endotélio corneano. Cirurgia de catarata. Vitrectomia. Facoemulsificação. Acuidade visual. Densidade de células endoteliais. Espessura corneana. 
Abstract 
LUCENA, D. R. Combined pars plana vitrectomy and phacoemulsification versus pars plana vitrectomy and deferred phaco for phakic patients with epiretinal membrane or macular hole and no significant cataract at baseline Analysis of changes in the anterior segment: one-year outcomes - randomized trial. 2020. 160f. Tese (Doutorado) - Faculdade de Medicina de Ribeirão Preto, Universidade de São Paulo. Ribeirão Preto. 2020.

Purpose: Two surgical plans (pars plana vitrectomy associated with immediate or deferred phacoemulsification) were compared in this propective clinical study to assess differences in preserving the integrity of the anterior segment of the eye after cataract surgery by phacoemulsification. Casuistic and Methods: Eighty-two patients (84 eyes) with symptomatic macular hole or epiretinal membrane undergoing pars plana vitrectomy were randomized to surgery associated with phacoemulsification at the same surgical time (Combined surgery group: PPV + phaco) $(n=42)$ or in different surgical time (Deferred surgery group: PPV + deferred phaco) $(n=42)$. Patients underwent ophthalmological evaluations in the preoperative period and in the 1st, 3rd, 6th, 9th and 12th months after the vitrectomy. The evaluation included the best visual acuity corrected by the ETDRS table, anterior and posterior segment biomicroscopy, retinal mapping, specular microscopy, corneal pachymetry, Optical Coherence Tomography (OCT) and microperimetry. The primary endpoint was the endothelial cells density (ECD). Secondary outcomes included comparative analysis in relation to central corneal thickness (CCT), obtained by pachymetry, and the coefficient of variability in the size of endotelial cells (CV), obtained by specular microscopy; comparative analysis of the best corrected visual acuity (BCVA) between the two groups at the end of twelve months; comparative analysis with respect to the final refractometric error; to evaluate the incidence of surgical complications of the anterior and posterior segment of the eyeball (iris trauma, posterior synechiae, posterior capsule rupture or endophthalmitis) in both groups; comparative analysis of variations in intraocular pressure between the two groups and assess the occurrence and progression of cataracts in the deferred group after 12 months of follow-up. Deferred group patients could perform phacoemulsification up to 12 months after vitrectomy if significant cataracts were detected. Results: Seventy eight patients ( 80 eyes) (40 - combined surgery group and 40 - deferred surgery group) completed the 12-month follow up. The mean density of endotelial cells (ECD) in the preoperative period and at 12 months was $2408.70 \pm 56,60$ and $2117.10 \pm 77.74$, respectively, in the combined group and $2472.85 \pm 56,60$ and $2105.67 \pm 77.74$, respectively, in the deferred group. There was a significant decrease in the mean ECD at all study visits in the combined group $(p<0.05)$ and after 6 months in the sequential group $(p<0.05)$, with no significant difference between groups at any study visit $(p=0,707)$. The mean pachymetry (CCT) in the preoperative period and at 12 months was $533.93 \pm 6.55$ and $533.3 \pm 6.51$, respectively, in the combined group and $530.2 \pm 6.55$ and $522.23 \pm 6.51$, respectively, in the deferred group. And the mean CV in the preoperative period was $36.1 \pm 1.49 \%$ in the combined group and $34.6 \pm 1.49 \%$ in the sequential group, and at month 12 it was $32.18 \pm 1.22 \%$ in the combined group and $31.1 \pm 1.22 \%$ in the sequential group. There were no significant differences in CCT and CV between groups at the end of 12 months of follow-up. The mean visual acuity ( \pm SEM LogMAR BCVA) was $0.92 \pm 0.04$ and $0.90 \pm 0.04$ at the baseline and significantly improved to 
$0.60 \pm 0.05$ and $0.58 \pm 0.05$ at month $12(p<0.0001)$ in the combined and sequential groups, respectively. There was no significant difference between groups in the mean BCVA. Conclusions: The PPV + combined phacoemulsification group showed rates of reduction of ECD, CCT and CV, values of BCVA, final spherical equivalent, complications in the anterior segment and intraocular pressure variations in one year similar to those of the PPV and sequential phacoemulsification group in patients with epiretinal membrane and macular hole.

Key words: Corneal endothelium. Cataract surgery. Vitrectomy. Phacoemulsification. Visual acuity. Endothelial cell density. Corneal thickness. 
Lista de Figuras 
Figura 1 - Anatomia topográfica da região macular normal, criada a partir da retinografia de um olho contralateral de paciente do estudo. (A) Fóvea contendo a fovéola (a). (B) Parafóvea. (C) Perifóvea .....29

Figura 2 - Histologia da mácula normal: fóvea (A) contendo a fovéola (a); zona livre de capilares (cfz); umbo (u)

Figura 3 - Tomografia de coerência ótica mostrando uma AVM sem tração

Figura 4 - Tração vitreomacular focal com pseudocisto 38

Figura 5 - Exemplo de BM. Exame de retinografia de paciente do estudo

Figura 6 - Buraco macular em um exame de SD-OCT de paciente do estudo

Figura 7 - OCT mostrando a medida do índice de buraco macular de paciente do estudo.

Figura 8 - $\quad$ (A) Retinografia e (B) OCT de MER de paciente do estudo 48

Figura 9 - Comportamento da densidade endotelial e seus desvios padrão durante a vida

Figura 10 - $\quad$ O tamanho e a forma da imagem refletida da fonte de luz são modificados pela superfície refletora

Figura 11 - Fotografia de microscópio especular de não-contato mostrando a paquimetria

Figura 12 - Fotografia de microscópio especular de não-contato 57

Figura 13 - Córneas com densidade de células endoteliais e coeficentes de variação diferentes. (A) densidade de 1470 céls./mm, (B) densidade de 2625 céls $/ \mathrm{mm}$

Figura 14 - Diferentes coeficientes de variação com a mesma contagem celular

Figura 15 - Perfeito padrão hexagonal. (A) córnea com densidade de 1600 céls $/ \mathrm{mm}^{2}$. (B) córnea com densidade de 2500 céls $/ \mathrm{mm}^{2}$.... 59

Figura 16 - Diagrama do desenho do estudo ………...................................74

Figura 17 - Técnicas para analisar a densidade das células endoteliais. 78 
Figura 18 - Fotografia mostrando a obtenção das medidas da morfologia endotelial da córnea através do método central em um paciente do estudo

Figura 19 - Fotografia mostrando a análise da morfologia endotelial da córnea: DCE, CV, pleomorfismo e paquimetria em um paciente do estudo

Figura 20 - Registro fotográfico do cristalino com catarata em paciente do grupo sequencial

Figura 21 - Evolução da catarata em paciente de grupo sequencial.

Figura 22 - Distribuição das patologias nos grupos cirurgia combinada e cirurgia sequencial

Figura 23 - Graus de catarata nuclear dos pacientes nos grupos cirurgia combinada e cirurgia sequencial.

Figura 24 - Graus de catarata cortical dos pacientes nos grupos cirurgia combinada e cirurgia sequencial.

Figura 25: Médias e intervalo de confiança 95\% das medidas da densidade de células endoteliais no pré-operatório e durante o seguimento de 12 meses para os dois grupos.

Figura 26 - Médias e intervalo de confiança 95\% das medidas da paquimetria no pré-operatório e durante o seguimento de 12 meses para os dois grupos

Figura 27 - Médias e intervalo de confiança 95\% das medidas do coeficiente de variação do tamanho celular no pré-operatório e durante o seguimento de 12 meses para os dois grupos

Figura 28 - Distribuição comparativa da MAVC no pré-operatório entre os grupos nos pacientes com BM.

Figura 29 - Distribuição comparativa da MAVC no pré-operatório entre os grupos nos pacientes com MER

Figura 30 - Evolução da acuidade visual (em logMAR) após 12 meses da vitrectomia divididas pelas patologias BM e MER.

Figura 31 - Evolução da acuidade visual ao longo do tempo nos dois grupos. Os círculos representam as médias e as barras de erro mostram os intervalos de confiança de $95 \%$ das diferenças das acuidades visuais medidas durante o seguimento 
Figura 32 - Evolução da refração esférica nos grupos combinado e sequencial ao longo dos 12 meses do estudo. Houve diferença significativa da média da refração esférica entre os grupos nas visitas de um mês e três meses

Figura 33 - Evolução do astigmatismo nos grupos combinado e sequencial ao longo dos 12 meses do estudo. Não houve diferença na média do astigmatismo entre os grupos em nenhum dos períodos $(p>0.05)$

Figura 34 - Evolução do equivalente esférico nos grupos cirurgia combinada e cirurgia sequencial.

Figura 35- Distribuição comparativa do tempo de realização da facoemulsificação entre as duas patologias. A barra em negrito na caixa representa a mediana em meses, o tamanho da caixa representa a dispersão dos valores entre o primeiro e terceiro quartis (mostrando a maior concentração dos dados) e as barras periféricas representam os valores máximos e mínimos em meses

Figura 36 - Distribuição dos períodos, por trimestre, em que foi realizada a cirurgia de facoemulsificação no grupo cirurgia sequencial

Figura 37 - Os círculos representam as médias e as barras de erro os intervalos de confiança de $95 \%$ das diferenças das médias de pressão intraocular medidas durante o seguimento, menos a basal, para os dois grupos

Figura 38 - Distribuição comparativa da média de pressão intraocular entre os grupos nos pacientes portadores de BM 109

Figura 39 - Distribuição comparativa da média de pressão intraocular entre os grupos nos pacientes portadores de MER 
Tabela 1 - O Sistema Internacional de Classificação de Estudos da Adesão Vitreomacular, Tração Vitreomacular e Buraco Macular....

Tabela 2 - Classificação do BM por Gass …………….....................................45

Tabela 3 - Classificação do BM por Gaudric ...................................................... 45

Tabela 4 - Plano de avaliação e de exames.....................................................

Tabela 5 - Características dos pacientes no pré-operatório nos grupos cirurgia combinada e cirurgia sequencial .......................................... 86

Tabela 6 - Características anatômicas do buraco macular nos dois grupos ..........87

Tabela 7 - Características anatômicas da membrana epirretiniana nos dois grupos no pré-operatório e aos 12 meses.

Tabela 8 - Comparação da acuidade visual entre o pré operatório e os demais períodos em ambos os grupos

Tabela 9 - Média e erro padrão da refração esférica por grupo e patologia...........98

Tabela 10 - Média e erro padrão do astigmatismo por grupo e patologia .98

Tabela 11 - Teste de Wilcoxon para comparação do astigmatismo e refração esférica entre o pré-operatório e após 12 meses de ambos os grupos

Tabela 12 - Teste de Wilcoxon para comparação do astigmatismo e refração esférica entre o pré-operatório e após 12 meses dos pacientes de grupo cirurgia combinada

Tabela 13 - Teste de Wilcoxon para comparação do astigmatismo e refração esférica entre o pré-operatório e após 12 meses dos pacientes do grupo cirurgia sequencial

Tabela 14 - Teste de Wilcoxon para comparação da refração esférica esperada e após 12 meses no grupo cirurgia combinada....

Tabela 15- Teste de Wilcoxon para comparação do Refração esférica esperada e após 12 meses no grupo cirurgia sequencial .....

Tabela 16 - Teste Mann Whitney de comparação de médias do astigmatismo entre grupos

Tabela 17 - Teste Mann Whitney de comparação de médias da refração esférica entre grupos. 
Tabela 18 - Média e erro padrão do equivalente esférico por grupo e período .....103

Tabela 19 - Comparação da pressão intraocular entre o pré-operatório e os demais períodos em ambos os grupos avaliando somente os pacientes com BM

Tabela 20 - Comparação da pressão intraocular entre o pré-operatório e os demais períodos em ambos os grupos avaliando somente os pacientes com MER

Tabela 21 - Comparação da pressão intraocular entre o pré-operatório e os demais períodos em ambos os grupos 
Lista de Símbolos e Abreviaturas 
AOG- Avaliação Oftalmológica Geral

AV- $\quad$ Acuidade visual

AVM- Adesão vitreomacular

BM- Buraco Macular

CA- Câmara anterior

CEP- Comitê de Ética em Pesquisa

CV- $\quad$ Coeficiente de variabilidade

DCE- Densidade de células endoteliais

DMRI- Degeneração macular relacionada à idade

DVP- Descolamento do vítreo posterior

ECC- $\quad$ Espessura central da córnea

EMD- $\quad$ Edema macular diabético

EPR- $\quad$ Epitélio pigmentar da retina

ETDRS- $\quad$ Early Treatment Diabetic Retinopathy Study

Faco- $\quad$ Facoemulsificação

HCFMRP-USP- Hospital das clínicas da Faculdade de Medicina de Ribeirão Preto da Universidade de São Paulo

IVM- Interface vitreomacular

IVR- Interface vitreorretiniana

LIO- $\quad$ Lente intraocular

LOCS III- Lens Opacities Classification System

MAVC- Melhor Acuidade Visual Corrigida

MER- $\quad$ Membrana Epirretiniana

MLE- $\quad$ Membrana limitante externa

MLI- $\quad$ Membrana limitante interna 
OCT- Tomografia de Coerência Óptica

OPM- Órteses, próteses e materiais

PIO- $\quad$ Pressão intraocular

SD-OCT- $\quad$ OCT com tecnologia spectral domain

SS-OCT- $\quad$ OCT com tecnologia swept source

SUS- $\quad$ Sistema Único de Saúde

TCLE- $\quad$ Termo de Consentimento Livre e Esclarecido

TVM- Tração vitreomacular

VPP- Vitrectomia posterior via pars plana

VPP + Faco- $\quad$ Cirurgia combinada de vitrectomia e facoemulsificação 


\section{SUMÁRIO}

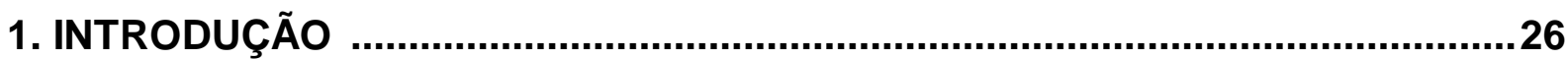

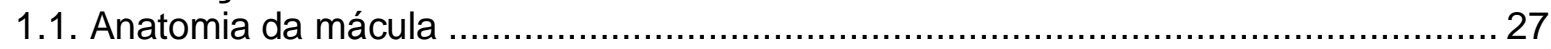

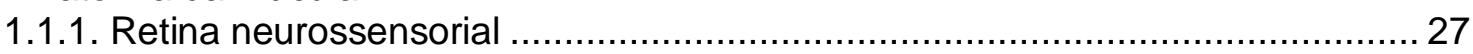

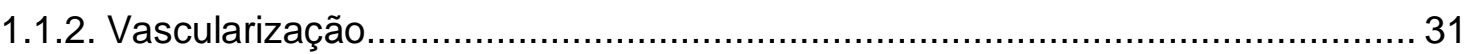

1.1.3. Epitélio pigmentar da retina e membrana de Bruch......................................... 32

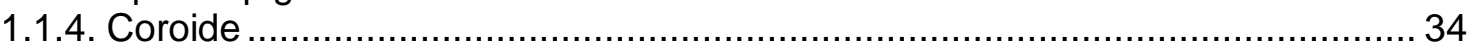

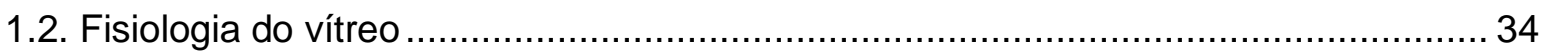

1.3. Adesão vitreomacular e tração vitreomacular....................................................... 36

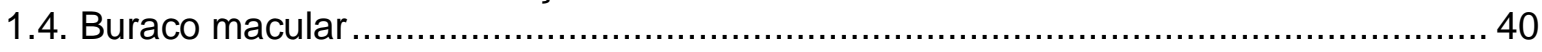

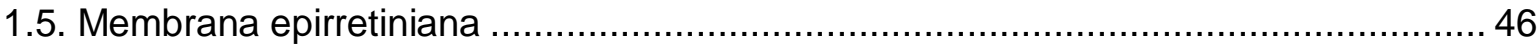

1.6. Anatomia da córnea e fisiologia do endotélio corneano........................................... 48

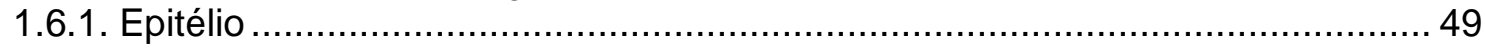

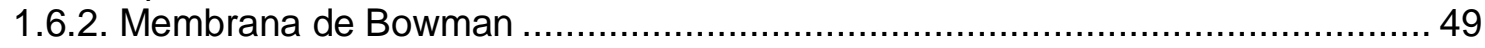

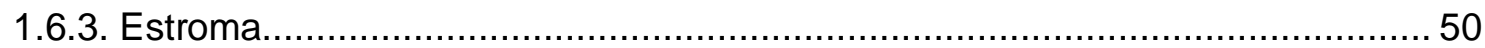

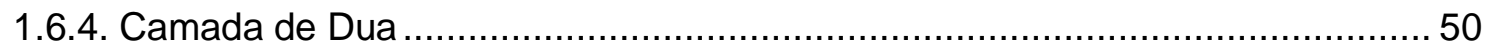

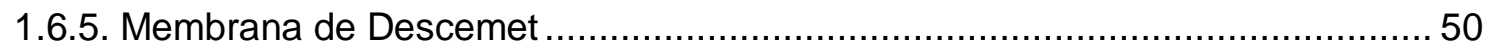

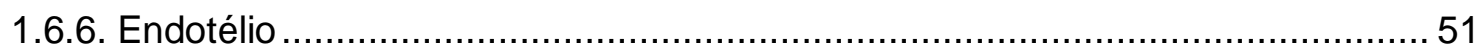

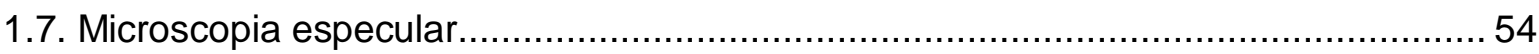

1.7.1 Importância da microscopia especular na análise de dano corneano ................60 60

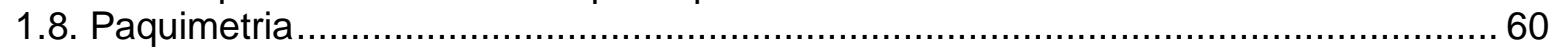

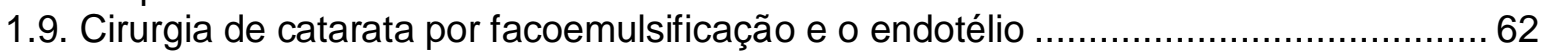

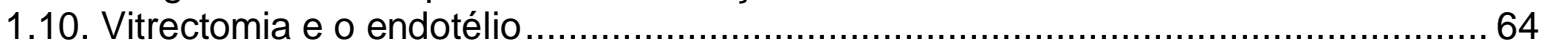

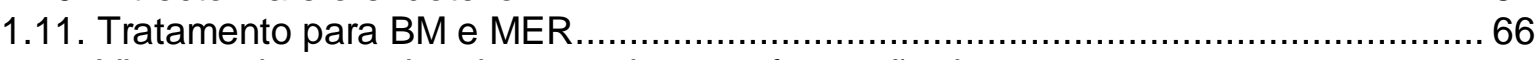

1.12. Vitrectomia posterior via pars plana e a formação de catarata ............................. 67

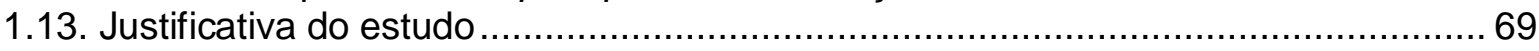

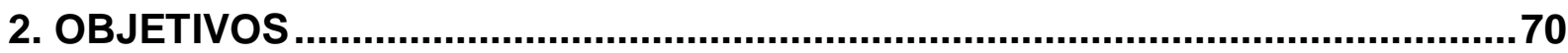

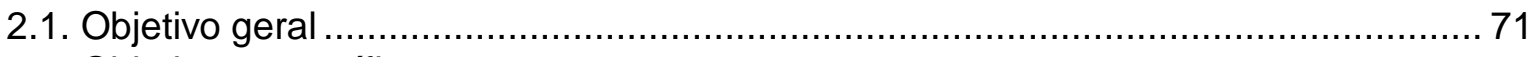

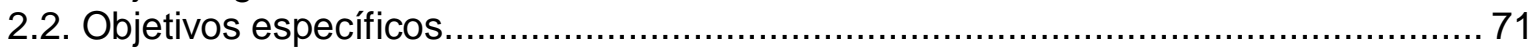

3. CASUÍSTICA E MÉTODOS ...........................................................................72

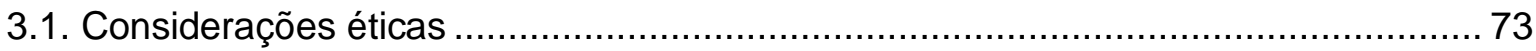

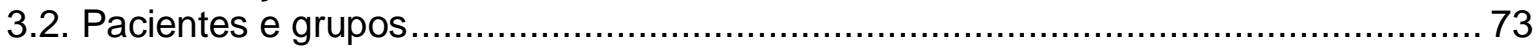

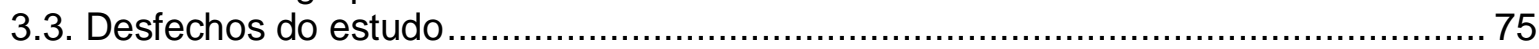

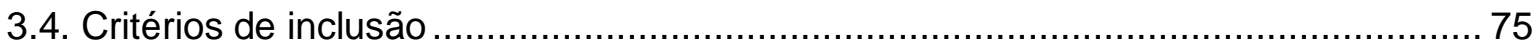

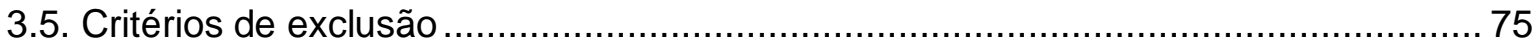

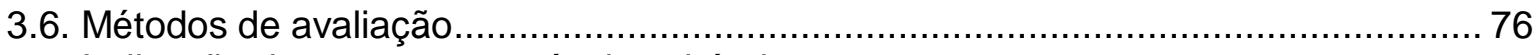

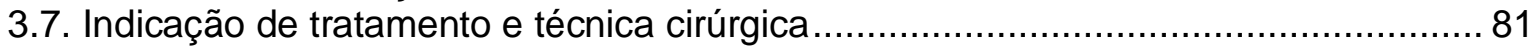

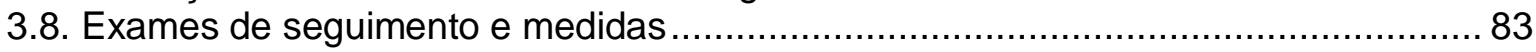

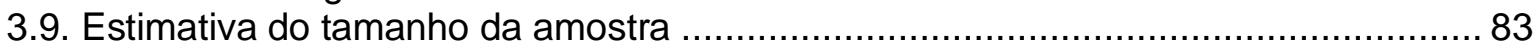

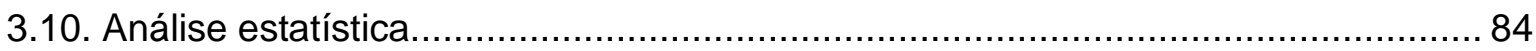

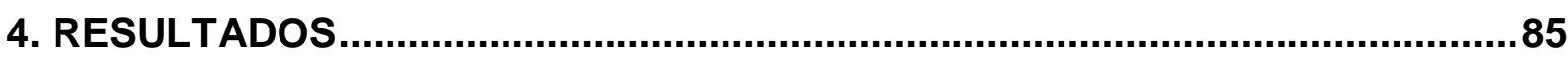

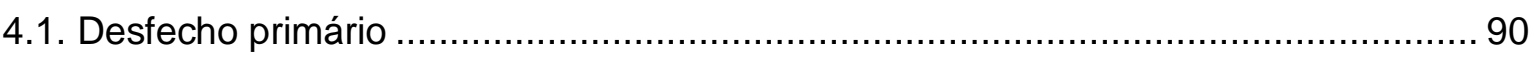

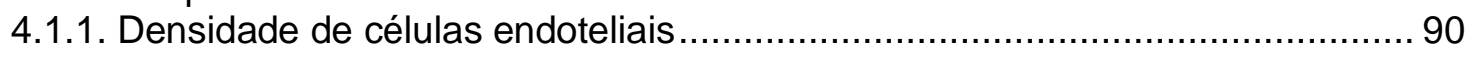

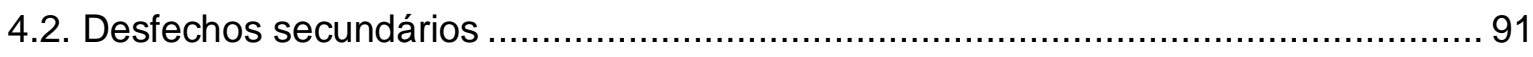

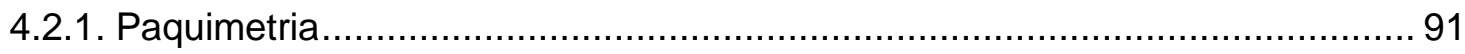

4.2.2. Coeficiente de variação do tamanho celular (CV) .................................... 92 
4.2.3. Melhor acuidade visual corrigida (MAVC) .................................................... 93

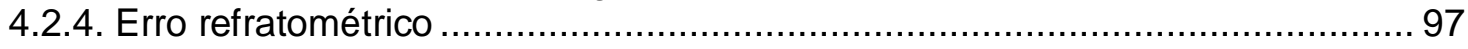

4.2.4.1. Refração esférica e astigmatismo ................................................. 97

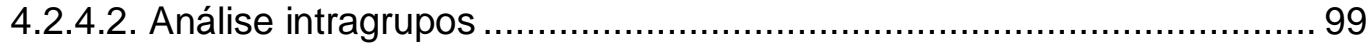

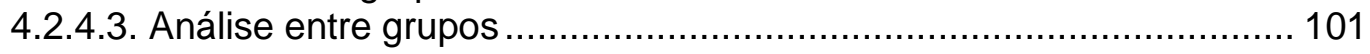

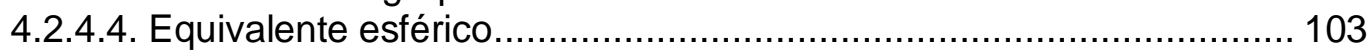

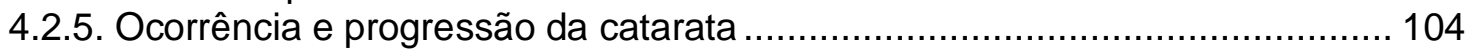

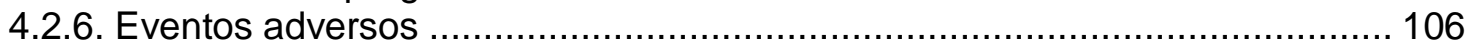

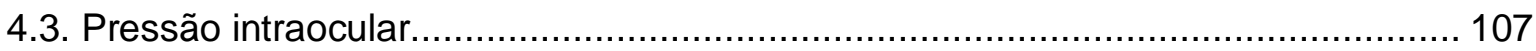

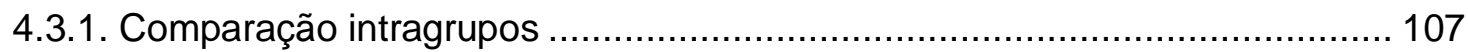

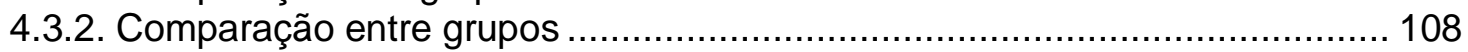

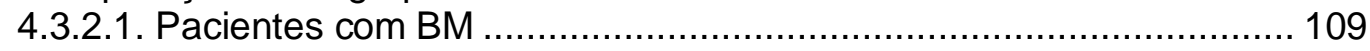

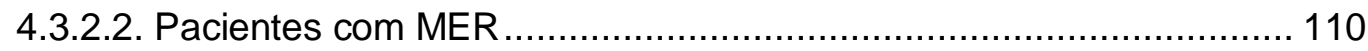

4.3.2.3. BM e MER ......................................................................... 112

5. DISCUSSÃO ...........................................................................................113

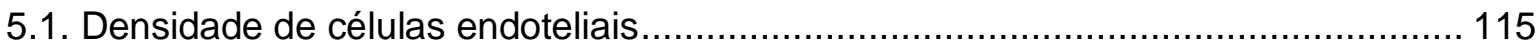

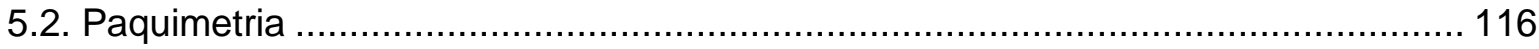

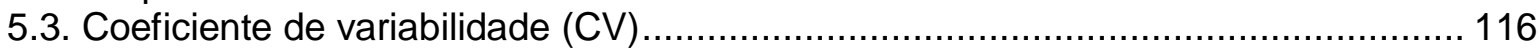

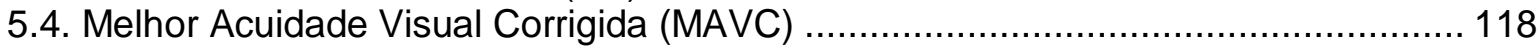

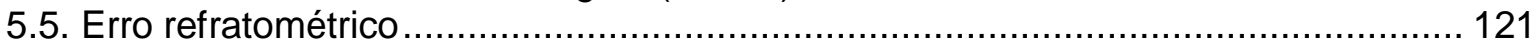

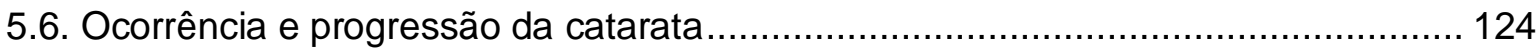

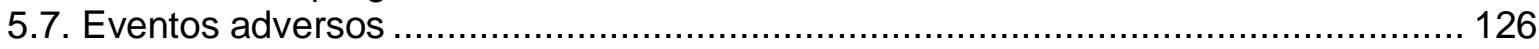

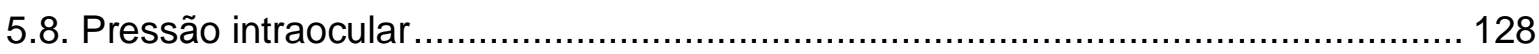

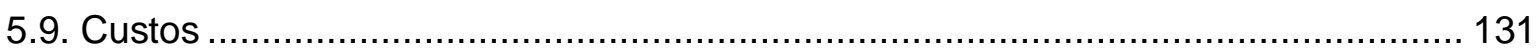

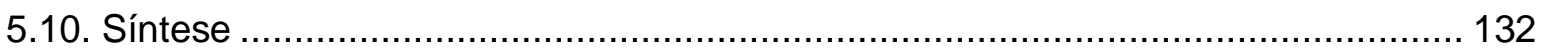

6. CONCLUSÕES .......................................................................................... 134

7. REFERÊNCIAS BIBLIOGRÁFICAS ............................................................. 137

8. ANEXO

9. APÊNDICE 
1- Introdução 
A vitrectomia via pars plana (VPP) é o procedimento de escolha para o tratamento de várias anormalidades do segmento posterior, como o buraco macular (BM) e a membrana epirretiniana (MER). A complicação mais comum da VPP é a catarata nuclear, relatada em $75 \%$ a $95 \%$ dos casos dentro de dois anos após a cirurgia. Idade, esclerose nuclear pré-existente e uso intraoperatório de óleo de silicone e gás são os fatores de risco para a formação de catarata. Muitos pacientes também apresentam diferentes graus de catarata antes da VPP (CHANG et al, 2002; THOMPSON et al, 1995).

A remoção do cristalino durante a vitrectomia é controversa. No entanto, a cirurgia de catarata após a VPP é tecnicamente mais difícil, devido à perda do suporte vítreo, maior profundidade da câmara anterior (CA), miose intraoperatória e fraqueza da cápsula posterior (BIRÓ, KOVACS, 2002). Além disso, a remoção do cristalino garante melhor visualização das estruturas vítreas anteriores e da retina. Portanto, a cirurgia combinada de vitrectomia e facoemulsificação (VPP + Faco) elimina o inconveniente de uma segunda cirurgia e reduz o tempo médio de recuperação (LAHEY; FRANCIS; KEARNEY, 2003). No entanto, em alguns estudos, foi relatada incidência aumentada de inflamação no pós-operatório e elevada taxa de opacificação da cápsula posterior do cristalino após a cirurgia combinada VPP + Faco (LEE et al., 2012). Mas, apesar disso e de muitos acreditarem que o cristalino fornecia uma barreira com efeitos protetores no segmento anterior e na retina, com a melhoria do instrumental cirúrgico e o uso da fotocoagulação a LASER intraoperatória os cirurgiões começaram a remover o cristalino em combinação com a VPP. Existem vários estudos sobre a segurança dessa técnica combinada no tratamento das doenças vitreorretinianas (CHUNG T. Y., CHUNG H., LEE, 2002; DEMETRIADES et al., 2003; DUGAS et al., 2010).

\subsection{Anatomia da Mácula}

\subsubsection{Retina neurossensorial}

A retina é uma estrutura organizada em camadas, composta por uma grande diversidade de células que formam, morfológica e funcionalmente, circuitos distintos 
que funcionam em paralelo e em combinação para produzir uma resposta visual complexa. Os mecanismos do desenvolvimento que estabelecem a estrutura e a função dos neurônios da retina hoje são cada vez mais compreendidos, em grande parte devido aos avanços na biologia molecular, métodos eletrofisiológicos e técnicas de imagem (HOON et al., 2014). A porção da retina, onde se desenvolvem o BM e a MER, é a mácula.

A mácula é reconhecida como a região especializada da retina responsável pela acuidade visual (AV) de alta resolução. Anatomicamente, pode ser definida como a parte central da retina posterior que contém o pigmento xantofila e duas ou mais camadas de células ganglionares (mácula lútea). Esta região mede cerca de $5,5 \mathrm{~mm}$ de diâmetro e está localizada aproximadamente a $4 \mathrm{~mm}$ temporal e 0,8 $\mathrm{mm}$ inferior ao centro do disco óptico. Corresponde, clinicamente, ao pólo posterior e é limitada pelas arcadas vasculares temporais superior e inferior (AGARWAL, 2012).

Com base na anatomia microscópica, a área macular pode ser subdividida em várias zonas. O que é clinicamente referido como mácula corresponde à fóvea anatômica. Esta é uma depressão na superfície interna da retina, no centro da mácula, mede aproximadamente $1,5 \mathrm{~mm}$, ou um diâmetro de disco, e é mais fortemente pigmentada do que o tecido retiniano circundante. A região central da fóvea é chamada de fovéola. A fovéola anatômica, frequentemente referida clinicamente como fóvea, mede aproximadamente $0,35 \mathrm{~mm}$ de diâmetro. Está dentro da zona foveal avascular, que mede aproximadamente $0,5 \mathrm{~mm}$ de diâmetro na maioria dos pacientes. Uma pequena depressão no centro da fovéola é chamada de umbo, onde a retina tem apenas $0,13 \mathrm{~mm}$ de espessura. Há ainda a área parafoveal, uma zona de anel com 0,5 mm de largura, onde a camada de células ganglionares, a camada nuclear interna e a camada plexiforme externa de Henle são as mais espessas, e a área perifoveal, uma zona de 1,5 $\mathrm{mm}$ que cerca a área parafoveal (Figura 1) (AGARWAL, 2012). 
Figura 1 - Anatomia topográfica da região macular normal, criada a partir da retinografia de um olho contralateral de paciente do estudo. (A) Fóvea contendo a fovéola (a). (B) Parafóvea. (C) Perifóvea

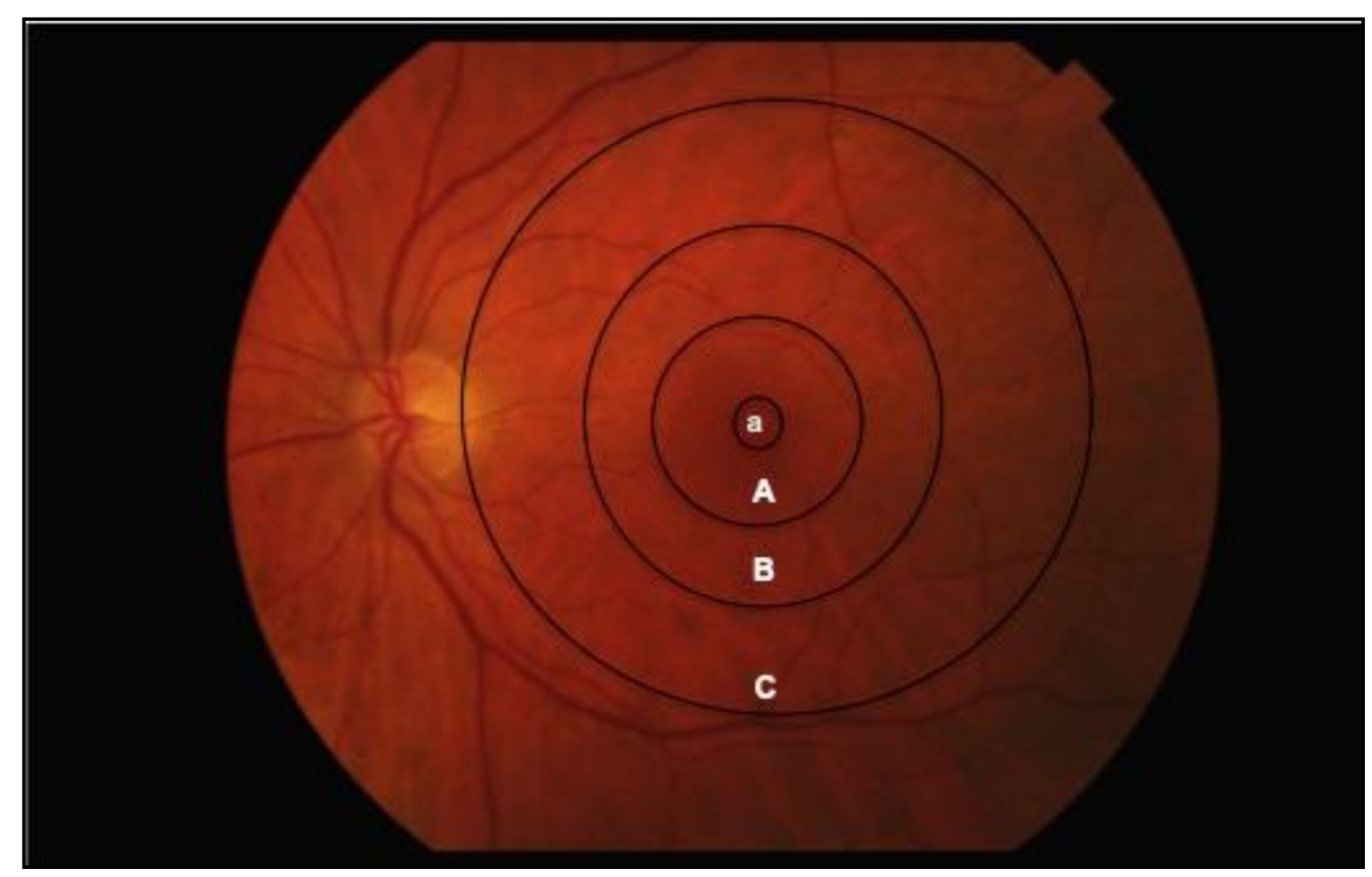

As subdivisões anatômicas da mácula são mal definidas oftalmoscopicamente. Tanto as margens da fovéola (de 0,35 mm de diâmetro) como as da fóvea (de 1,5 mm de diâmetro) são difíceis de definir. Uma zona mal definida de maior pigmentação (de um quarto a um diâmetro do disco) corresponde ao centro da mácula, que é máximo na área foveolar. O reflexo foveal está presente na maioria dos olhos normais e fica bem em frente ao centro da fovéola. É possível observar a depressão foveal com o feixe estreito da lâmpada de fenda (AGARWAL, 2012).

$A$ retina perde sua transparência normal poucas horas após a morte. $A$ xantofila é um pigmento amarelo composto por dois carotenoides (zeaxantina e luteína). É aparente no centro da mácula e altamente concentrada na área foveolar. A concentração máxima do pigmento xantofila está nas camadas nuclear e plexiforme externas. Entretanto, é possível encontrar a xantofila na camada plexiforme interna na área foveal. A maior concentração de pigmento está nos axônios dos cones centralmente (NUSSBAUM; PRUETT; DELORI, 1981). 
Na mácula, encontra-se a porção mais espessa da retina ao redor da porção mais fina, a área foveolar. No umbo, a retina neural consiste apenas na camada limitante interna (MLI), camada de fibras de Henle, camada nuclear externa, membrana limitante externa (MLE) e nos segmentos externo e interno dos fotorreceptores. A histologia neurorretiniana típica é estabelecida a partir da fovéola, sendo constituída, de interno para externo, por MLI, na camada de fibras nervosas, camada de células ganglionares, camada plexiforme interna (processos sinápticos entre células bipolares e células ganglionares), camada nuclear interna (núcleos das células bipolares, horizontais e amácrinas e células de Müller), camada plexiforme externa (processos sinápticos entre células bipolares e fotorreceptores), camada nuclear externa (núcleos dos bastonetes e cones), MLE (formada por junções celulares entre fotorreceptores e os processos ópticos terminais das células de Müller) e a camada de fotorreceptores (cones e bastonetes). As células bipolares, células ganglionares, fibras da camada plexiforme externa (camada de fibras de Henle) e células de Müller são deslocadas circunferencialmente e mostram uma orientação oblíqua na mácula que causa espessamento da zona marginal e afinamento central da retina, formando a fóvea (Figura 2) (BLANKS, 2001).

Figura 2 - Histologia da mácula normal: fóvea (A) contendo a fovéola (a); zona livre de capilares (cfz); umbo (u)

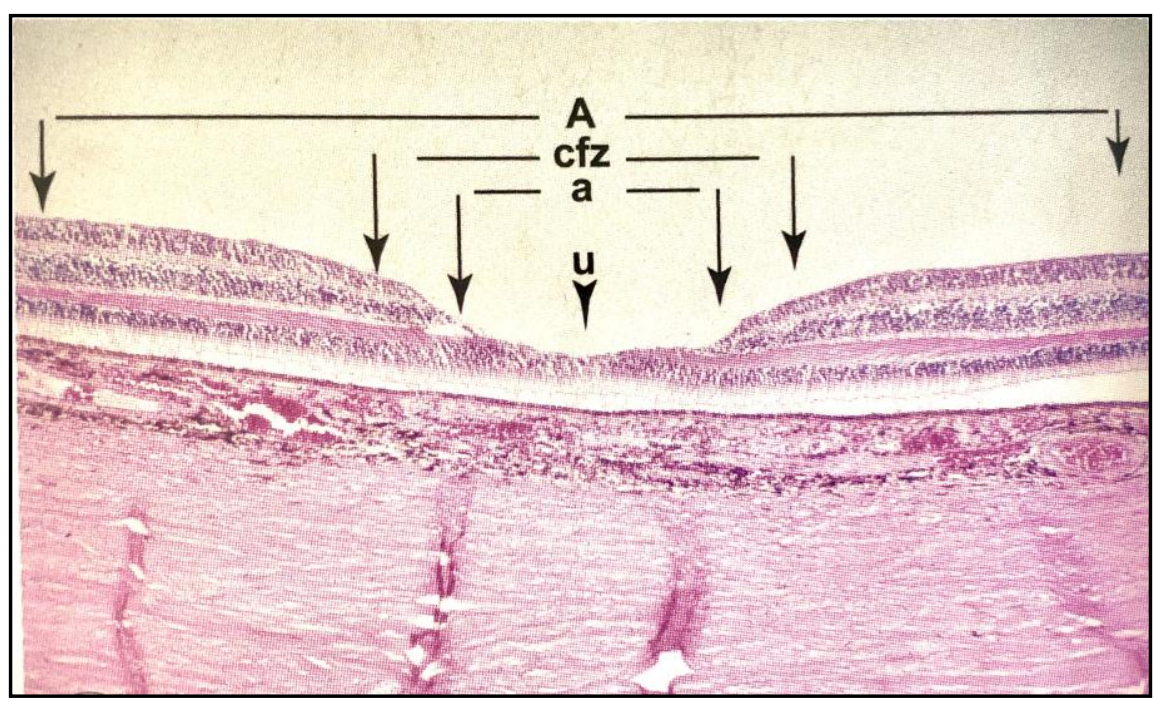

Fonte: (AGARWAL, 2012). 
As células de Müller são células gliais modificadas. Elas abrangem a região desde a MLI até a MLE e dão suporte aos elementos neurais da retina. A MLI consiste em uma membrana basal, que é uma modificação da superfície do corpo vítreo e dos processos vítreos expandidos das células de Müller. Essa membrana é relativamente espessa na região macular, exceto na área da fovéola, e serve como estrutura de ancoragem para a estrutura do colágeno do vítreo. A MLE é formada pelos complexos juncionais entre as membranas celulares das células de Müller e os segmentos internos dos fotorreceptores. As células de Müller são conectadas às células visuais por um sistema de barreira terminal. Esses complexos juncionais provavelmente fornecem pelo menos uma barreira parcial à passagem de grandes moléculas em qualquer direção (BLANKS, 2001).

A fovéola é composta inteiramente de cones onde os $100 \mu \mathrm{m}$ centrais contêm apenas cones vermelhos e verdes. O pico de densidade do cone foveal é, em média, de quase 200.000 por $\mathrm{mm}^{2}$ e cai rapidamente com o aumento da excentricidade, de modo que a densidade dos cones diminui quase 10 vezes a $1 \mathrm{~mm}$ do umbo. A densidade do cone azul é mais alta em uma zona entre 100 e $300 \mu \mathrm{m}$ do centro da fóvea. Os cones foveais assumem uma forma mais semelhante a uma haste; os cones azuis na mácula tendem a ter segmentos internos $10 \%$ mais altos e com forma mais cilíndrica do que seus pares vermelhos e verdes. Os bastonetes diferem dos cones, com seus segmentos externos constituídos por pilhas de discos de membrana achatados separados da membrana plasmática (BLANKS, 2001).

\subsubsection{Vascularização}

A artéria central da retina é responsável pelo suprimento sanguíneo da metade interna da retina. Geralmente, se divide em tronco superior e inferior na cabeça do nervo óptico. Esses troncos se dividem em um ramo nasal e um ramo temporal. Os ramos venosos correspondentes têm a mesma distribuição das artérias. Eles emitem ramos arteriolares e venulares que, posteriormente, correm em ângulo reto com o vaso parental, e se dividem de maneira dicotômica à medida que se dirigem para a periferia. Os ramos em ângulo reto são chamados de arteríolas e vênulas de primeira ordem. Uma ou mais artérias ciliorretinianas derivadas da 
circulação ciliar suprem a área papilomacular em aproximadamente $20 \%$ dos pacientes e, ocasionalmente, toda a mácula. O local de entrada das artérias ciliares posteriores curtas e longas pode ser visualizado após a remoção da coroide. As artérias ciliares posteriores curtas estão concentradas na área macular ao longo da margem temporal da fóvea e na área peripapilar. A artéria ciliar posterior longa temporal e o nervo ciliar entram cerca de um e meio diâmetros de disco temporal ao centro da fóvea. Não há circulação retiniana na fovéola (AGARWAL, 2012).

Os vasos sanguíneos da retina suprem sua metade interna. Os principais ramos do sistema arterial retiniano possuem a estrutura de pequenas artérias, persistindo até além do equador. As artérias da retina não possuem lâmina elástica interna; no entanto, eles têm um músculo bem desenvolvido (cinco a sete camadas de células musculares lisas posteriormente e uma ou duas camadas periféricas). Perto do disco óptico, as veias da retina têm de três a quatro camadas de células musculares lisas e, após uma curta distância, as células musculares são substituídas por fibroblastos. Há controvérsia sobre o padrão de distribuição da rede capilar na retina (arranjo difuso ou arranjo de duas ou três camadas). A rede superficial é predominantemente pós-arteriolar e a rede profunda é pré-venular. Existe uma rede capilar peripapilar radial distinta; essa rede se interconecta ricamente com a camada capilar interna da retina. As grandes arteríolas e vênulas da circulação da retina viajam na camada de fibras nervosas e na camada de células ganglionares. Perto da zona livre de capilares (0,4-0,5 mm de diâmetro), os capilares formam uma camada única, mas em outros lugares, os capilares estão presentes em duas ou mais camadas e se estendem para a camada nuclear interna. A zona livre de capilares é normalmente vascularizada durante o desenvolvimento pré-natal da retina e essa vascularização sofre obliteração capilar espontânea logo antes ou logo após o nascimento (HENKIND et al., 1975).

\subsubsection{Epitélio pigmentar da retina e membrana de Bruch}

O epitélio pigmentar da retina (EPR) é uma monocamada de células hexagonais densamente aderidas umas às outras por um sistema de junções celulares apertadas ou barras terminais que compõem a barreira externa 
hematoretiniana, a qual mantém o espaço sub-retiniano em um estado de deturgescência. Na fóvea, existem 30 cones por célula do EPR, enquanto na periferia são 22 bastonetes por célula do EPR. A interdigitação das células do EPR com os segmentos externos dos bastonetes e cones fornece apenas uma adesão tênue do EPR à retina sensorial. As células do EPR na região macular são mais altas e contêm quantidades aumentadas do pigmento melanina do que em outros lugares. Existe uma relação inversa entre a concentração de melanina e lipofuscina no EPR. A concentração de lipofuscina no EPR aumenta inicialmente durante as duas primeiras décadas de vida e depois novamente na sexta década e é significativamente maior em pessoas de pele clara do que escura, enquanto a concentração de melanina no epitélio pigmentar é semelhante em pessoas de pele clara e escura. O conteúdo de melanina do epitélio pigmentar e dos melanócitos da coroide diminui com a idade. Em indivíduos jovens e de meia idade, o EPR é firmemente aderido à membrana de Bruch subjacente por meio de sua própria membrana basal e essa adesão diminui com o avanço da idade. A membrana de Bruch consiste na membrana basal do EPR, a camada colágena interna, uma camada elástica, uma camada colágena externa e a membrana basal da coriocapilar. Devido à sua estrutura porosa, provavelmente desempenha um papel mínimo na regulação do movimento de substâncias através dela (AGARWAL, 2012).

O EPR é parte integrante do ciclo visual. É um componente importante da renovação de fotorreceptores; novos discos do segmento externo são adicionados continuamente proximalmente à base e os discos mais antigos na extremidade distal dos segmentos externos são fagocitados pelas células do EPR. Ele também transporta resíduos metabólicos da retina para a coriocapilar. A melanina dentro das células do EPR absorve a luz que não foi capturada pelos fotorreceptores, evitando assim sua dispersão excessiva no olho. A absorção de melanina também pode conferir proteção ao estresse foto-oxidativo. Pensa-se também que as células do EPR secretam fatores de crescimento essenciais para a diferenciação adequada de fotorreceptores durante o desenvolvimento (AGARWAL, 2012). 


\subsubsection{Coroide}

A coroide é a parte posterior do trato uveal; é suprida pelas artérias ciliares curtas, concentradas na mácula e na região peripapilar. Essas artérias formam uma rica rede anastomótica que esvazia rapidamente grandes quantidades de sangue na coriocapilar (rede sinusoidal). A coriocapilar é fenestrada e disposta em um padrão lobular, com uma arteríola de alimentação no centro de cada lóbulo e várias vênulas periféricas.

Na região macular há a maior taxa de fluxo sanguíneo de qualquer tecido do corpo. Possivelmente, funcione para estabilizar a temperatura ambiente da retina porque o fluxo sanguíneo excede em muito o necessário para atender às demandas nutricionais da retina. A coriocapilar supre o EPR e as camadas externas da retina e possui um endotélio com fenestrações de tamanho suficiente para permitir que algumas moléculas maiores, incluindo proteínas, escapem para o espaço extravascular. Não há canais linfáticos no olho; os espaços perivasculares e perineurais na esclera provavelmente funcionam como canais linfáticos. Assim, o endotélio da coriocapilar controla a quantidade de líquido extracelular normalmente presente na coroide (AREVALO; FERNANDEZ; MENDOZA, 2006).

\subsection{Fisiologia do vítreo}

O gel vítreo, uma estrutura clara e gelatinosa com volume de $4 \mathrm{ml}$ em adultos, é responsável pela estabilização do globo ocular; as fibras de colágeno (principalmente tipo II) correm em direção anteroposterior através do centro, misturase com a base vítrea anterior e insere-se no córtex vítreo posterior (LE GOFF; BISHOP, 2008; STEEL; LOTERY, 2013). Os espaços entre as fibrilas de colágeno são mantidos pela proteína opticina e o glicosaminoglicano associado à fibrila, sulfato 3,5 de condroitina. Esses espaços são preenchidos com água (que constitui mais de $98 \%$ do gel vítreo) e ácido hialurônico. O gel vítreo, portanto, é construído para resistir tanto às forças de tração como às compressivas. Recentemente, muito interesse tem sido demonstrado em uma característica comum do vítreo normal, conhecida como a bolsa vítrea precortical posterior. Isso foi descrito pela primeira 
vez por Worst (1977), e pode aparecer na tomografia de coerência óptica (OCT) como lacunas em forma de barco na região macular, com um fino córtex vítreo posterior, que é mais fino na fóvea. No entanto, sua exata função fisiológica é desconhecida.

O vítreo é ligado a todas as estruturas do olho interno, incluindo a MLI da retina. A interface entre o gel vítreo e a retina (interface vitreorretiniana - IVR) é uma estrutura complexa. As fibrilas de colagéno mais densamente agrupadas do córtex vítreo posterior (que tem 100 a $300 \mu \mathrm{m}$ de espessura) deitam-se sobre a mácula e são superficialmente inseridas na MLI da retina (SEBAG, 1992). Elas são ligadas por moléculas de adesão como laminina, fibronectina e proteoglicanos de heparan sulfato, que interagem com a opticina do gel vítreo. O vítreo é mais firmemente aderido à retina na base vítrea, disco óptico e fóvea e ao longo das grandes arcadas vasculares. A adesão na base vítrea é muito forte e geralmente é fixa, a menos que ocorra um traumatismo grave. De fato, essa adesão é tão intensa que, sob tais circunstâncias, o epitélio da pars plana também se destaca com a base vítrea. Por outro lado, é possível desfazer as adesões no disco óptico, fóvea e grandes vasos cirurgicamente na maioria dos casos, embora com maior dificuldade em pacientes mais jovens (STEEL; LOTERY, 2013).

O envelhecimento normal é acompanhado por uma série de mudanças fisiológicas no gel vítreo. Depois dos 40 anos, ele sofre liquefação progressiva, com fluido escapando pelos defeitos do córtex vítreo posterior, como o orifício no disco óptico, por exemplo. Isto resulta no desenvolvimento de bolsões cheios de líquido, que geralmente iniciam em frente à mácula, ampliando o bolsão vítreo pré-macular, mas também a cavidade vítrea central. Em torno da idade de 80 anos, cerca de $50 \%$ do gel vítreo torna-se liquefeito. Isto corresponde à diminuição simultânea do volume e agregação lateral das fibrilas de colágeno. Ao longo do tempo, os bolsões de líquido coalescem e aumentam de tamanho, ocorrendo também a destruição gradual da rede de colágeno-hialuronato, resultando em enfraquecimento da adesão vítreoretiniana (LE GOFF; BISHOP, 2008). Isto leva ao desenvolvimento da separação localizada superficial do gel vítreo da região perifoveal da retina, que progride ao longo do tempo. Finalmente, o colapso total das fibrilas de colágeno (sinérese) leva ao completo descolamento do vítreo posterior (DVP) de sua adesão à retina e o gel 
vítreo agora ocupa uma posição anterior na cavidade vítrea (SEBAG, 1987). Este processo ocorre ao longo de vários meses ou anos. Em muitos casos, o DVP é assintomático até que a separação vítrea do disco óptico ocorra. Os sintomas de DVP completo agudo incluem flashes luminosos e moscas volantes. Os flashes luminosos são causados pela tração vítrea sobre a retina periférica, enquanto as moscas volantes podem ocorrer devido à presença de sangue, condensações do colágeno do vítreo ou tecido glial arrancado do nervo óptico (anel de Weiss) (SEBAG, 1987).

Estudos em adultos saudáveis com olhos normais têm mostrado que o DVP perifoveal focal ocorre em cerca de $50 \%$ na faixa etária de 30 a 39 anos, enquanto o DVP completo é observado em $50 \%$ ou mais dos indivíduos com idade de 70 anos ou mais velhos. O DVP é significativamente mais comum em mulheres na pósmenopausa do que nos homens. Acredita-se que isso ocorra devido aos efeitos da diminuição da produção de estrogênio nos tecidos conjuntivos, tais como aqueles dentro do vítreo. A presença de miopia também está associada com risco três a quatro vezes maior de DVP, comparado com a população não míope (UCHINO; UEMURA; OHBA, 2001).

\subsection{Adesão vitreomacular e tração vitreomacular}

A separação inadequada ou incompleta da IVR pode resultar em DVP anômalo com o potencial de causar alterações patológicas subsequentes na interface vitreomacular (IVM). Nos casos em que a contração ou a liquefação do gel supera o desprendimento do córtex vítreo, uma aderência anormal desse córtex com a MLI estará presente e uma gama de condições anômalas maculares poderá resultar, variando de acordo com a força e a posição das aderências restantes. $O$ resultado disso é um DVP anômalo, que é definido como um descolamento parcial do vítreo com adesão persistente na região macular, caracterizando uma força anômala de adesão para uma ou mais estruturas no polo posterior, resultando em deformação tracional do tecido retiniano. As variações anatômicas oculares locais, como ocorrem na alta miopia, ou forças extrínsecas como traumatismo ou cirurgia 
intraocular podem também desempenhar um papel nesse processo (JOHNSON, 2010).

Tais aderências podem ser focais ou amplas, englobando apenas a fovéola, ou uma região mais ampla da área macular e do disco óptico. A adesão vitreomacular (AVM) simples (assintomática) não está associada à distorção estrutural da arquitetura macular (Figura 3). Entretanto, tais aderências podem exercer forças tracionais na mácula (tração vitreomacular- TVM), que aumentam durante os movimentos sacádicos, causando distorção e ruptura da retina (KOIZUMI et al., 2008). O aumento da largura da AVM está associado à menor força tracional e, portanto, à redução da deformação foveal. Por exemplo, as menores aderências na fóvea podem resultar em cavitação retiniana interna focal (cisto foveal) (Figura 4), enquanto adesões vitreorretinianas maiores $(\geq 1500 \mu \mathrm{m})$ podem levar ao achatamento do perfil foveal mais generalizado (ou seja, diminuição ou perda da depressão foveal) e descolamento (JOHNSON, 2010). A AVM e a TVM podem ser diferenciadas por sintomas clínicos (principalmente: perda visual, visão borrada e metamorfopsia) e pela OCT. No entanto, alguns casos de TVM podem não demonstrar efeitos deletérios óbvios sobre a visão (JOHNSON, 2005).

Uma metanálise estimou que a AVM (incluindo TVM) é encontrada em 23\% dos olhos de pacientes com degeneração macular relacionada à idade (DMRI) exsudativa (úmida) e, frequentemente, na área de adesão corresponde à área da neovascularização coroidal. A natureza dessa relação não é clara e seu significado etiológico incerto. Pode representar um fenômeno secundário, embora ainda exacerbe o curso da doença e a resposta ao tratamento (LEE, S. J.; LEE, C. S.; $\mathrm{KOH}, 2009$; SCHULZE et al., 2008). Da mesma forma, a relação entre TVM e edema macular diabético (EMD) também foi examinada. Na recente metanálise realizada por Jackson et al. (2013) estimou-se que TVM (e MER com tração) estivesse presente em 29\% dos casos de EMD agendados para cirurgia. Estudos individuais estimaram a prevalência de qualquer tipo de tração epimacular, incluindo MER, vitreosquise e TVM clássica ocorrendo, em geral, em 24-32\% dos olhos com EMD. Foi relatado que a presença de AVM assintomática aumenta o risco de EMD difuso em mais de três vezes quando comparada com pacientes diabéticos que demonstram DVP completo ou ligação vitreorretiniana completa. A AVM 
assintomática também está associada à probabilidade significativamente reduzida de resolução espontânea de EMD em relação aos pacientes cujos olhos demonstram DVP completo.

Figura 3 - Tomografia de coerência ótica mostrando uma AVM sem tração

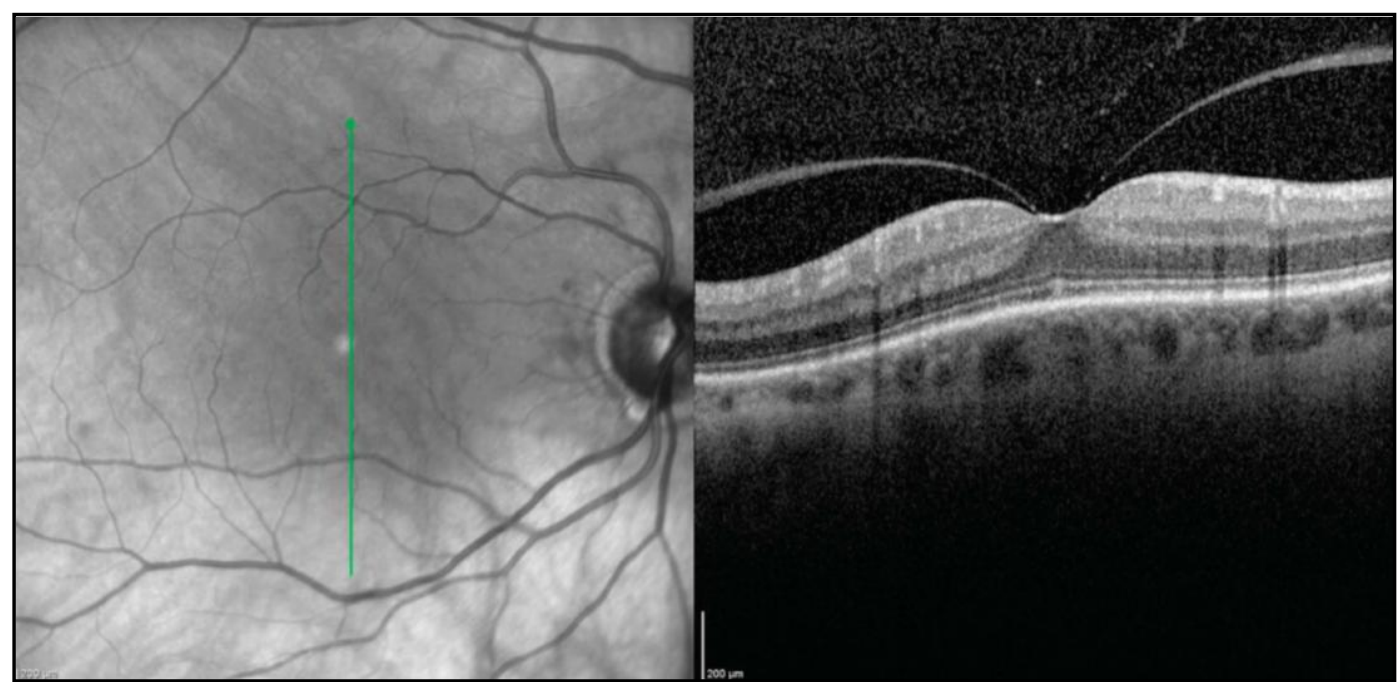

Fonte: (STEEL; LOTERY, 2013).

Figura 4 - Tração vitreomacular focal com pseudocisto

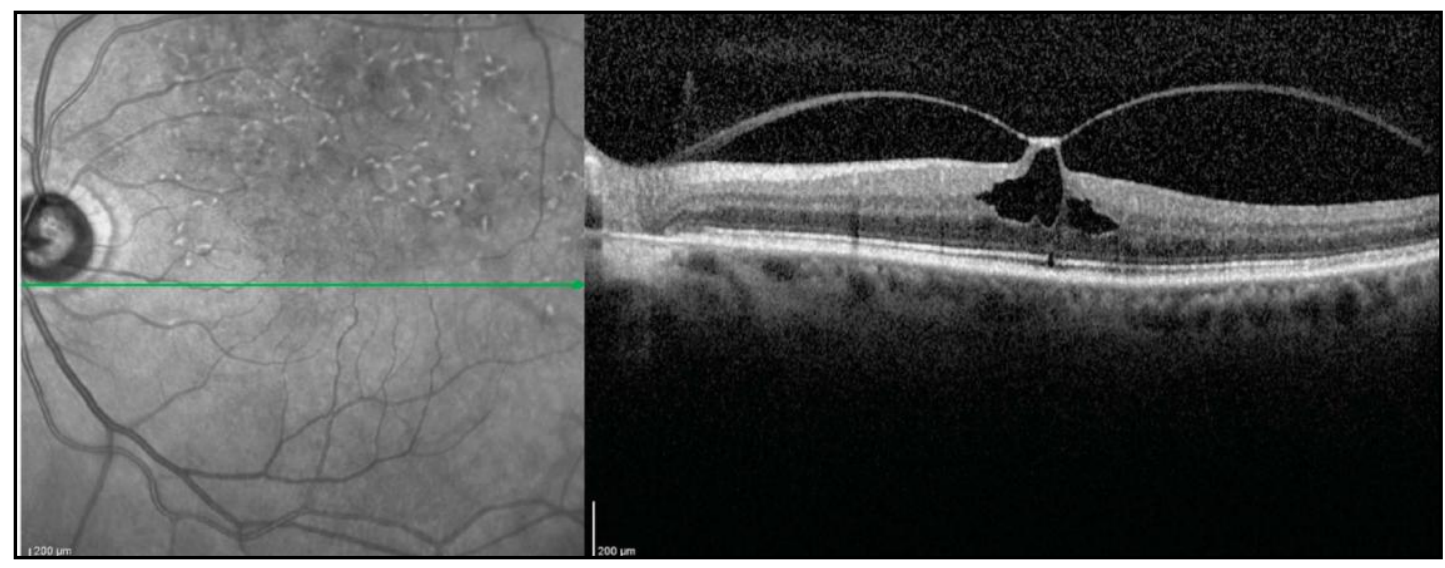

Fonte: (STEEL; LOTERY, 2013). 
Dado o conhecimento atual das potenciais complicações do DVP anômalo é necessário um esquema para classificar as configurações anatômicas anômalas do vítreo e seus efeitos sobre a mácula. Esta nova classificação anatômica das doenças da IVM baseada em OCT fornece uma nomenclatura consistente para uso clínico, tomada de decisão médica e cirúrgica, estudos futuros e comparações entre estudos (Tabela 1). A nova classificação é baseada em evidências atuais e está sujeita à adaptação à medida que mais conhecimento é adquirido (DUKER et al., 2013).

Tabela 1 - O Sistema Internacional de Classificação de Estudos da Adesão Vitreomacular, Tração Vitreomacular e Buraco Macular

\begin{tabular}{ll}
\hline \multicolumn{1}{c}{ CLASSIFICAÇÃO } & \multicolumn{1}{c}{ SUBCLASSIFICAÇÃO } \\
\hline Adesão vitreomacular & $\begin{array}{l}\text { Tamanho: focal }(\leq 1500 \mu \mathrm{m}) \text { ou largo }(>1500 \mu \mathrm{m}) \text { Isolado ou } \\
\text { concorrente }\end{array}$ \\
Tração vitreomacular (TVM) & $\begin{array}{l}\text { Tamanho: focal }(\leq 1500 \mu \mathrm{m}) \text { ou largo }(>1500 \mu \mathrm{m}) \text { Isolado ou } \\
\text { concorrente }\end{array}$ \\
& $\begin{array}{l}\text { Tamanho: pequeno }(\leq 250 \mu \mathrm{m}), \text { médio }(>250 \text { e } \leq 400 \mu \mathrm{m}) \text { ou } \\
\text { grande }(>400 \mu \mathrm{m})\end{array}$ \\
Buraco macular de espessura total & $\begin{array}{l}\text { Status do vítreo: com ou sem TVM } \\
\text { Causa: primária ou secundária }\end{array}$ \\
\hline
\end{tabular}

Como mostrado na Tabela 1, a AVM e a TVM podem ser subclassificadas em focal ou ampla, dependendo da largura da fixação vítrea. Áreas amplas de adesão com tração podem causar espessamento generalizado da mácula, vazamento vascular na angiografia com fluoresceína, schisis macular e edema macular cistoide. As áreas focais de fixação do vítreo com tração tendem a distorcer a superfície foveal, elevar o assoalho foveal, formar pseudocistos na mácula central ou resultar em uma combinação dos mesmos. A presença de pseudocistos está, geralmente, associada à diminuição da $A V$ e distorção visual. Após a liberação da tração, os pseudocistos normalmente desaparecem com o tempo, com pouco déficit visual resultante (DUKER et al., 2013). 


\subsection{Buraco Macular}

O BM é uma patologia que ocorre predominantemente em idosos, com prevalência estimada em torno de 0,1 a $0,8 \%$ da população acima de 40 anos e incidência de 7,8 a 8,69 por 100000 da população geral por ano. Aproximadamente dois terços dos pacientes são mulheres e a condição é unilateral em torno de $80 \%$ dos casos (CHEW et al., 1999; McCANNEL et al., 2009; STEEL; LOTERY, 2013). Trata-se de uma abertura ou deiscência na fóvea e alguns pesquisadores acreditam que no BM há perda dos cones na região foveal (EZRA et al., 2001; TANNER et al., 2001), embora outros como Jensen e Larsen acreditem no deslocamento centrífugo dos cones no local do buraco (GASS, 1995; JENSEN; LARSEN, 1998).

Ainda com patogenia pouco esclarecida, sabe-se que a maioria dos BMs não tem causa bem determinada, sendo considerados idiopáticos, mas o BM pode ser secundário a trauma, descolamento agudo do vítreo posterior e inflamação ocular (AABERG; BLAIR; GASS, 1970). Porém, não há dúvidas da importância da TVM, tangencial ou anteroposterior na fisiopatogenia do $B M$, haja vista a baixa incidência deste em olhos com DVP completo (GASS, 1988, 1995; JOHNSON; GASS, 1988; LEWIS et al., 1996).

Vários fatores têm sido sugeridos como responsáveis por aumentar o risco de desenvolvimento do BM, como o fibrinogênio plasmático elevado, enquanto que em mulheres a terapia de reposição do estrógeno está associada com risco reduzido de BM. Em pacientes com alta miopia (-14 a -32 dioptrias), a prevalência de BM é elevada em relação à população geral (em torno de 6\%) (STEEL; LOTERY, 2013). Já o risco do desenvolvimento de BM no olho contralateral sem descolamento vítreo manifesto tem sido estimado por volta de 7 a $12 \%$ depois de cinco anos e 17\% em 10 anos (KUMAGAl et al., 2012).

O BM pode ocorrer concomitantemente com edema macular associado com uma variedade de doenças da retina, incluindo edema macular diabético, DMRI, oclusões vasculares da retina e uveíte. Alguns destes casos devem ser classificados como BMs primários se for demonstrado que a TVM desempenhou um papel em sua formação. Em um pequeno número de casos, o BM pode se desenvolver em um olho com edema macular sem TVM anterior ou simultânea. 
Também tem sido relatada a ocorrência de BM após determinados procedimentos cirúrgicos intraoculares, incluindo VPP para descolamento de retina e remoção do cristalino. Recentemente, observou-se que essa desestabilização da fóvea resultante de dano induzido por tração à fóvea interna, ocorrendo antes ou coincidente com a separação vitreofoveal espontânea, pode predispor à formação de BM em alguns olhos. Para os casos em que o vítreo obviamente foi removido antes da formação do BM, a designação de BM secundário é provavelmente mais precisa (STEEL; LOTERY, 2013).

À biomicroscopia de fundo de olho nota-se perda das camadas da retina na região foveal e os pacientes têm como principais queixas baixa AV central associada à metamorfopsia (distorção visual), micropsia (diminuição de objetos dentro do campo visual), mais raramente fotopsia (raios luminosos ou flashes) e visão turva, além de queixas inespecíficas como: diminuição da capacidade de leitura, limitação para a prática de atividade física e diminuição da interação social, bem como efeitos emocionais. A leitura de sinais de trânsito e a capacidade para dirigir à noite também podem ser afetadas. O impacto da doença na qualidade de vida do indivíduo é substancial (OKAMOTO et al., 2010; STEEL; LOTERY, 2013).

Existem várias tecnologias que permitem a visualização do vítreo e da retina que podem auxiliar na identificação e caracterização da TVM e/ou BM; elas permitem a diferenciação de outros distúrbios fundoscopicamente semelhantes, como retinopatia serosa central, drusa subfoveolar e maculopatia solar. A visibilização do fundo de olho deve incluir a retina periférica para excluir patologias como roturas na retina e lesões vasculares. Fotografia do fundo de olho e, em particular, imagens de "red-free" podem destacar a presença de MER associada à distorção vascular e também de MER com pseudo-BM. Fundoscopicamente, o BM pode exibir alguns ou todos os seguintes itens: depósitos amarelos finos, semelhantes a drusas, na base do buraco, manguito circundante de líquido subretiniano, margem circular distinta ao redor do buraco e opérculo (visto como uma pequena opacidade redonda suspensa dentro do gel vítreo sobre a fóvea) (Figura 5). Um DVP completo é caracterizado por um anel pré-papilar móvel de Weiss, associado a uma membrana hialoide posterior levemente visível e a um espaço subhialoide opticamente vazio. No entanto, o exame do fundo de olho não identifica o 
DVP raso localizado (isto é, assintomático) sem espessamento posterior do córtex vítreo e não pode detectar aderências translúcidas do gel vítreo na mácula (JOHNSON, 2010).

Figura 5 - Exemplo de BM. Exame de retinografia de paciente do estudo

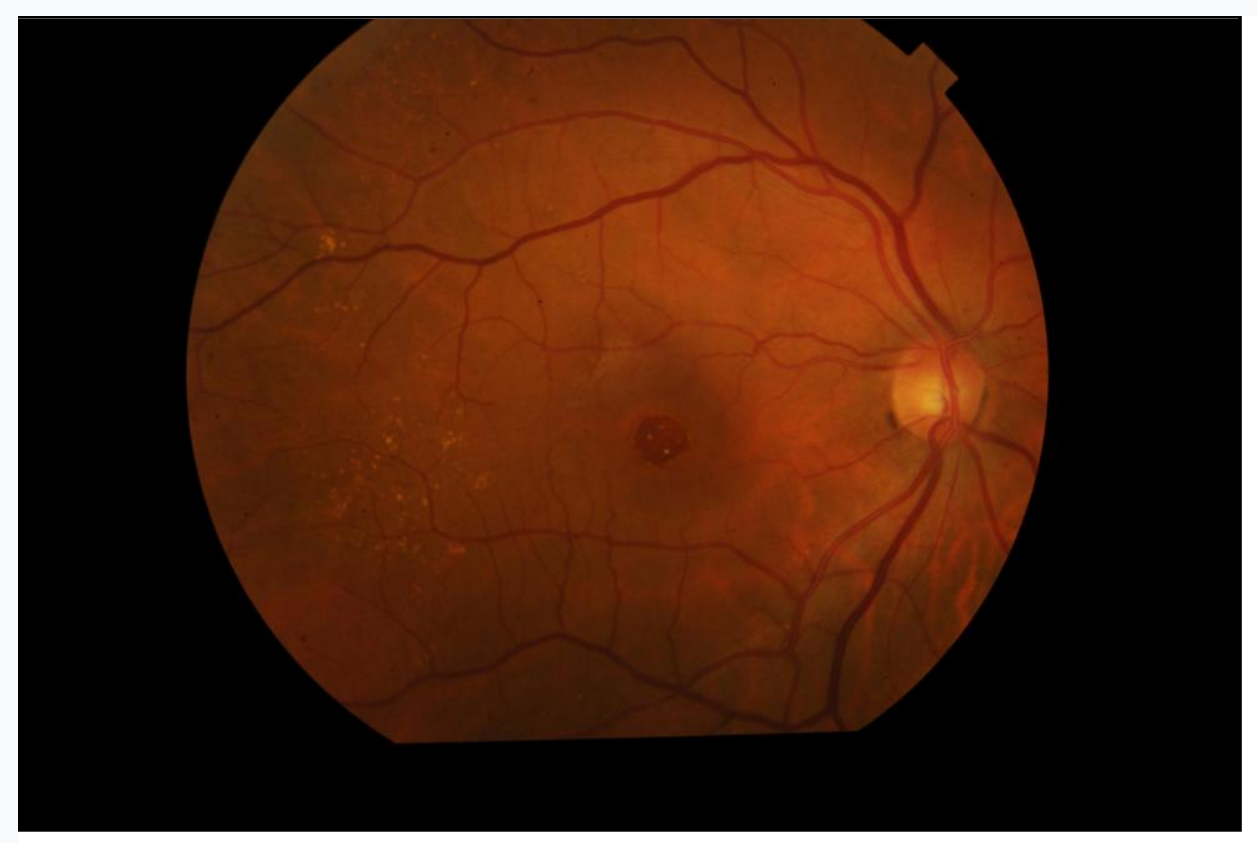

O ultrassom dinâmico de varredura B permite a visualização dos estágios iniciais do DVP e também a presença de um opérculo. Pode facilitar a diferenciação do BM do enrugamento macular idiopático causado por MER (que exibe caracteristicamente um anel completo de DVP e Weiss). No entanto, fornece imagens de resolução relativamente baixa em relação à OCT (TANNER et al., 2001).

A OCT continua sendo o método mais preciso para visualizar a IVR e identificar TVM e/ou BM. Nos últimos anos, a OCT com tecnologia spectral domain (SD-OCT) ou swept source (SS-OCT) tornou-se mais amplamente disponível, fornecendo imagens de mais alta resolução (resoluções axiais de pouco mais de 5 $\mathrm{mm}$ ) e reduzindo artefatos produzidos pelas partes móveis da OCT convencional. Essa tecnologia aprimorada pode, portanto, fornecer visualização detalhada da TVM 
e/ou MER, distorção da retina e descolamento macular. Isso inclui a quantificação precisa de aderências vítreas (horizontais e verticais) e a cavitação foveal em pacientes com TVM. A SD-OCT também pode discriminar pseudocistos secundários à TVM e edema macular cistoide (Figura 6) (KOIZUMI et al., 2008; STEEL; LOTERY, 2013).

Figura 6 - Buraco macular em um exame de SD-OCT de paciente do estudo

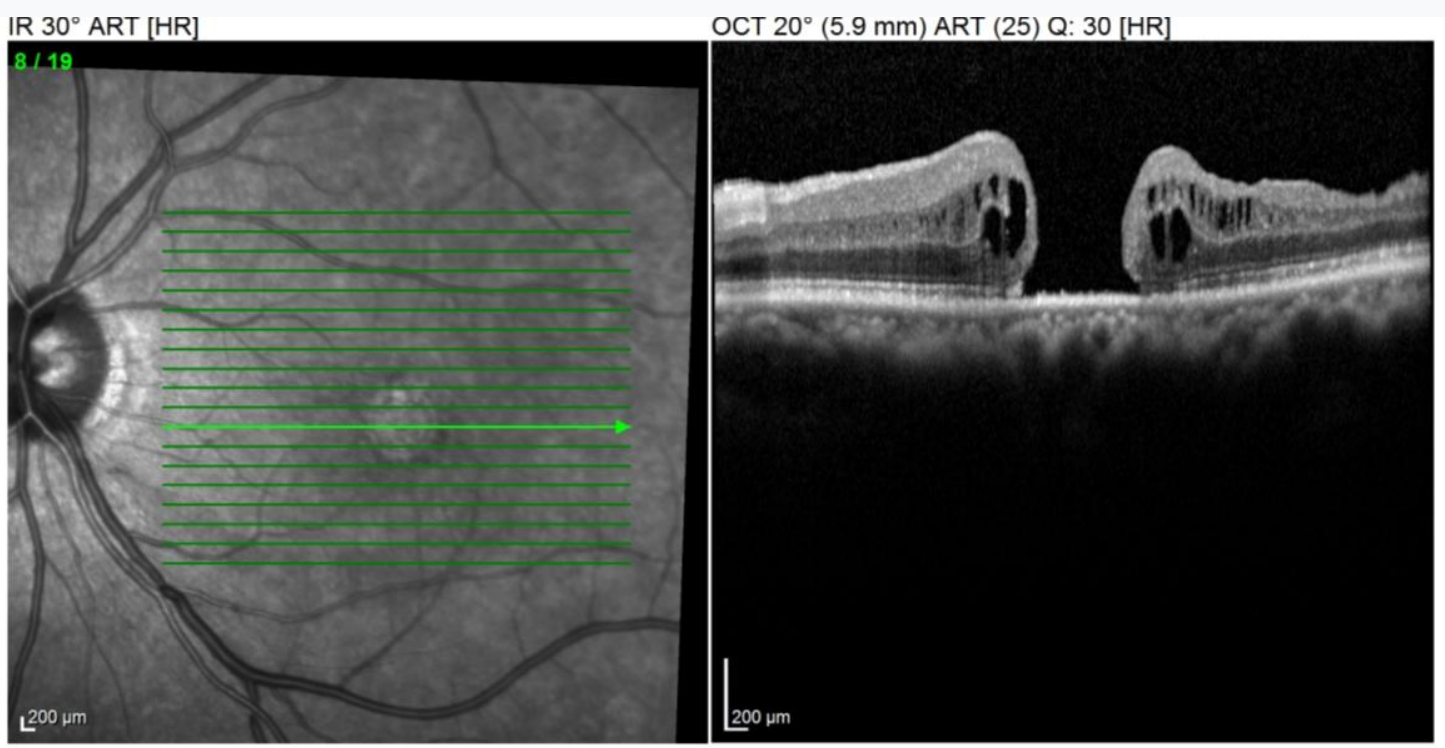

A SD-OCT, assim como a SS-OCT, permitiu um estadiamento mais preciso do BM idiopático. A visualização da anatomia foveal (incluindo cavitação intrarretiniana) pode identificar alterações indicando BMs iminentes, potencialmente permitindo a intervenção precoce. A SD-OCT também pode ser usada para medir com precisão várias características dos BMs, incluindo largura da base, diâmetro linear mínimo, altura e uma variedade de proporções de furos maculares, incluindo o índice de BM (Figura 7), bem como distinguir entre BM, pseudo-BM ou buraco lamelar. Uma consideração clínica importante é a escolha do protocolo de escaneamento usado especialmente na avaliação dos orifícios maculares - as verticais e horizontais com amplo espaçamento entre linhas podem perder áreas de fixação do vítreo focal ou defeitos da retina de espessura total ou subestimar o 
tamanho verdadeiro do BM. Usar o protocolo de espaçamento de linha mais baixo disponível ou varredura de padrão radial através da fóvea pode reduzir esse risco (DUKER et al., 2013).

Figura 7 - OCT mostrando a medida do índice de buraco macular de paciente do estudo

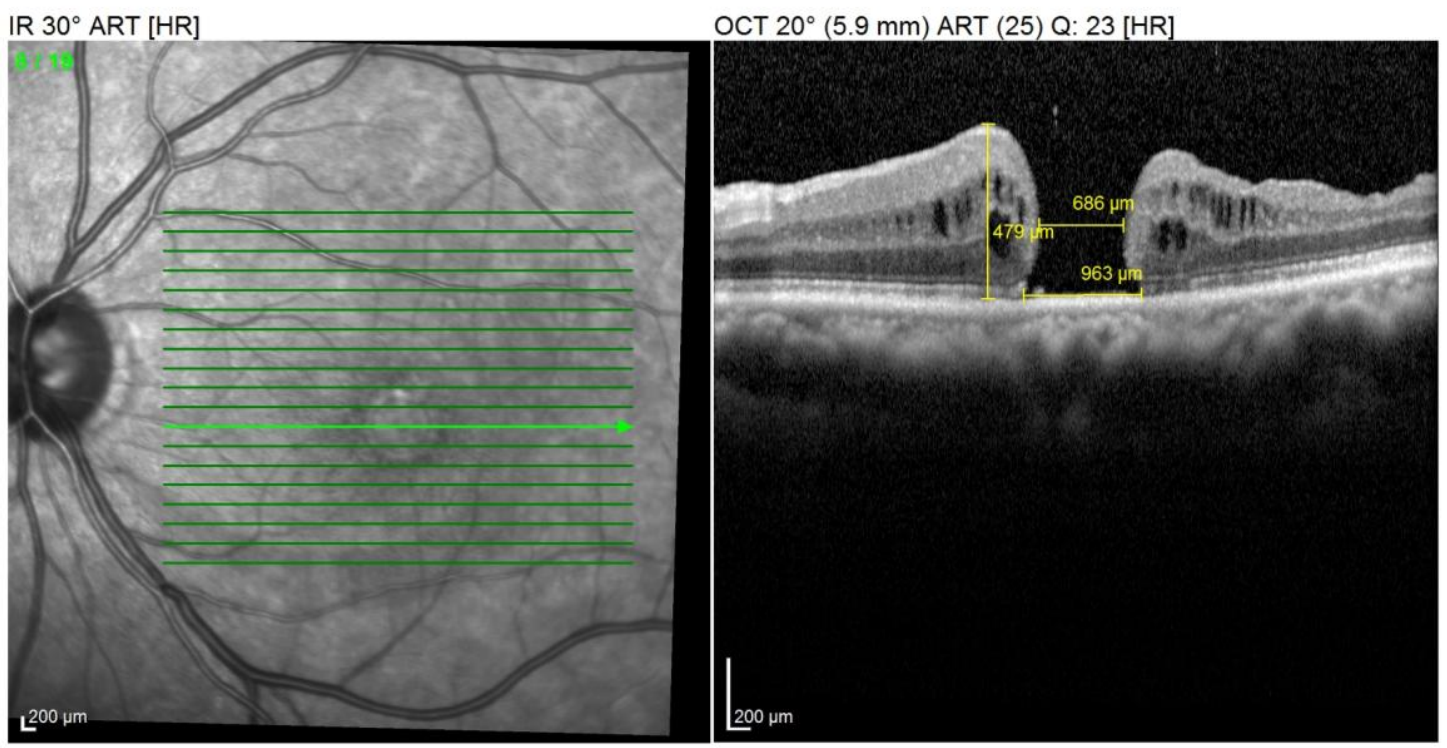

Tanto na TVM quanto no BM, a SD-OCT permite acompanhamento e monitoramento precisos dos pacientes submetidos a procedimentos cirúrgicos ou outros, ou durante um período de observação. Um prognóstico mais preciso para a recuperação da visão pode ser possível avaliando a integridade estrutural dos fotorreceptores no local do defeito da junção IS/OS, a integridade da MLE e o diâmetro externo do defeito foveal antes e após a intervenção. Estudos também indicaram que o diâmetro base pré-operatório, diâmetro interno de abertura e diâmetro linear mínimo podem prever o resultado da VPP para BM (STEEL; LOTERY, 2013). A angiografia com fluoresceína também pode ser empregada em alguns casos em que se suspeite que outras patologias possam estar presentes, como neovascularização de coroide, telangiectasia parafoveal ou oclusão prévia e clinicamente oculta da veia da retina (STEEL; LOTERY, 2013). 
Além da classificação do BM por Duker et al. (2013), baseada na OCT e apresentada na Tabela 1, o BM também foi classificado por Gass (1995) em quatro estágios, de acordo com a aparência da lesão na biomicroscopia de fundo, com o tamanho do buraco e com a presença ou não de DVP (Tabela 2) (GASS, 1995), e um novo esquema de classificação e graduação foi proposto por Gaudric et al. (1999), baseado na OCT (Tabela 3).

Tabela 2 - Classificação do BM por Gass

\section{Achado Fundoscópico}

Um ponto amarelo na fóvea $(1 \mathrm{~A})$, ou um anel amarelo na fóvea (1B), com perda da depressão foveal

Ausência de todas as camadas da retina na região
Estágio 2 foveal, $<400 \mu \mathrm{m}$, redondo ou oval, com vítreo posterior
Estágio 2 foveal, $<400 \mu \mathrm{m}$, redondo ou oval, com vítreo posterior
aderido Ausência de todas as camadas da retina na região

Estágio 3 Ausência de todas as camadas da retina na região
foveal, $\geq 400 \mu \mathrm{m}$, redondo, com vítreo posterior aderido

Ausência de todas as camadas da retina na região

Estágio 4 foveal $\geq 400 \mu \mathrm{m}$, redondo, com vítreo posterior totalmente descolado
Indicação de Cirurgia

Não há

Indicada com bom

Prognóstico

Indicada

Indicada com prognóstico reservado

Fonte: (GASS, 1995)

Tabela 3 - Classificação do BM por Gaudric

\section{Achado na OCT}

\begin{tabular}{ll}
\hline Grau 1 & Achado na OCT \\
Grau 2 & Rompimento excêntrico deste cisto por tração vítrea \\
Grau 3 & BM total com hialóide posterior completamente descolada
\end{tabular}

Fonte: (GAUDRIC et al., 1999) 
No estudo caso-controle de doenças oculares, após três anos de acompanhamento em pacientes com BM pré-existente, 21,7\% apresentaram aumento; esse número aumentou para 37,1\% após seis anos, sendo observada regressão espontânea ou resolução do BM idiopático em $9 \%$ dos pacientes após seis anos de acompanhamento. Durante o período de pelo menos um ano, a deterioração na AV de duas linhas de Snellen, ou mais, foi relatada em $30 \%$ dos pacientes no estágio 1, 68\% no estágio 2, 29\% no estágio 3 e 13\% no estágio 4 de BM. No entanto, o descolamento central da retina secundário ao BM parece estar limitado a pacientes com alta miopia. Geralmente, a maioria dos pseudo-BMs e BMs lamelares tendem a não progredir anatomicamente por um período de vários anos e, geralmente, não estão associados a reduções significativas na AV. No entanto, determinados pseudo-BMs podem estar associados à diminuição da AV em alguns casos (por exemplo, com clivagem lamelar das bordas) e, nesses casos, a cirurgia pode ser realizada (VPP com peeling de MER e MLI). A manutenção da AV nos olhos com buracos lamelares está associada à preservação da MLE. Como nos pseudo-BMs, a VPP com descamação da MLI pode ser realizada em pacientes com AV comprometida ou distorção sintomática. Resultados ótimos são obtidos quando a junção IS/OS e MLE estão intactas (BENSON et al., 2001; PASSEMARD et al., 2010).

\subsection{Membrana epirretiniana}

Com a progressão da DVP, mesmo na ausência de um anel de Weiss, o tecido vítreo residual geralmente é deixado na superfície interna da retina. Os estudos de autópsia revelam que o vítreo residual permanece na superfície da retina em quase metade de todos os olhos com DVP. Essa condição é chamada vitreosquise. Esse vítreo residual pode proliferar para formar uma MER (MER) em qualquer estágio da separação do vítreo. Estudos clínicos mostram uniformemente alta incidência de DVP aparente nos olhos com enrugamento macular. As MERs são compostas, primariamente, por células da glia e laminócitos (histiócitos) que se ligam a um andaime de remanescentes do córtex vítreo na superfície interna da retina. Pensa-se que esses remanescentes sejam deixados na IVM com DVP clínico e/ou 
representam deiscência laminar do córtex vítreo posterior ou ambos (DUKER et al., 2013).

Histologicamente, dois tipos de MER podem ser observados: uma MER simples ou do tipo 1, que cresce diretamente na MLI, composta por uma monocamada de células gliais da retina que produz colágeno tipo IV (EPR, células fibroblásticas e inflamatórias estão ausentes); e uma MER mais complexa ou do tipo 2 , às vezes contendo células como astrócitos fibrosos, miofibroblastos, fibrócitos, macrófagos e células do EPR, além das células gliais. Folhas de células multicamadas podem ser vistas e são separadas da MLI por uma camada de colágeno vítreo nativo (tipo II) remanescente após DVP incompleto. Os fatores de crescimento na IVR podem contribuir para a proliferação fibrocelular. Pensa-se que o colágeno nativo facilite a proliferação de MER, atuando como um andaime. O lado correspondente do córtex vítreo dividido e destacado, formando a superfície externa do "cone", também atua como um andaime e, portanto, a proliferação celular ocorre ao longo dos dois lados desta IVR aberrante e acredita-se que contribua para a tenacidade da AVM na TVM (BANACH et al., 2001).

A presença e o tipo de MER também contribuem para as alterações morfológicas observadas na IVR. A MER simples (não contrátil) está associada à maculopatia por celofane da superfície retiniana (um brilho irregular) observada no reflexo da luz sem distorção da retina interna. No entanto, a contração dos miofibroblastos no tipo mais complexo de MER foi proposta exercer uma tração tangencial na IVR, o que pode resultar em enrugamento, espessamento, dobramento ou descolamento da retina, juntamente com distorção vascular (Figura 8). A contração da MER complexa pode, portanto, exercer efeitos profundos na visão e aumentar significativamente o efeito de qualquer AVM. A TVM e qualquer MER associada também podem ser associados a alterações na vasculatura da retina. À medida que a retina é separada, há redução na pressão do líquido intersticial, com subsequente influxo de líquido da vascularização da retina (ou seja, vazamento de sangue) e células, levando ao edema macular (FRASER-BELL et al., 2003). 
Figura 8 - (A) Retinografia e (B) OCT de MER de paciente do estudo
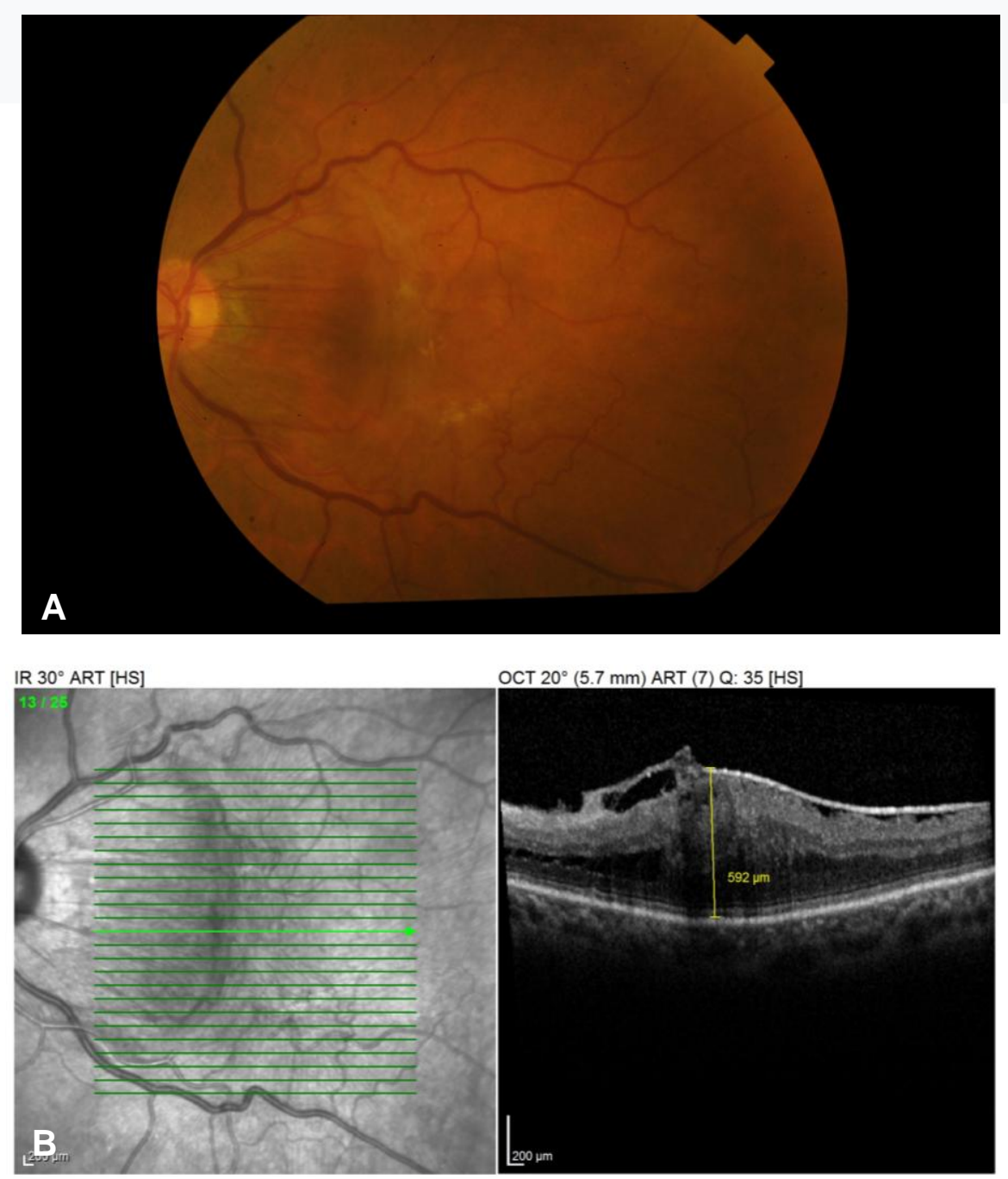

\subsection{Anatomia da córnea e fisiologia do endotélio corneano}

Nas cirurgias de VPP, associada ou não à Faco, podem ocorrer alterações da córnea, cuja anatomia e fisiologia serão descritas a seguir.

A córnea é uma estrutura transparente, com face anterior elíptica, medindo aproximadamente $12,6 \mathrm{~mm}$ no meridiano horizontal $\mathrm{e}, 11,7 \mathrm{~mm}$ no vertical. Apresenta espessura média de $0,520 \mathrm{~mm}$ na região central e de 0,650 $\mathrm{mm}$ ou mais, na região periférica. Sua face anterior não apresenta curvatura uniforme, sendo mais curva na região central e mais plana na região periférica. Apresenta um raio de curvatura médio de $7,8 \mathrm{~mm}$ na face anterior da região central, e de $6,6 \mathrm{~mm}$ na face 
posterior. Possui poder refracional de 44,00 dioptrias. É uma estrutura não vascularizada e sua inervação é desprovida de bainha de mielina, o que garante a sua total transparência. A córnea possui seis camadas: epitélio, membrana de Bowman, estroma, camada de Dua, membrana de Descemet e endotélio (ROBINETT; KAHN, 2008; DUA et al, 2013).

\subsubsection{Epitélio}

O epitélio é a camada mais superficial da córnea, compondo-se, por sua vez, de quatro a seis outras camadas de células do tipo epitélio escamoso, estratificado e não queratinizado. Ocupa aproximadamente 10\% da espessura total da córnea e detém alta capacidade de regeneração. Nas camadas mais profundas, as células são colunares, com atividade mitogênica onde, na medida em que as células mais superficiais vão descamando, vão sendo repostas por outras (mais jovens) que, naturalmente, vão assumindo a forma estratificada, anteriormente descrita. O tempo, a partir da mitose até a célula alcançar a superfície, é de sete dias. O epitélio em seu todo funciona como uma espécie de barreira contra a perda de líquidos e penetração de microrganismos, bem como apresenta uma superfície lisa e brilhante, o que garante o seu poder refrativo. As bordas laterais das células basais apresentam extensões digitais, unindo-se entre si através de "zonula adherens" e "gap junctions". A face posterior das células basais é plana e aderida à lâmina basal através de hemidesmossomas. (SASSANI et al., 1984; TSUBOTA; YAMADA; NAOI, 1991).

\subsubsection{Membrana de Bowman}

A membrana de Bowman é uma camada acelular de 8 a $12 \mu \mathrm{m}$ de espessura, formada por fibras de colágeno e proteoglicanas densamente entrelaçadas. Se lesada, não se regenera; sendo, por consequência, ocasionada a perda de sua transparência. É formada a partir de células do epitélio basal, da lâmina basal, bem como de fibras do estroma anterior. O diâmetro das fibras de colágeno da membrana de Bowman é de aproximadamente dois terços do diâmetro das fibras de colágeno do estroma como um todo. A membrana de Bowman tem por função manter a 
integridade e a organização epitelial, bem como de separar o epitélio do estroma (WARING et al., 1982).

\subsubsection{Estroma}

O estroma representa aproximadamente $90 \%$ da espessura total da córnea e é composto por fibras de colágeno. Sua densidade celular é reduzida, estando os ceratócitos localizados entre as lamelas, os axônios dos nervos e as células de Schwann. Os ceratócitos são encontrados nos terços anterior e médio do estroma (JOLBERT; STAPLETON, 2005). O estroma corneano naturalmente absorve água devido a dois fatores: as glicosaminoglicanas, que exercem uma pressão osmótica que puxa a água para dentro do estroma, e sua função de bomba que osmoticamente retira a água do mesmo. A barreira endotelial é vazada, mas a taxa de vazamento normalmente se equipara à taxa da bomba metabólica, de forma que o endotélio mantém o conteúdo aquoso do estroma de $78 \%$ e a espessura corneana média de 0.520 mm (WARING et al., 1982).

\subsubsection{Camada de Dua}

Esta nova camada, descoberta em 2013, está localizada na parte de trás da córnea, entre o estroma corneano e a membrana de Descemet. Com 15 micrômetros de espessura, é forte o suficiente para resistir a 1,5 bar de pressão. Segundo os pesquisadores, esta descoberta ajudará na compreensão de uma série de doenças, incluindo a hidrópsia aguda, Descemetocele e as distrofias da pré-Descemet (DUA et al, 2013).

\subsubsection{Membrana de Descemet}

A membrana de Descemet é formada a partir do endotélio e funciona como a lâmina basal do mesmo. É composta de colágeno e glicoproteínas (incluindo a fibronectina). Sua formação inicia-se aos quatro meses de gestação e a camada anterior completa-se próximo ao nascimento. Estudos têm demonstrado que a 
membrana de Descemet apresenta espessamento ao longo da vida. Observa-se que embora sua camada anterior não varie significativamente, permanecendo ao redor de $3 \mu \mathrm{m}$, sua camada posterior chega a variar de 2 para $10 \mu \mathrm{m}$ com o passar dos anos. Por ser formada a partir do endotélio, a membrana de Descemet é facilmente regenerada (WARING et al., 1982).

\subsubsection{Endotélio}

O endotélio corneano consiste de uma monocamada de células na superfície posterior da córnea que forma uma barreira física entre o estroma corneano e o humor aquoso. O endotélio normal apresenta disposição regular de células predominantemente hexagonais com aproximadamente a mesma área celular. Esse formato hexagonal regular (para uma área fixa) é o padrão mais estável que pode cobrir a superfície de um plano. Esse modelo minimiza o limite celular total ou perímetro, resultando em energia de tensão de superfície reduzida (OLSEN, 1979). O endotélio é banhado, posteriormente, pelo humor aquoso, estando anteriormente em íntimo contato com a membrana de Descemet. Lateralmente, continua como endotélio do trabeculado escleral, e possui uma população de 400 a 500 mil células, (aproximadamente 3000 céls $/ \mathrm{mm}^{2}$ ), cada uma medindo 18 a $20 \mu \mathrm{m}$ de diâmetro, arranjadas em uma monocamada contínua de 4 a $6 \mu \mathrm{m}$ de espessura (WATSKY et al., 1990).

A espessura e transparência normais da córnea são mantidas pela função de barreira e pela bomba ativa de fluidos das células corneanas endoteliais (MISHIMA, 1982). Essas células são responsáveis por manter o estado de deturgescência do estroma por meio da bomba de sódio/potássio-adenosina trifosfato (ATPase), cujos sítios estão presentes nas membranas celulares basolaterais, e da via da anidrase carbônica intracelular. A atividade desses dois sistemas produz um fluxo do estroma para o humor aquoso. A função de barreira do endotélio é algo único, de tal forma que ele é permeável até ao ponto de permitir o fluxo de íons necessário para estabelecer o gradiente osmótico (WATSKY et al., 1990). Se a função endotelial falha, a água difunde para dentro do estroma, rompendo a estrutura ordenada das fibras de colágeno, com resultante dispersão da luz e opacificação da córnea. A 
água pode também passar através do estroma e se acumular como microcistos e bolhas abaixo e dentro do epitélio (WARING et al., 1982).

O endotélio da córnea tem capacidade proliferativa limitada in vivo, mas responde por meio de sua expansão nos processos de cicatrização depois de uma injúria (JOYCE, 2005). Ao nascimento, a densidade das células endoteliais (DCE) é aproximadamente 5000 células $/ \mathrm{mm}^{2}$ e há rápida diminuição nessa densidade até a idade de 20 anos. A partir daí, mantém perda lenta e constante de 0,6\% a cada ano (KISS et al., 2003). Baseada na DCE do adulto, a córnea humana tem vasta reserva fisiológica capaz de possuir células endoteliais suficientes para uma vida de mais de 100 anos.

O mosaico endotelial com padrão normal caracteriza-se por apresentar DCE normal para a idade e ausência de estruturas anexas, tais como excrescências da membrana de Descemet e depósitos endoteliais de qualquer natureza. A Figura 9 demonstra o comportamento da DCE nas várias décadas de vida (ABIB, 2001).

Figura 9 - Comportamento da densidade endotelial e seus desvios padrão durante a vida

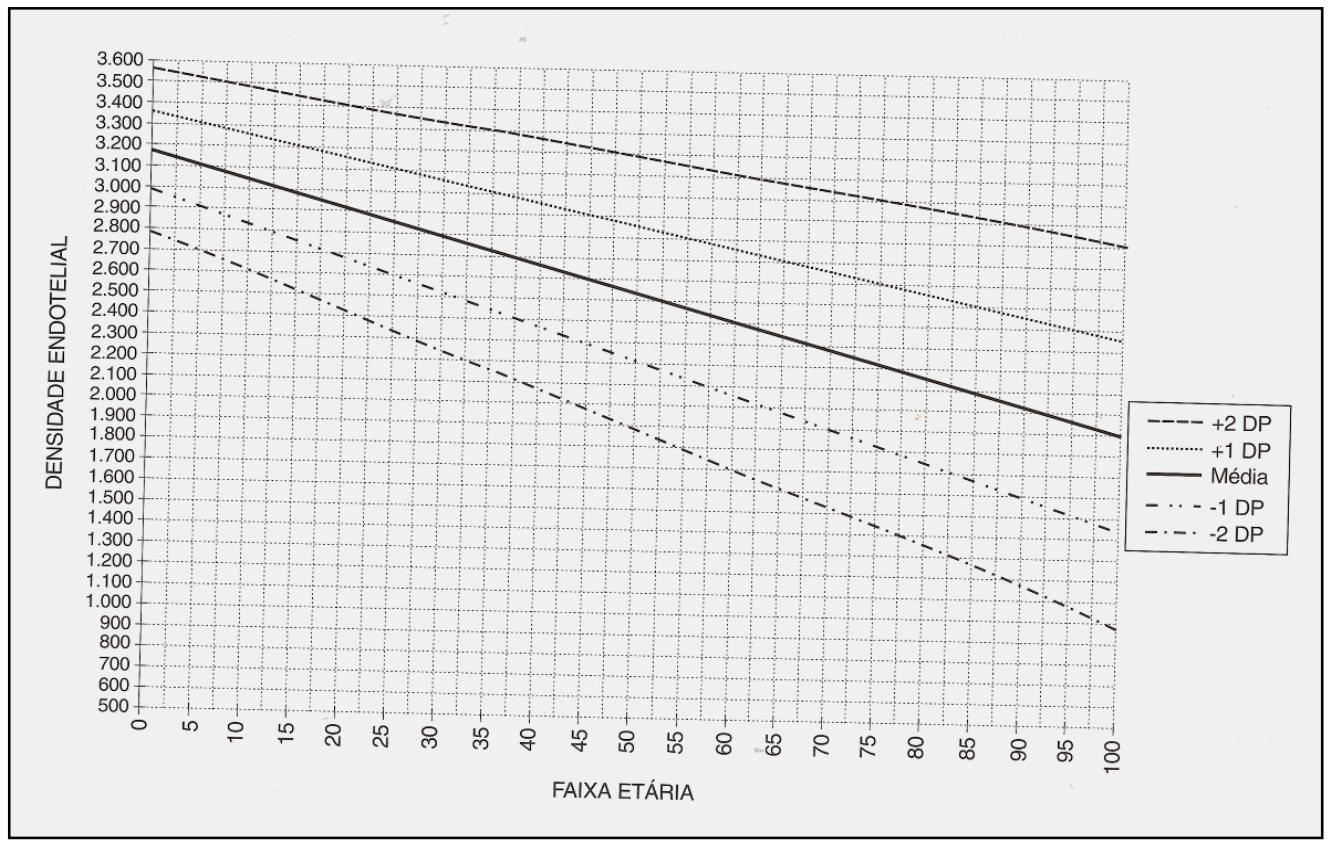

Fonte: (ABIB, 2001). 
Tomando como base o conhecimento estatístico aplicado à variável DCE, assumindo que tenha comportamento de distribuição normal, aproximadamente $68 \%$ das ocorrências estarão contidas no intervalo de um desvio padrão relativo à média esperada para a idade, e aproximadamente $95 \%$ no intervalo com limite até o segundo desvio padrão. Os $5 \%$ restantes se dividem igualmente em valores de DCE acima e abaixo do segundo desvio padrão (ABIB, 2001). Merecem especial destaque os 2,5\% que apresentam DCE abaixo do segundo desvio padrão negativo referente à média (Figura 9), área que a literatura mundial não caracteriza doença endotelial, pois existe somente densidade diminuída para a idade. Esses casos recebem a denominação de degeneração endotelial não-guttata e a microscopia especular não demonstra nenhuma alteração endotelial, de forma a excluir-se doença do endotélio corneano (ABIB, 2001).

Vários estudos mostraram mudanças na morfologia das células endoteliais com o aumento da idade (LAING et al., 1976; SUDA, 1984; YEE et al., 1985). Essas mudanças incluem aumento na média do tamanho da célula endotelial e o consequente aumento do polimegatismo em torno de $23 \%$ (definido como o coeficiente de variação do tamanho celular), aumento do pleomorfismo celular (com a consequente diminuição da porcentagem de células endoteliais hexagonais). Laing et al. (1976) descobriram que a área celular endotelial média aproximadamente dobra dos 20 aos 80 anos de idade. Suda (1984) encontrou diminuição na porcentagem de células hexagonais de $70 \%$ aos 20 anos para $58 \%$ aos 70 anos.

Há também variações genéticas na DCE corneano. Matsuda, Yee e Edelhauser (1985) mostraram que o endotélio corneano em uma população japonesa apresentava uma densidade celular significativamente mais alta quando comparado com uma população americana da mesma faixa etária. Um estudo realizado por Makitie, Annas e Koskenvuo (1983) com gêmeos mono e dizigóticos sugeriu que a DCE corneano é determinada mais por um componente genético do que por fatores ambientais. Contudo, a cirurgia intraocular ou refrativa e o uso de lentes de contato são fatores externos que exercem papel importante na alteração da densidade e morfologia das células endoteliais da córnea. A manipulação intraocular, como a que ocorre durante a cirurgia de catarata por Faco, causa turbulência de fluidos e fragmentos do cristalino, que pode levar a dano endotelial, 
tal qual uma função comprometida transitoriamente ou perda celular permanente (DICK et al., 1996; ROPER-HALL; WILSON, 1982).

\subsection{Microscopia especular}

Microscopia especular é uma técnica não invasiva para avaliar a estrutura e a função do endotélio da córnea, através da visualização e do registro da imagem da camada de células endoteliais. Existem múltiplos modelos de microscópio especular, cada um deles capturando imagens celulares de diferentes magnificações e calibrações (McCAREY; EDELHAUSER; LYNN, 2008).

Os microscópios especulares são todos derivados do microscópio laboratorial projetado por Maurice (1968) para produzir uma imagem de alta magnificação da luz especular refletida do endotélio da córnea. O reflexo especular ocorre na interface lisa, regular, de dois índices refrativos, com a luz proveniente do sujeito tendo um ângulo de incidência igual ao ângulo de reflexão do observador. As células endoteliais podem ser visualizadas porque o seu índice refrativo é 1.336 vezes maior que o índice do humor aquoso refletindo, portanto, 0.022\% da luz projetada (LAING; SANDSTROM; LEIBOWITZ, 1979).

A área de superfície do reflexo especular é dependente da curvatura da superfície refletora (Figura 10). Então, a luz refletida de uma superfície plana irá reproduzir a área da fonte de luz; a luz refletida de um cilindro será condensada em 90 ao eixo do cilindro, e a luz refletida da superfície de uma esfera será condensada em todos os eixos. Portanto, o raio de curvatura da superfície refletora dita a área do reflexo especular (McCAREY; EDELHAUSER; LYNN, 2008). 
Figura 10 - O tamanho e a forma da imagem refletida da fonte de luz são modificados pela superfície refletora

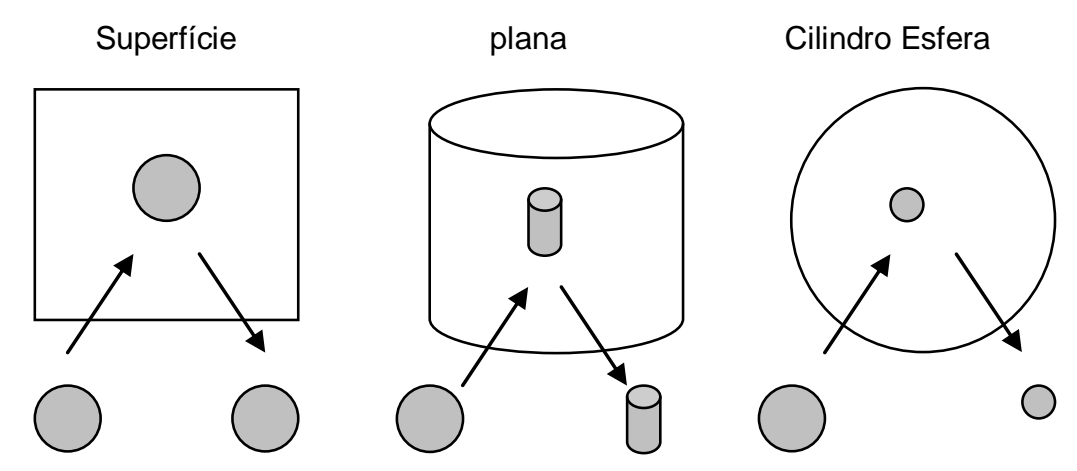

Fonte: (McCAREY et al., 2008).

Uma restrição adicional na área do reflexo da luz é causada pela proximidade de duas superfícies concêntricas (epitélio e endotélio). A superfície epitelial é altamente refletiva devido à grande diferença de índice de refração entre o ar e o conjunto epitélio/lágrima. Como o feixe de luz passa através da córnea, ele é refletido para fora da interface lágrima/epitélio e interface endotelial. A área especular visível está compreendida entre a largura do feixe de luz e a espessura da córnea. Devido a essa restrição, a área visível do endotélio é um retângulo, e o raio de curvatura da córnea dita a altura do retângulo (McCAREY; EDELHAUSER; LYNN, 2008).

O microscópio especular laboratorial original introduzido por Maurice (1968) tem sido redesenhado por várias empresas comerciais. Todos os instrumentos disponíveis atualmente utilizam computadores para a captura da imagem e análise da morfologia das células endoteliais. Esses instrumentos podem ser de contato com o epitélio da córnea ou de não-contato. O microscópio especular de contato tem uma lente objetiva que aplaina a superfície da córnea, necessitando de anestesia tópica. Durante a aplanação, a curvatura da córnea é nivelada e a área do reflexo especular aumenta. Os instrumentos de não-contato utilizam tecnologia de foco de imagem automático. A área do reflexo especular é menor do que nos microscópios especulares de contato devido à superfície refletora curva da córnea (McCAREY; EDELHAUSER; LYNN, 2008). Em ambos os casos, a área endotelial visível é limitada pela superfície refletora epitelial e pela espessura da córnea, de forma que 
as larguras dos retângulos de células endoteliais com os dois tipos de microscópio especular são equivalentes. Já a altura desse retângulo, por ser determinada pela curvatura da córnea, é maior nos microscópios especulares de contato. A imagem endotelial capturada com um microscópio especular de contato que apresenta densidade de 2500 células $/ \mathrm{mm}^{2}$ terá $700-800$ células visíveis. Uma imagem endotelial comparável capturada com um microscópio especular de não-contato terá somente 150-170 células (Figuras 11 e 12).

Figura 11 - Fotografia de microscópio especular de não-contato mostrando a paquimetria

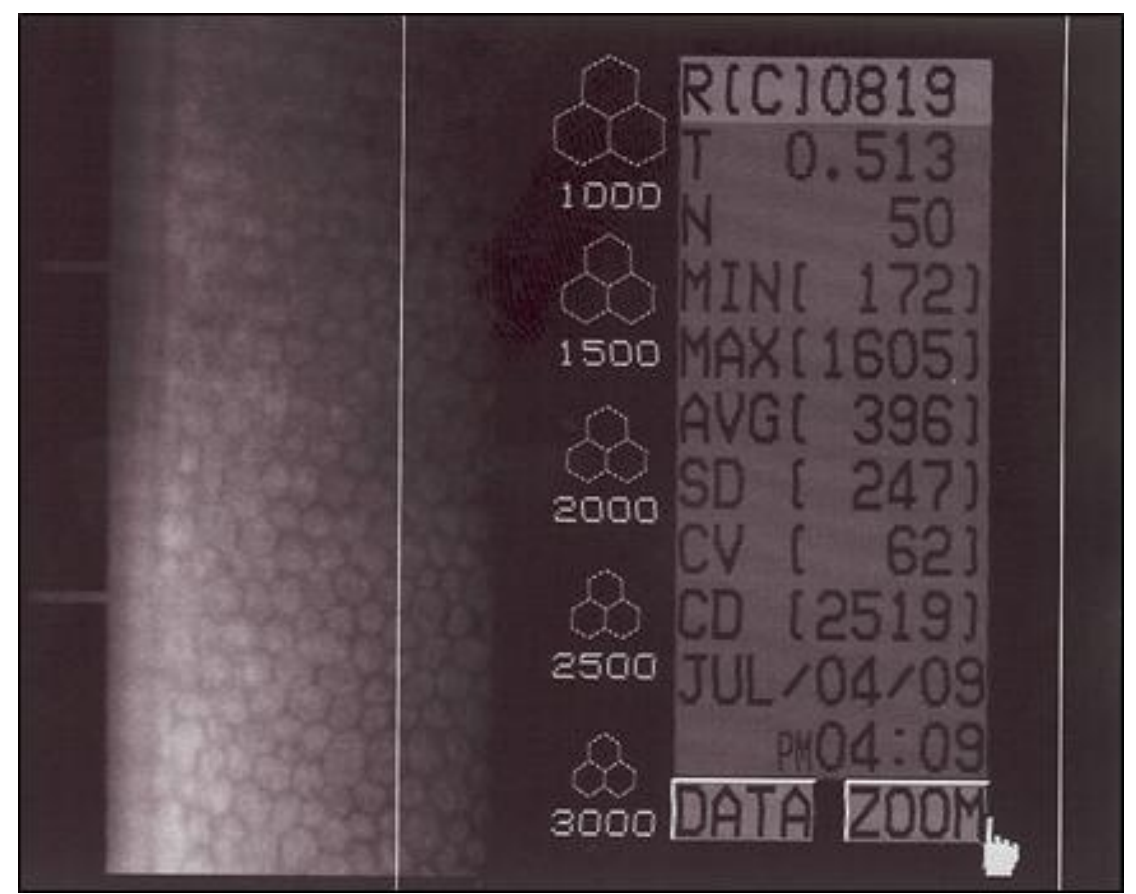

Fonte: (LUCENA, 2009). 
Figura 12 - Fotografia de microscópio especular de não-contato

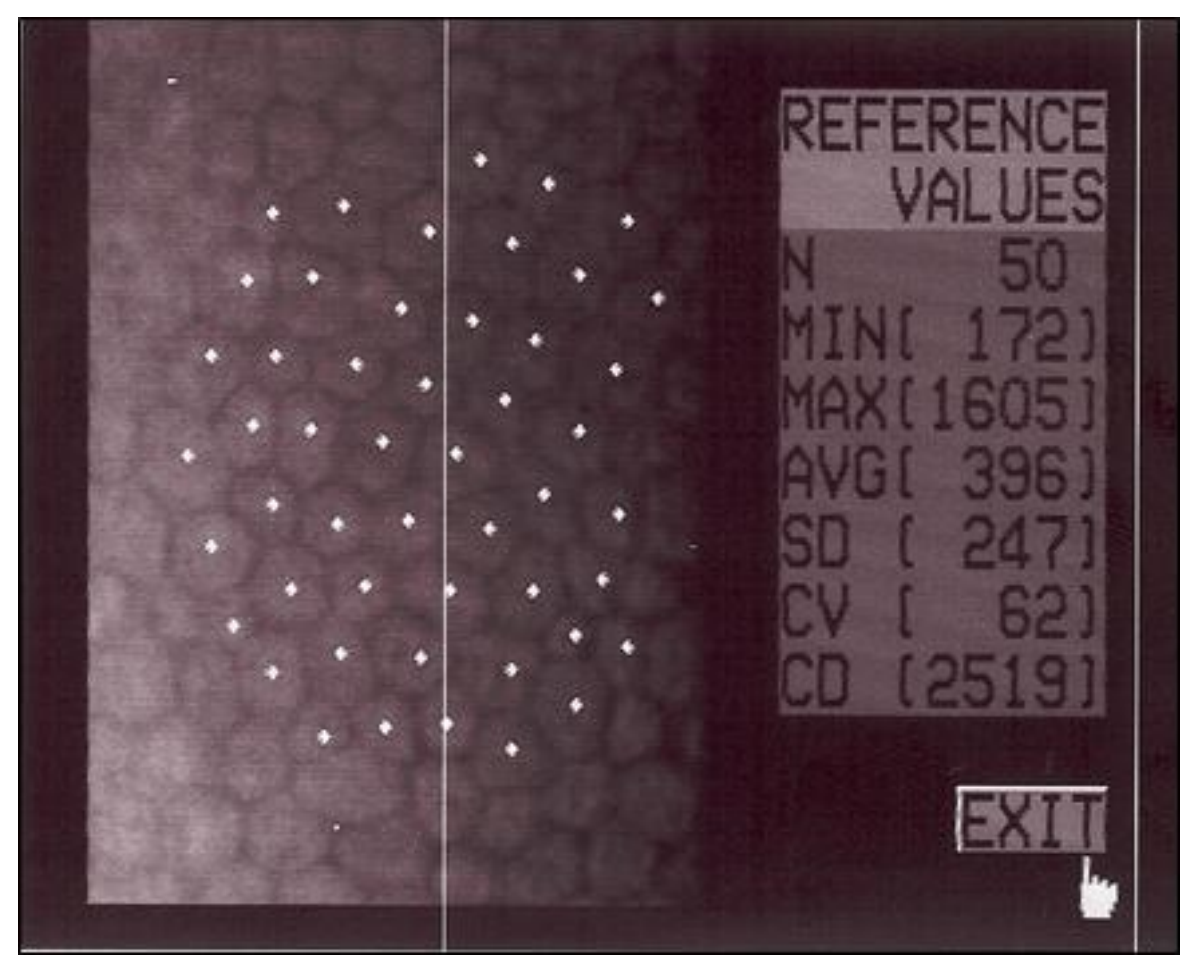

Fonte: (LUCENA, 2009).

As diferenças entre os dois aparelhos derivam de seus princípios de captação de imagem levemente distintos. Na microscopia especular de contato, a superfície ocular é indentada com um cone de $3.0 \mathrm{~mm}$ de diâmetro, havendo a possibilidade de gerar tecido excessivo de córnea para a medida. Em contraste, as imagens especulares de não-contato são afetadas pelo poder refrativo da superfície anterior da córnea e pela variação entre os índices refrativos ar-córnea. No entanto, as medidas de DCE são comparáveis com as duas técnicas, de forma que os dois tipos de microscópio especular podem ser usados alternadamente para avaliar a contagem e morfologia celular em olhos normais e naqueles com patologias na córnea (ISAGER et al., 2000; MÓDIS Jr.; LANGENBUCHER; SEITZ, 2002; OHNO et al.,1999).

Quando o endotélio corneano humano é danificado, a cicatrização é um processo de alargamento celular e expansão para criar uma camada contígua de células endoteliais. O grau de perda endotelial pode ser documentado com 0 microscópio especular como um aumento da área de superfície de cada célula e 
uma diminuição da DCE corneano. O processo de reparo ao dano endotelial também é refletido pelo aumento na variação das áreas celulares individuais, que é o coeficiente de variação (CV) ou polimegatismo (Figuras 13 e 14). Células de seis lados são indicação de distribuição equilibrada da tensão de superfície da membrana e de células normais. O polígono que tem a maior área de superfície relativa ao seu perímetro é o hexágono. Portanto, a forma celular mais eficiente para cobrir determinada área é o hexágono (uma córnea perfeita deveria ter $100 \%$ de hexágonos) (McCAREY; EDELHAUSER; LYNN, 2008) (Figura 15). Uma córnea saudável tem aproximadamente $60 \%$ de suas células endoteliais como hexágonos. A análise da morfologia do endotélio da córnea inclui, portanto, os seguintes parâmetros: área celular $\left(\mu \mathrm{m}^{2}\right)$, densidade celular (células $\left./ \mathrm{mm}^{2}\right)$, polimegatismo $(\mathrm{CV})$ e pleomorfismo (percentagem de células hexagonais).

Figura 13 - Córneas com densidade de células endoteliais e coeficentes de variação diferentes. (A) densidade de 1470 céls. $/ \mathrm{mm}$, (B) densidade de 2625 céls $/ \mathrm{mm}$

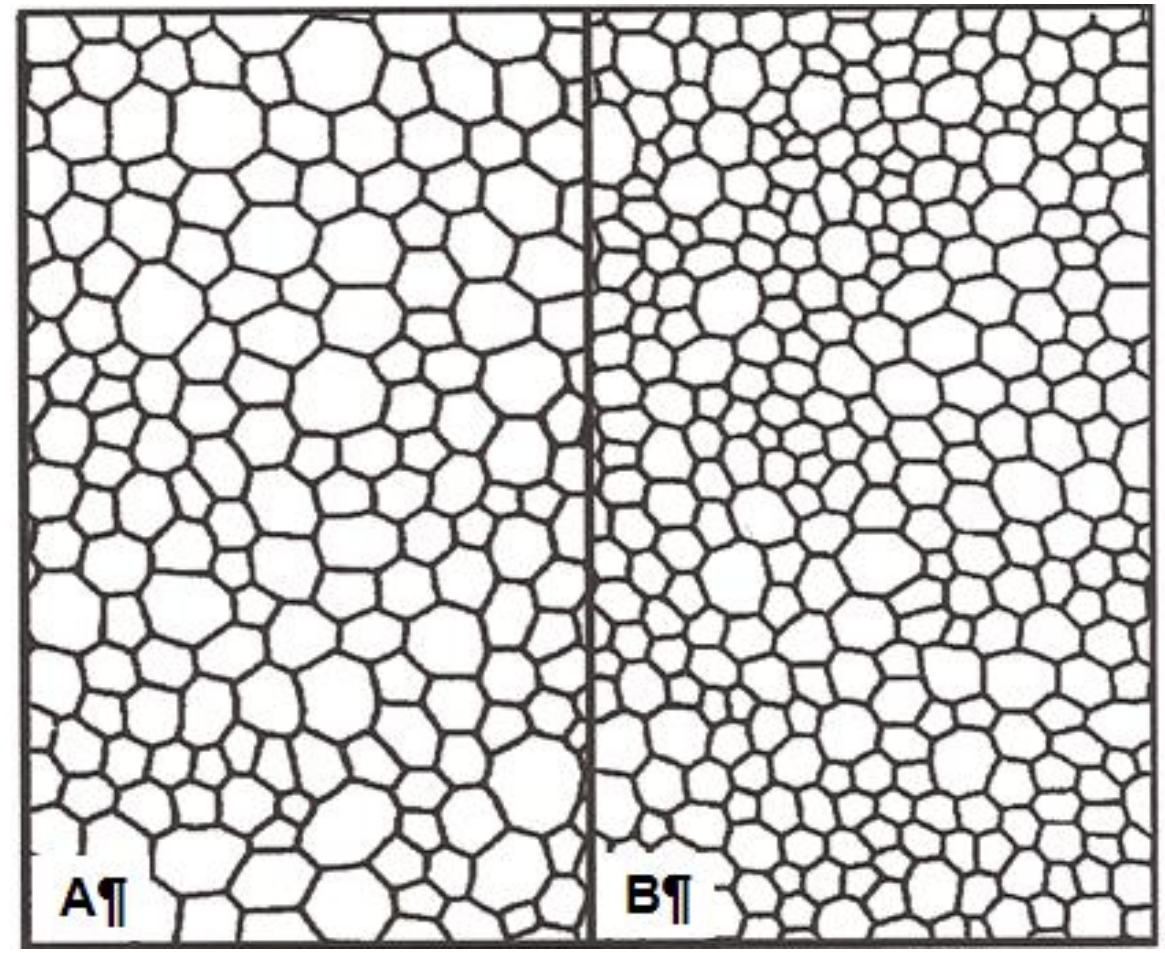

Fonte: (McCAREY; EDELHAUSER; LYNN, 2008). 
Figura 14 - Diferentes coeficientes de variação com a mesma contagem celular

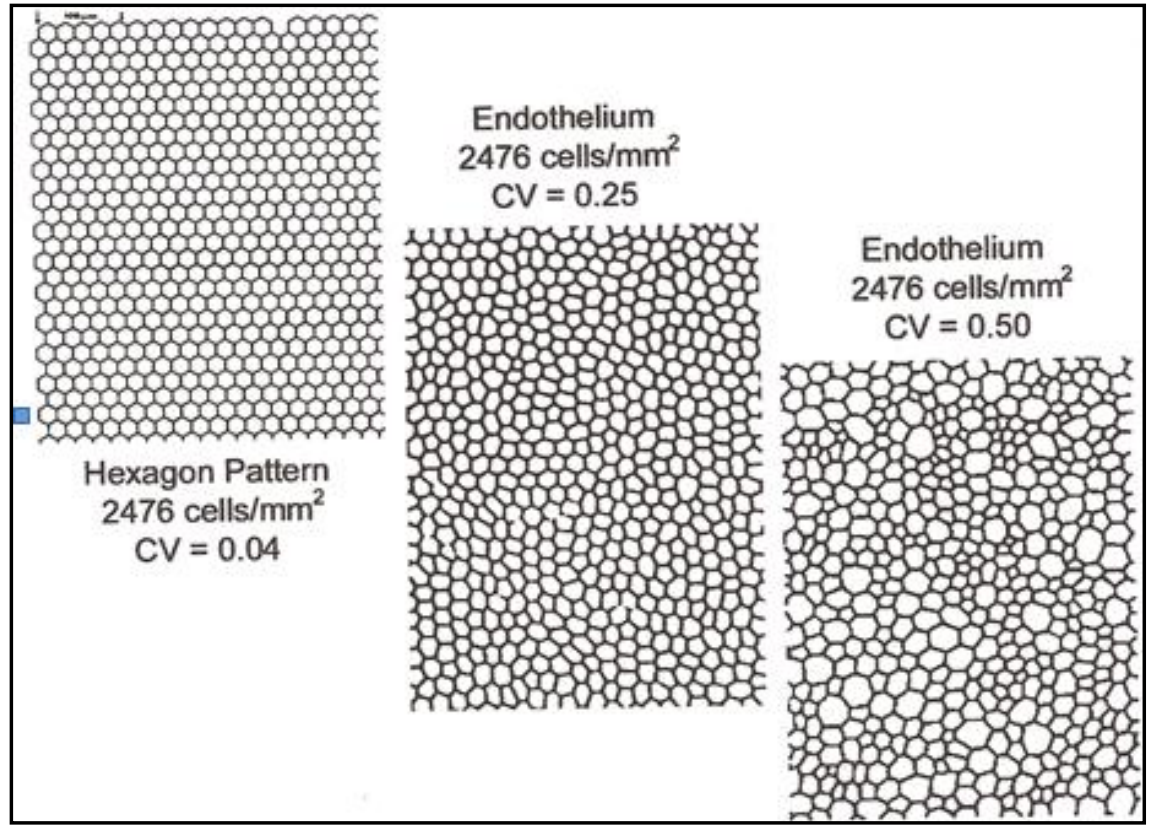

Fonte: (McCAREY; EDELHAUSER; LYNN, 2008).

Figura 15 - Perfeito padrão hexagonal. (A) córnea com densidade de 1600 céls $/ \mathrm{mm}^{2}$. (B) córnea com densidade de 2500 céls $/ \mathrm{mm}^{2}$

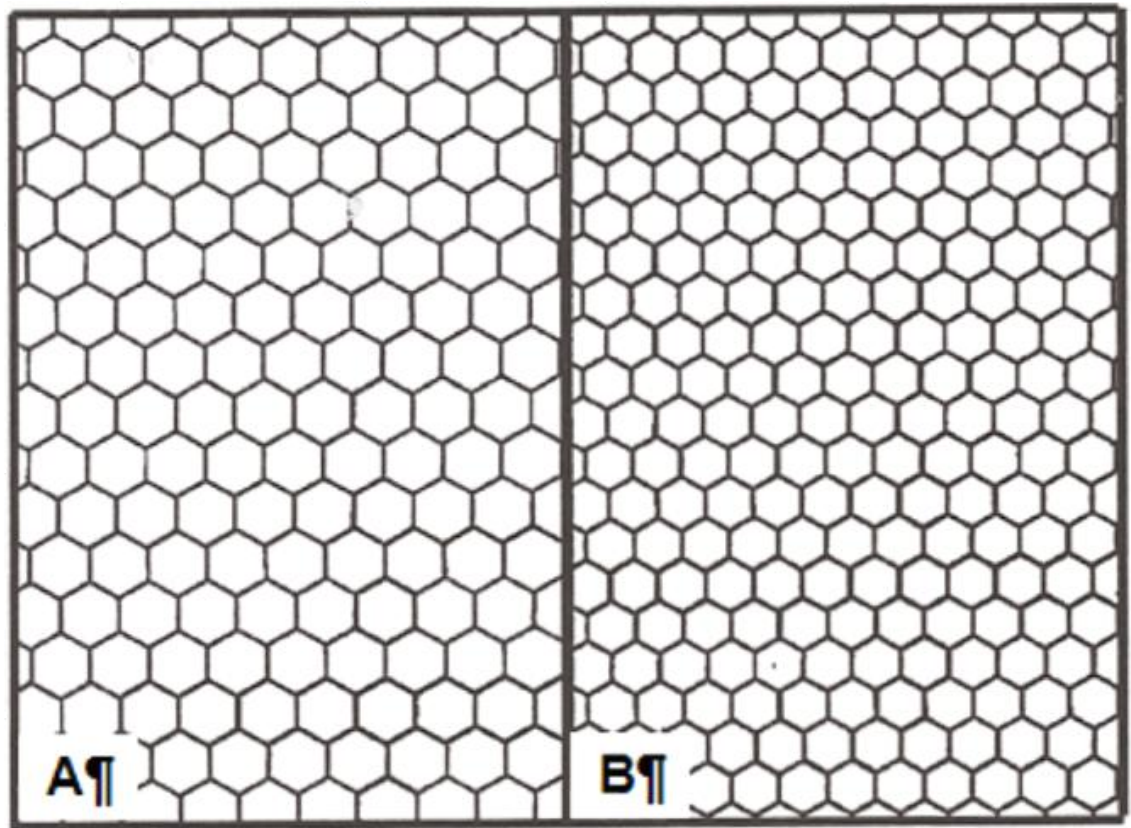

Fonte: (McCAREY; EDELHAUSER; LYNN, 2008). 


\subsubsection{Importância da microscopia especular na análise de dano corneano}

Alterações no pleomorfismo e/ou polimegatismo, quando presentes, são indicativos de sofrimento endotelial e existe diminuição da reserva funcional da bomba endotelial. Dessa forma, a análise do mosaico endotelial torna-se mais objetiva, pois alia-se à DCE (análise quantitativa), à análise da morfologia das suas células (análise qualitativa), mediante índices que refletem o polimegatismo e o pleomorfismo (ABIB, 2001). Se essas alterações no polimegatismo e/ou polimorfismo, estiverem presentes na córnea de um olho a ser operado, haverá maior sofrimento corneano devido à diminuição da reserva funcional da bomba endotelial, tornando-se lógico pressupor que a córnea com menor margem de segurança endotelial, conforme já definido anteriormente, possuirá maior perda celular percentual e, consequentemente, maior risco de descompensação. Então, quão maior o polimegatismo e/ou pleomorfismo para uma mesma DCE em mesma idade, maior será o seu risco de descompensação (BLATT et al., 1979).

\subsection{Paquimetria}

A espessura da córnea dos recém-nascidos é mais alta durante as primeiras 24 horas depois do nascimento e diminui significativamente depois de 48 horas (PORTELINHA; BELFORT, 1991). Esse processo de afinamento continua uniformemente até a idade de três anos, época em que a espessura da córnea adulta é atingida (EHLERS et al., 1976). A partir de então, há uma gradual, mas insignificante diminuição na espessura desse tecido (HERSE; YAO, 1993).

A lesão moderada do endotélio da córnea durante a cirurgia de catarata por Faco pode levar ao aumento transitório na espessura da córnea, medido pelo paquímetro, apesar de os dados relacionados a esse fato serem contraditórios. Alguns autores têm demonstrado que todos os pacientes recuperam os valores préoperatórios depois de quatro semanas (CHENG et al., 1988), enquanto outros têm encontrado aumentos sustentados por seis meses (OLSEN; ERIKSEN, 1980), ou mesmo um ano após a cirurgia (KOHLHAAS et al., 1997). Essas discrepâncias podem refletir inexatidões na medida da espessura central da córnea (ECC), ou na 
estimativa da densidade numérica das células endoteliais, ou ainda podem ser devidas à presença de anormalidades pré-existentes na morfologia das células endoteliais. Ademais, a taxa de diminuição da espessura da córnea após o edema, medida como a percentagem de recuperação por hora, é significativamente mais alta em pacientes jovens do que em idosos (POLSE et al., 1989).

Os estudos de Cheng et al. (1988) mostraram que a densidade numérica das células endoteliais dentro dos limites fisiológicos não se correlaciona com a ECC, cujos valores retornam aos níveis pré-operatórios depois de dois a doze meses, a despeito da severidade da perda endotelial. Em pacientes com aumento do polimegatismo endotelial esse retorno aos valores pré-operatórios de espessura corneana é significativamente mais lento do que em pacientes com endotélio normal (RAO et al., 1979).

Medidas precisas da espessura da córnea podem, portanto, servir como parâmetro para avaliar a função endotelial global em córneas com um endotélio comprometido ou com uma contagem baixa de células endoteliais. Em córneas com células endoteliais saudáveis, a espessura corneana não aumenta muito, pois um endotélio normal é capaz de manter a desidratação da córnea mesmo com grande variação na contagem de células endoteliais. Nessas situações, para avaliar o grau do trauma cirúrgico e o estado do endotélio, critérios morfológicos são mais precisos. Isso acontece porque a capacidade funcional do endotélio é substancial e a depleção das células da córnea não é refletida nas medidas de espessura corneana até que haja perda substancial de células endoteliais (VENTURA; WALTI; BOHNKE, 2001).

Na prática clínica, o conhecimento da associação entre a espessura corneana e a perda de células endoteliais tem menos utilidade do que o conhecimento da probabilidade de uma grande perda celular para determinada variação na espessura da córnea (CHENG et al., 1988). Isso sugere que o aumento considerável da espessura corneana tem alguma importância como um prenúncio de perda celular (LUNDBERG; JONSSON; BEHNDIG, 2005), ou seja, um aumento da espessura corneana de $75 \mu \mathrm{m}$, ou mais, em 48 horas e $100 \mu \mathrm{m}$, ou mais, em cinco dias deve fornecer indicadores clínicos de grande perda celular. 
Existem várias técnicas para medir a ECC, como a microscopia confocal, paquimetria óptica, paquimetria ultrassônica e OCT. Há vantagens e desvantagens nos diferentes instrumentos. A paquimetria óptica é uma técnica fácil, que pode ser realizada rapidamente e não exige contato com a córnea do paciente, sendo mais confortável. A paquimetria ultrassônica requer anestesia tópica e contato com a córnea, o que acarreta a possibilidade de lesão epitelial (MÓDIS Jr.; LANGENBUCHER; SEITZ, 2002). A OCT é uma técnica de não-contato que permite uma imagem de corte transversal de alta resolução da córnea, que comparada às paquimetrias óptica e ultrassônica tem uma reprodutibilidade muito maior (BECHMANN et al., 2001). Estudos de comparação entre as paquimetrias óptica e ultrassônica demonstraram que a média da ECC foi significativamente mais alta com o paquímetro ultrassônico (BOVELLE et al., 1999; MÓDIS Jr.; LANGENBUCHER; SEITZ, 2002). Esses resultados mostram que, para a paquimetria, os dois aparelhos não podem ser usados alternadamente. Por essa razão, a paquimetria ultrassônica ainda é o método de referência para medida da espessura de córnea. No entanto, quando o objetivo clínico é medir a DCE e a paquimetria, a aplicação do mesmo instrumento (microscópio especular) é recomendada para o seguimento de pacientes em longo prazo (MÓDIS Jr.; LANGENBUCHER; SEITZ, 2002).

\subsection{Cirurgia de catarata por facoemulsificação e o endotélio}

Independente da técnica cirúrgica utilizada, observa-se perda celular endotelial média imediata com a cirurgia de catarata moderna, em córneas normais, de 10 a 20\% (VALLE et al., 1998), e perda progressiva crônica durante, no mínimo, 10 anos após a cirurgia, de 2,5\% ao ano (BOURNE; NELSON; HODGE, 1994). Essa perda é de 2,5 a oito vezes maior que a perda anual normal, devido ao envelhecimento de um olho não operado. Já a perda crônica endotelial após facectomia em córnea guttata passa para $7,5 \%$ ao ano (BOURNE; NELSON; HODGE, 1994).

Bates, Hiorns e Cheng (1992) observaram que pacientes submetidos à Faco têm em média 40 anos de pós-operatório com córnea transparente, quando então surge a descompensação, e o valor médio encontrado para tal é de 542 células $/ \mathrm{mm}^{2}$ 
(400 a 700 células $/ \mathrm{mm}^{2}$ ). Portanto, o cirurgião de catarata precisa saber, de forma precisa, a DCE do olho a ser operado e, consequentemente, a margem de segurança endotelial para estimar o risco corneano inerente ao procedimento. Entende-se por margem de segurança endotelial a quantidade de células endoteliais contidas entre a densidade estimada por ocasião do exame pré-operatório e o limite de descompensação (400 a 700 céls $/ \mathrm{mm}^{2}$ ). A descompensação será iminente quando a perda endotelial de 0,56\% ao ano (KISS et al., 2003), acrescida da perda anual pela Faco, levar a córnea ao limite de 400 a 700 células $/ \mathrm{mm}^{2}$ durante a expectativa de vida.

Tudo isso é válido para cirurgias sem complicações per e pós-operatórias e também para os casos em que não exista doença endotelial de qualquer natureza. Em caso de doença endotelial, a perda celular nos períodos per e pós-operatório imediato e mediato será maior e, consequentemente, o limiar de descompensação poderá ser atingido mais precocemente. Ou seja, na vigência de determinada DCE, o mosaico endotelial que apresente mais polimegatismo e/ou pleomorfismo estará sujeito a maior perda celular e poderá se aproximar mais do limiar crítico para a manutenção da transparência corneana (400 a 700 células $\left./ \mathrm{mm}^{2}\right)$ (ABIB, 2001).

Um dos maiores fatores de insulto ao endotélio corneano, independente da técnica cirúrgica, é a pouca habilidade do cirurgião em manipular os instrumentos cirúrgicos e a lente intraocular (LIO) na CA (ELVIRA; HUESO; TOLDOS, 1999). O conhecimento do fator cirurgião na perda endotelial é de inegável importância e o condiciona à melhora da técnica cirúrgica, além do que o alerta para cuidados adicionais nos casos de DCE limítrofe ou de doença do mosaico endotelial.

Atualmente, a Faco realizada corretamente proporciona menor perda endotelial devido a vários fatores, entre eles o menor tempo cirúrgico, associado à maior experiência do cirurgião. Diversos são os fatores que podem lesar o endotélio durante a Faco, além dos já citados:

a) Tipo de incisão: as incisões em córnea clara induzem discreto aumento na perda endotelial em relação ao túnel escleral, entretanto diferença nãosignificativa (Dick et al., 1996);

b) Tamanho da incisão: quanto menor a incisão, menor a perda endotelial (Dick et al., 1996); 
c) Toque de fragmentos do núcleo no endotélio corneano: esse talvez seja o fator mais importante de agressão ao endotélio e está diretamente relacionado à dureza do núcleo (HAYASHI, 1996);

d) Efeito "surge": após o término da emulsificação de um fragmento nuclear com alto vácuo, a desoclusão súbita da ponteira da caneta de faco provoca um colapso abrupto da CA. Diversos mecanismos foram desenvolvidos nas máquinas modernas de Faco para controlar esse efeito, protegendo o endotélio (HAYASHI, 1996);

e) Tempo de ultrassom, turbulência ultrassônica, movimentação de fluidos: atualmente, as incisões pequenas proporcionam menor quantidade de movimentação de fluidos na CA e maior controle da mesma. Os aparelhos mais potentes e com controle "anti-surge" possibilitam menor turbulência ultrassônica na CA (KWITKO, 2003);

f) Técnicas de Faco: a técnica ideal, especialmente para os núcleos mais densos, deve ser aquela que quebra o núcleo em diversos fragmentos, antes da Faco propriamente dita, para diminuir o tempo de ultrassom e a quantidade de fragmentos nucleares lançados contra 0 endotélio corneano (KOHLHAAS et al., 1998);

g) Angulação da abertura da ponteira de titânio da caneta de faco: a maior angulação da abertura da ponteira de titânio da caneta de faco (como a ponteira tipo Kelman) proporciona maior eficiência, diminuindo o tempo de ultrassom necessário para emulsificar um fragmento nuclear denso (KWITKO, 2003).

Além desses fatores, a perda endotelial cirúrgica pode ser potencializada por intercorrências nos períodos per e pós-operatório, tais como contato direto do endotélio corneano com a íris, hialoide anterior e/ou LIO, glaucoma, reação inflamatória, ou recrudescimento de uveíte quiescente.

\subsection{Vitrectomia e o endotélio}

As complicações da córnea na cirurgia vitreorretiniana, descritas na literatura, incluem cicatrização mais lenta do epitélio da córnea, abrasões recorrentes e edema 
do estroma, geralmente relacionadas aos pacientes diabéticos submetidos a esses procedimentos (BRIGHTBILL; MYERS; BRESNICK, 1978; FOULKS et al, 1979). Com o surgimento de melhores soluções de irrigação, instrumentação microcirúrgica e evolução nas técnicas cirúrgicas, a descompensação da córnea no pós-operatório, sem dúvida, passou a ocorrer com menos frequência do que nos primeiros anos da cirurgia de VPP. Foi sugerido que o fator mais importante responsável pelos danos à córnea pós-VPP nos diabéticos são traumas cirúrgicos, tanto para o epitélio da córnea quanto para o endotélio. A observação de que o edema epitelial intraoperatório ocorre mais rapidamente nas córneas diabéticas sugere que a função prejudicada do epitélio corneano diabético pode ser a causa mais importante de alterações da córnea nesses procedimentos (BUETTNER; BOURNE, 1981).

Friberg, Doran e Lazenby (1984) não observaram perda apreciável de células apenas pela introflexão escleral nos olhos fácicos ou afácicos, ou pela VPP sozinha nos olhos fácicos. No entanto, quando a VPP com facectomia foi necessária, além da introflexão escleral para reparar um descolamento de retina, a perda de células endoteliais aumentou significativamente, principalmente em procedimentos mais extensos, como em roturas gigantes, proliferação vitreorretinianas, hemorragia vítrea e nos casos em que foi utilizado gás C3F8. O cristalino intacto protege o endotélio da córnea contra danos durante a VPP. Os autores relataram, ainda, perda significativamente maior de células nos olhos submetidos à VPP, facectomia e introflexão escleral, ou olhos afácicos submetidos à VPP e introflexão escleral, do que nos olhos fácicos. Acredita-se que isso se deva à diminuição do fluxo de líquido de infusão no segmento anterior de pacientes fácicos, minimizando os danos mecânicos ao endotélio e limitando as alterações químicas do humor aquoso. Waltman et al. (1975) descobriram que pacientes fácicos submetidos à VPP apresentam menos edema da córnea e outras complicações endoteliais do que aqueles afácicos.

Embora o dano endotelial grave e irreversível na cirurgia vitreorretiniana de rotina seja improvável, a cirurgia ocasionalmente é realizada em olhos cujo endotélio da córnea já foi substancialmente comprometido. A avaliação endotelial da córnea no pré-operatório, estimando a densidade celular e observando a presença de guttata, ajudará a identificar pacientes de maior risco. A perda de células endoteliais 
parece diretamente relacionada ao insulto cirúrgico, mas não há relatos de alteração significativa no percentual de perda de células com o tempo seguindo-se à cirurgia vitreorretiniana isolada.

\subsection{Tratamento para BM e MER}

O tratamento proposto em ambas as patologias estudadas é a VPP com a técnica 23 Gauge, com três esclerotomias, sem sutura, com descolamento da hialoide posterior, sempre que possível, e pelling da MLI nos casos de BM, e peeling da MER nos casos de MER (SPITERI CORNISH et al., 2014). É injetado gás perfluoroctano na câmara vítrea para assegurar melhores resultados. A indicação formal de cirurgia para o tratamento do BM é para os estágios 2, 3 e 4, pois não há evidências de melhora da AV nos pacientes em estágio 1 (BENSON et al., 2001), e para MER a cirurgia é indicada para aqueles pacientes com perda significativa da visão, pois se sabe que a visão raramente melhora ou piora drasticamente, sendo a conduta conservadora ainda bastante adotada nos casos em que a baixa acuidade não está afetando a qualidade de vida do paciente (BANACH et al., 2001; FRASERBELL et al., 2003).

O objetivo principal da cirurgia, nas duas patologias, é o restabelecimento da anatomia foveal. No caso de BM, o propósito é o fechamento do buraco com a aproximação de suas bordas. No caso da MER, é retirar a membrana para restaurar a espessura normal da retina. Com a anatomia restituída, ocorre melhora dos sintomas e estabilização ou melhora da AV e metamorfopsia (BROOKS Jr., 2000).

A taxa de fechamento do BM varia na literatura de 58\% (KELLY; WENDEL, 1991) a 78-100\% (MUSELIER et al., 2010; ROGERS et al., 2007) e de 81\% até 100\% em estudos mais recentes (NADAL; DELAS; PIÑERO, 2012; YAGI; TAKAGI; TOMITA, 2012). A melhora da AV pode chegar a $90 \%$ dos casos de BM e $82 \%$ dos casos de MER (BRITO et al., 2014; LÜKE et al., 2013).

A técnica cirúrgica de Faco consiste em uma incisão em córnea clara com lâmina de 2,75 mm, capsulorrexe e, então, é realizada a Faco e implante de uma LIO. Segundo Bollinger e Langston (2008), esta cirurgia somente deveria ser realizada quando a função visual do paciente diminuísse significativamente. 


\subsection{Vitrectomia posterior via pars plana e a formação de catarata}

A progressão acelerada da catarata esclerótica nuclear é uma complicação importante da VPP, particularmente em uma época em que complicações graves como descolamento de retina e endoftalmite infecciosa são raras. Atualmente, a VPP está sendo realizada em olhos com AV relativamente boa, porque a indicação cirúrgica para os BMs e MERs está ocorrendo mais precocemente devido a melhorias nas técnicas cirúrgicas. Nesses casos, a formação de catarata esclerótica nuclear frequentemente causa diminuição da AV, em comparação com a AV préoperatória, dentro de um ano a dois anos da cirurgia vítrea (CHERFAN et al., 1991). Essa progressão da esclerose nuclear não foi imediatamente reconhecida durante os primeiros anos de desenvolvimento da VPP porque durante a evolução das técnicas deste procedimento para retinopatia diabética o mais comum era a lensectomia combinada com VPP. O desenvolvimento de catarata após a VPP foi notado com o crescente uso da mesma para o tratamento das MERs no final da década de 1970. Também foi observado que a progressão da catarata subcapsular posterior nos olhos vitrectomizados por MERs era relativamente pouco frequente. $O$ reconhecimento da progressão da catarata nuclear após a VPP exigiu que os cirurgiões medissem o grau de opacidade do cristalino antes e depois da cirurgia, e os métodos qualitativos iniciais para avaliar essa opacidade usavam termos como claro, leve, moderado ou grave para a esclerose nuclear. Esse esquema de classificação foi usado em um estudo mostrando que os olhos operados com MER idiopática apresentaram progressão substancialmente maior da esclerose nuclear do que os olhos não vitrectomizados. A progressão da esclerose nuclear foi definida como o desenvolvimento de esclerose em um cristalino transparente ou progressão da esclerose nuclear de um nível para o seguinte, como de leve para moderado. A incidência da progressão da esclerose nuclear neste estudo foi de $31 \%$ nos olhos operados após 12 meses em comparação com 0\% nos olhos contralaterais e $72 \%$ nos olhos operados em 24 meses em comparação com 15\% nos olhos contralaterais (DE BUSTROS et al., 1988; OGURA et al., 1991).

Além da VPP para MER, aumento da esclerose nuclear foi relatado também para uma variedade de outras indicações, como após cirurgia para BM, para a 
síndrome de TVM, com ou sem MER, bem como na VPP para descolamento regmatogênico da retina.

A etiologia da esclerose nuclear acelerada é incerta, mas várias causas potenciais foram postuladas nos últimos 25 anos. Fatores causais sugeridos incluem: diferenças fisiológicas entre a composição iônica da solução de infusão e o vítreo nativo durante a VPP; diferenças na temperatura entre a solução para infusão (à temperatura ambiente) e a temperatura corporal do vítreo e cristalino normal; toxicidade da luz do microscópio para o cristalino durante a cirurgia e aumento da oxidação das proteínas do cristalino, possivelmente devido a alterações na permeabilidade da cápsula posterior (THOMPSON, 2003). Mas, entre todos esses fatores, a oxidação aumentada das proteínas do cristalino que se segue à VPP tem sido mais amplamente aceita como responsável pela aceleração do processo de esclerose nuclear. Acredita-se que a remoção do vítreo cause alterações no microambiente ao redor da lente, o que leva ao aumento da oxidação das proteínas da mesma (SAWA et al., 2001).

Foi reconhecido durante os primeiros anos do advento da cirurgia de VPP que o contato intraocular do gás com a cápsula posterior do cristalino causava opacificação da mesma. Isso evoluiria para uma catarata subcapsular posterior em muitos olhos se o paciente não aderisse ao posicionamento prono. A não adesão ao posicionamento prono explica por que algumas crianças desenvolvem catarata subcapsular posterior após o uso de uma bolha de gás intravítrea, mesmo que não desenvolvam esclerose nuclear. No entanto, não há consenso na literatura quanto à influência das bolhas de gás no aumento da esclerose nuclear. Dois estudos realizados não encontraram aumento da esclerose nuclear com o uso de ar ou hexafluoreto de enxofre em comparação com olhos sem bolhas de gás intravítreas (DE BUSTROS et al., 1988; OGURA et al., 1991) e outros dois encontraram evidências de aumento da esclerose nuclear em olhos tratados com tamponamento gasoso (HSUAN et al., 2001; THOMPSON, 2003).

Um estudo recente analisou a duração da cirurgia de VPP e a gravidade da esclerose nuclear após a cirurgia do BM para determinar se a duração do procedimento influencia a progressão da esclerose nuclear. Os pesquisadores concluíram que os olhos com cirurgias de maior duração não apresentaram aumento 
da taxa de progressão da esclerose nuclear em comparação com os olhos com cirurgias de menor duração, o que sugere que nem a toxicidade da luz do microscópio nem a temperatura da solução de infusão desempenham papel significativo na progressão da esclerose nuclear após VPP (CHENG et al., 2001).

\subsection{Justificativa do estudo}

Devido à frequência cada vez maior de cirurgias combinadas de catarata e VPP para tratar doenças retinianas resolve-se investigar, de forma prospectiva, se há ou não diferenças com relação às complicações corneanas entre as duas seguintes modalidades terapêuticas utilizadas para tratamento de BM e MER: VPP associada à Faco imediata ou VPP associada à Faco postergada. 
2. Objetivos 


\subsection{Objetivo geral}

Avaliar comparativamente entre os dois grupos e ao final de 12 meses de acompanhamento a densidade de células endoteliais (DCE).

\subsection{Objetivos específicos}

- Avaliar comparativamente entre os dois grupos e ao final de 12 meses:

- A ECC;

- O CV do tamanho das células endoteliais;

- A Melhor Acuidade Visual Corrigida (MAVC);

- O erro refratométrico final (equivalente esférico);

- A ocorrência de catarata no grupo VPP + Faco sequencial;

- A ocorrência de efeitos adversos;

- Variações da pressão intraocular (PIO). 
3. Casuística e Métodos 


\subsection{Considerações éticas}

Após a aprovação pelo Comitê de Ética em Pesquisa (CEP) do Hospital das Clínicas da Faculdade de Medicina de Ribeirão Preto da Universidade de São Paulo (HCFMRP-USP), sob o número do parecer 1.318.035 (Anexo), um estudo prospectivo e randomizado foi conduzido incluindo pacientes fácicos com diagnóstico de MER ou BM, sem opacificação do cristalino ou com catarata cortical/nuclear grau II (de acordo com o protocolo Lens Opacities Classification System III - LOCS III), submetidos a tratamento cirúrgico no Setor de Retina e Vítreo do Departamento de Oftalmologia do HCFMRP-USP, entre março de 2015 e março de 2017. Os pacientes foram randomizados para um dos dois grupos: Grupo combinado (VPP + Faco); Grupo sequencial: (VPP + faco em segundo tempo) e acompanhados por um ano.

Todos os participantes assinaram o Termo de Consentimento Livre e Esclarecido (TCLE) (Apêndice) antes de participar no estudo, o qual foi registrado em ensaios clínicos no site www.ensaiosclinicos.gov.br, sob nำRBR-3wmd9s.

\subsection{Pacientes e grupos}

Oitenta e oito pacientes foram convidados a participar do estudo no período de março de 2016 a março de 2017, dos quais seis não aceitaram participar da pesquisa. Oitenta e dois pacientes (84 olhos) foram randomizados em dois grupos: Grupo cirurgia combinada: VPP e faco imediata; Grupo cirurgia sequencial: VPP e faco postergada, se necessário. A randomização foi feita a partir de distribuição aleatória gerada com o programa de computador (Excel). Uma coluna foi criada com 42 nomes do grupo combinado e 42 nomes do grupo sequencial. Na coluna ao lado foi usada a fórmula do excel (Aleatório) desde a linha 1 até a 84 . A partir daí, foi gerada uma sequência aleatória em números decimais. Na terceira coluna foi utilizada a fórmula Ordem.eq, fixando o primeiro valor da coluna dois e selecionando todos os outros valores desta coluna. Com isso foi gerada uma sequência aleatória de 1 a 84. Os pacientes admitidos para randomização eram numerados e seu 
número buscado na tabela de randomização para saber em qual grupo ele seria alocado.

Foram incluídos no estudo 42 pacientes com diagnóstico de MER ou BM submetidos à cirurgia sequencial, ou seja, no primeiro momento realizou-se a cirurgia VPP e no segundo momento, se necessário, a Faco; e 42 pacientes com diagnóstico de MER ou BM submetidos à cirurgia simultânea, ou seja, Faco e VPP combinadas (Faco-VPP), atendidos no Serviço de Retina e Vítreo do HCFMRP-USP, que preencheram os critérios de inclusão e respeitaram os critérios de exclusão. Durante o acompanhamento, quatro pacientes foram excluídos da pesquisa: dois por perda de seguimento (falta de duas consultas consecutivas), um por não conseguir realizar os exames e um por apresentar descolamento de retina. Ao final, os dados de 78 pacientes (80 olhos) foram analisados (Figura 16).

Figura 16 - Diagrama do desenho do estudo

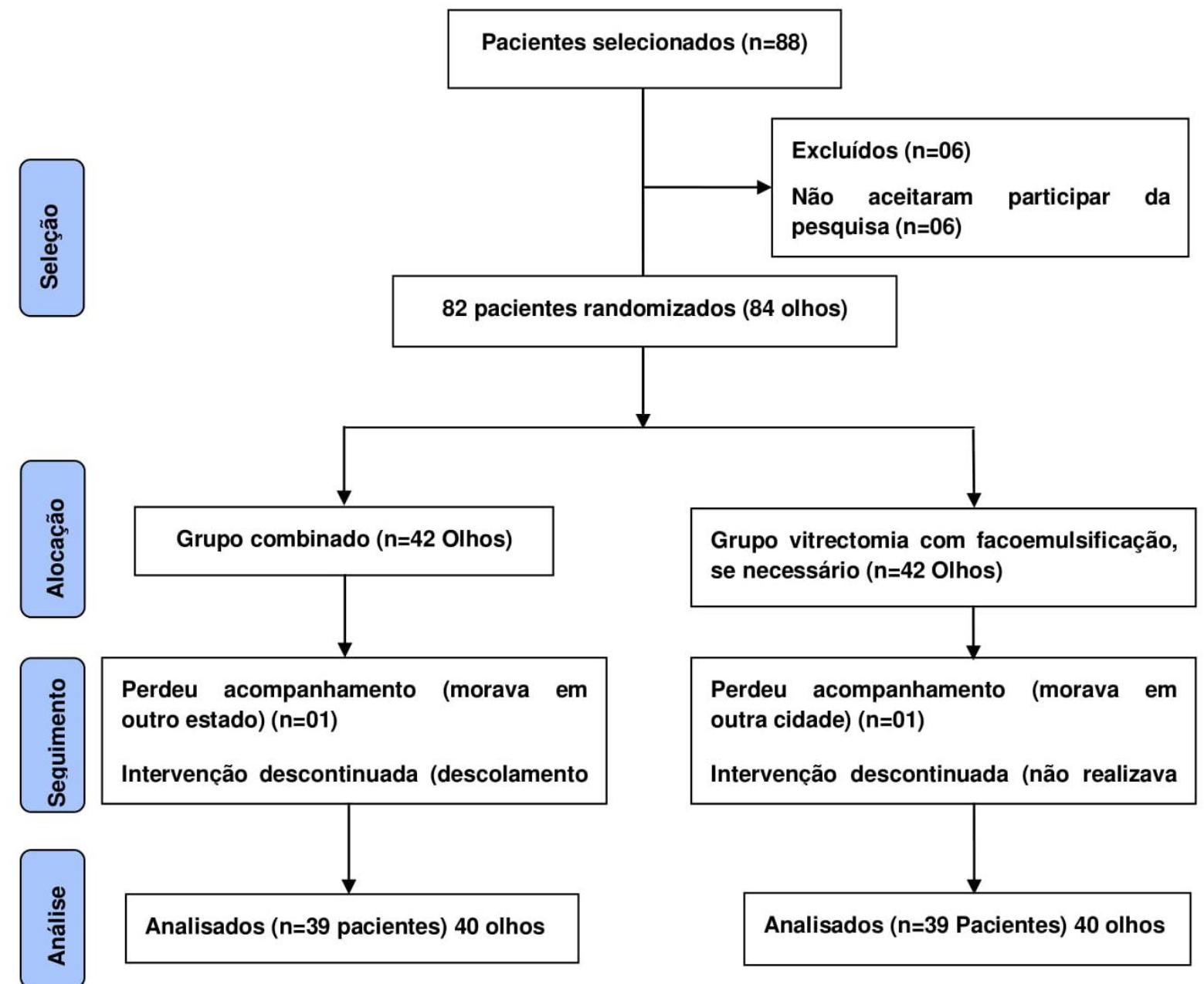




\subsection{Desfechos do estudo}

1. Desfecho primário: alteração na DCE.

2. Desfechos secundários: (1) variação da paquimetria; (2) alteração no CV; (3) alteração da AV; (4) erro refratométrico final (equivalente esférico); (5) ocorrência e progressão da catarata no grupo cirurgia sequencial (VPP) após 12 meses de seguimento; (6) incidência de complicações cirúrgicas do segmento anterior (traumas de íris, descolamento de Descemet, rotura de cápsula posterior, ou endoftalmite) entre o grupo de cirurgia sequencial e o grupo de cirurgia simultânea; e (7) variação da PIO.

\subsection{Critérios de inclusão}

1. Pacientes com diagnóstico de BM idiopático ou MER com indicação de cirurgia de VPP (grau do BM $\geq 2$ e grau de MER $\geq 1$ (classificação de Gass: 1-4 [GASS; 1995] e classificação de Gass: 0-2; [GASS, 1987]);

2. Pacientes sem catarata ou com opacificação do cristalino cortical $\leq 2$, nuclear $\leq 2$ e sem opacidade subcapsular posterior (LOCS III) (CHYLACK et al., 1993);

3. AV igual ou pior que 0,2 logMAR;

4. Assinado o TCLE.

\subsection{Critérios de exclusão}

1. Outra doença ocular;

2. Qualquer cirurgia ocular prévia;

3. Desordens sistêmicas que afetassem o olho;

4. Inabilidade de informar satisfatoriamente ou incapacidade de colaboração, impedindo a obtenção de exames bem documentados;

5. Opacidade do cristalino que interferisse na visualização da câmara vítrea, ou seja, subcapsular posterior de qualquer intensidade e nuclear ou cortical maior que 2 pelo escore de LOCS III; 
6. História de lesão de córnea ou patologias corneanas prévias;

7. Inflamação do segmento anterior;

8. Qualquer condição que impossibilitasse a obtenção de uma microscopia especular nítida no pré-operatório ou no seguimento;

9. Perda de seguimento por duas consultas consecutivas após as cirurgias.

Nesse momento, os pacientes que preenchiam os critérios de inclusão eram informados sobre a realização do referido estudo e apresentado aos mesmos o TCLE, que era lido pelo pesquisador e explicado de forma que o paciente pudesse entender corretamente, esclarecendo todas as dúvidas que surgissem com relação ao estudo, ou mesmo quanto às informações contidas no TCLE. Havendo concordância do paciente em participar do estudo, eram colhidas as assinaturas e os referidos registros gerais do pesquisador, do paciente e de uma testemunha que tivesse presenciado a leitura do termo e a aceitação do paciente. Para os pacientes que aceitaram participar do estudo, o exame de seleção foi usado como préoperatório, que ocorreu entre um e sete dias antes da cirurgia.

\subsection{Métodos de avaliação}

Todos os pacientes foram submetidos a exames pré-operatórios e de seguimento pelo mesmo examinador, que incluíram avaliação oftalmológica detalhada com:

- Medida da MAVC usando a tabela logMAR ETDRS (Early Treatment Diabetic Retinopathy Study), segundo padronização recomendada pelo ETDRS (Photocoagulation For Diabetic Macular Edema: Early Treatment Diabetic Retinopathy Study Report Number 1 Early Treatment Diabetic Retinopathy Study Research Group", 1985) (CAMPARINI et al., 2001; KLEIN et al., 1983);

- Tonometria de aplanação: PIO medida com tonômetro de Goldmann (HaagStreit, Berna, Suíça);

-Biomicroscopia do segmento anterior:

- A classificação da catarata foi realizada de acordo com o protocolo LOCS III (CHYLACK et al., 1993), que consiste de avaliação na lâmpada 
de fenda da opacidade do cristalino dando escores, em uma escala decimal, para cor do núcleo, opalescência nuclear, cataratas cortical e subcapsular posterior. A dureza do cristalino foi classificada usando-se uma escala de 0 a 4+. Para o cálculo do poder da LIO, a ceratometria foi realizada com o autorefrator Topcon (KR8800, Topcon, Tokio, Japão) e o eixo axial foi medido utilizando-se o biômetro OcuScan Alcon RXP AScan (Alcon, Fortworth, Texas).

- Biomicroscopia de fundo de olho em lâmpada de fenda com lente de 78 Dioptrias, marca Volk;

- Mapeamento de retina realizado com oftalmoscópio binocular indireto e lente de 20 Dioptrias, marca Volk;

- Microscopia Especular:

- O endotélio da córnea foi examinado com um microscópio especular de não-contato (Konan Noncon Robo-CA SP - 8000®). Três fotografias do endotélio foram obtidas por olho em cada visita, e a média das medidas foi calculada. Nesse método semiautomático, o operador digita o centro de cada célula (método central) (Figura 17). 
Figura 17 - Técnicas para analisar a densidade das células endoteliais

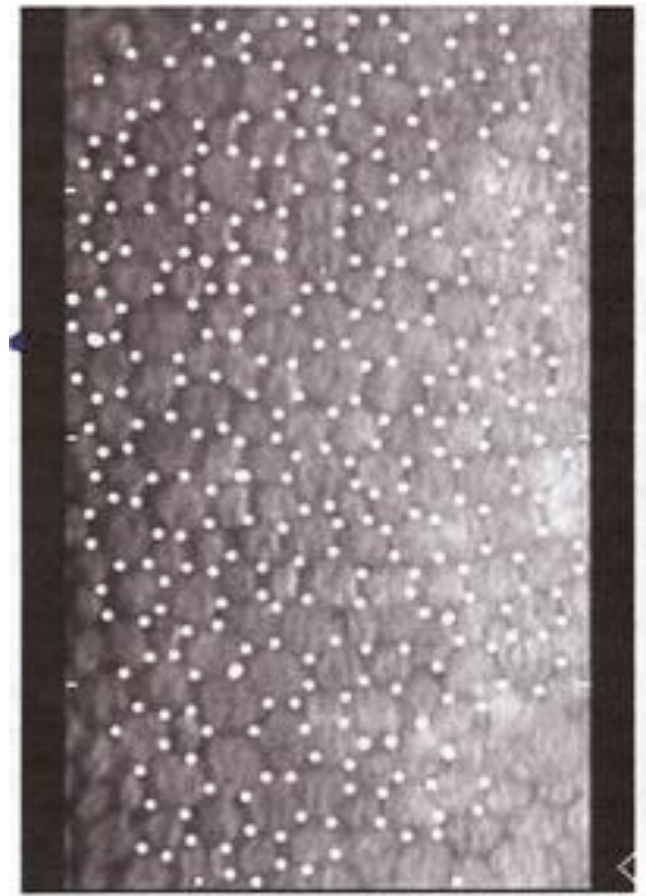

C: Corner Method

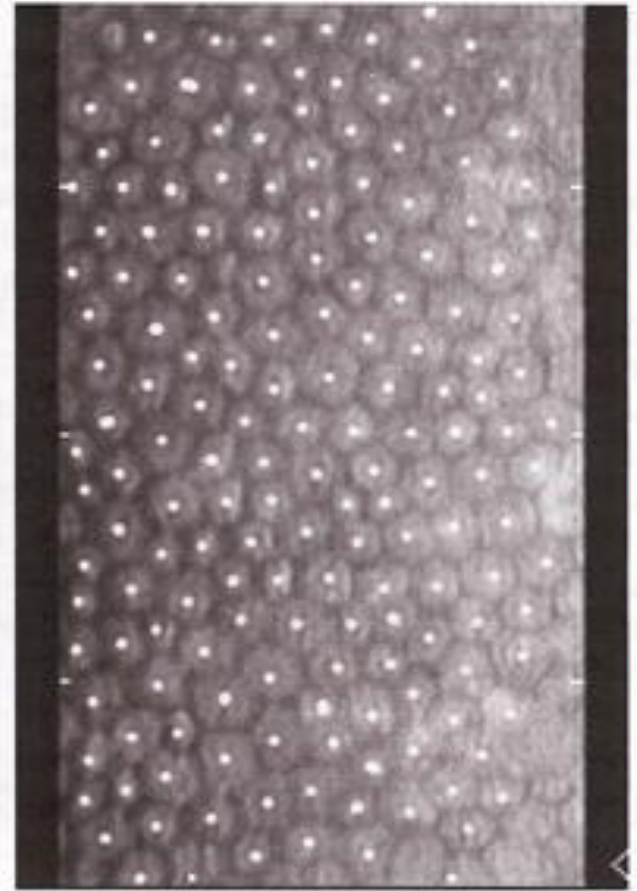

D: Center Method

Fonte: (McCAREY; EDELHAUSER; LYNN, 2008).

A morfologia endotelial da córnea foi calculada de um grupo central de 45 células de cada fotografia, como previamente detalhado (BEHNDIG et al., 2001) (Figura 18). A escolha de 45 células foi baseada no estudo de Lundberg e Behndig (2003), que detectou diferença de $5 \%$ na contagem celular com probabilidade de $95 \%$. As seguintes variáveis foram avaliadas (Figura 19):

1. DCE, definida como o número de células por $\mathrm{mm}^{2}$ de superfície;

2. A variabilidade do tamanho das células endoteliais centrais da cornea, ou $\mathrm{CV}$, ou ainda polimegatismo, definido pela fórmula:

polimegatismo = área da maior célula - área da menor célula área de uma célula média 
Figura 18 - Fotografia mostrando a obtenção das medidas da morfologia endotelial da córnea através do método central em um paciente do estudo

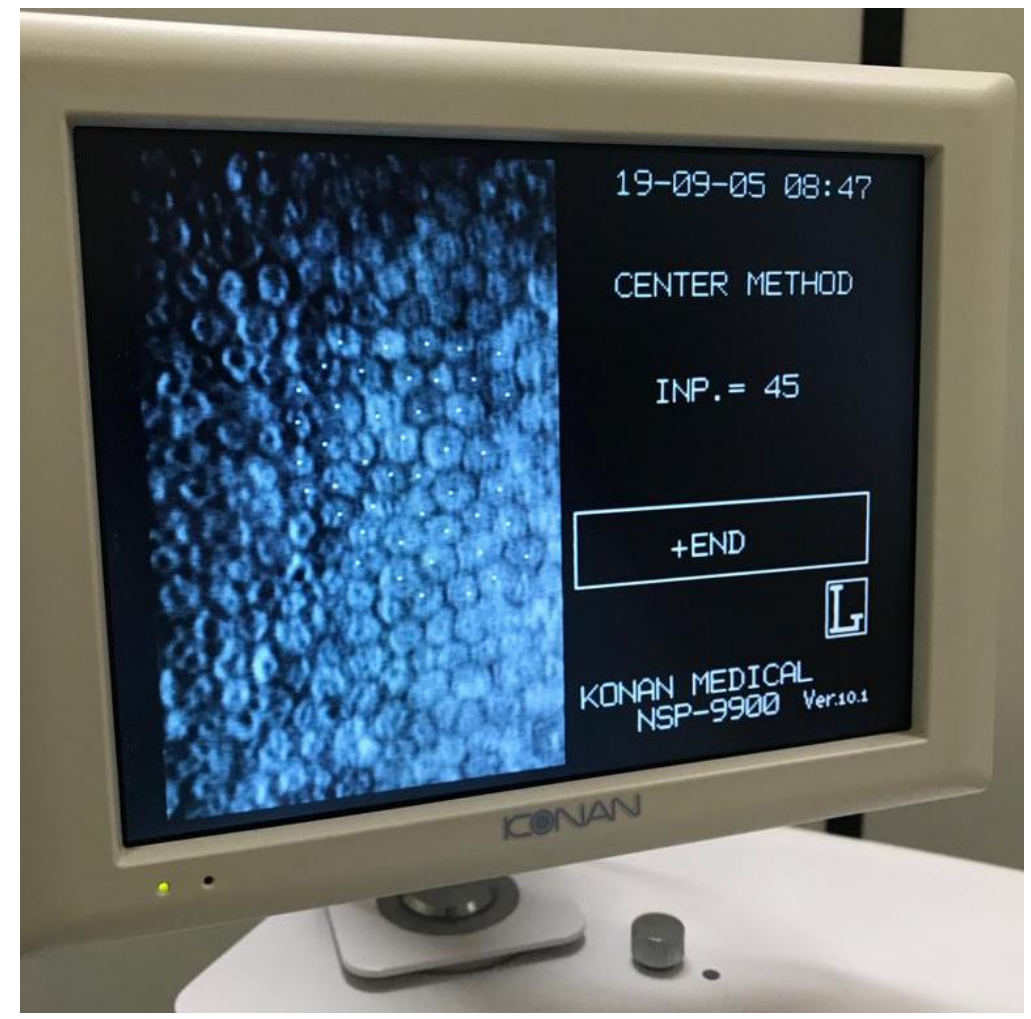

Figura 19 - Fotografia mostrando a análise da morfologia endotelial da córnea: DCE, CV, pleomorfismo e paquimetria em um paciente do estudo

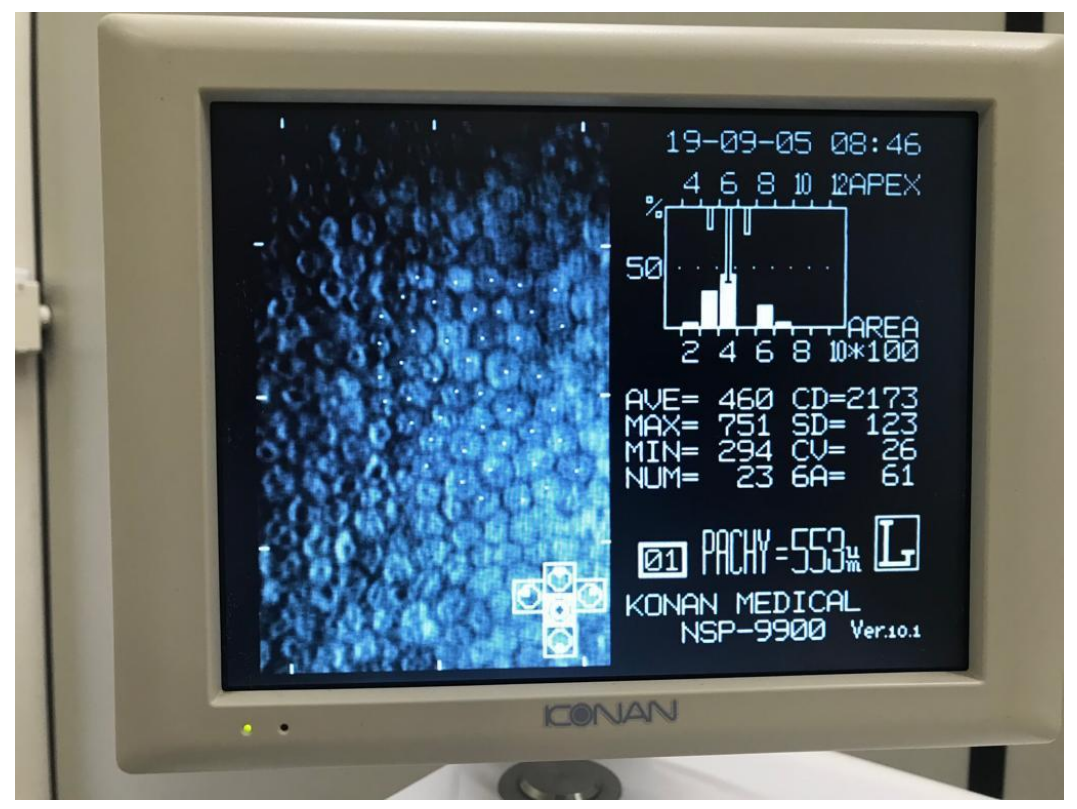


- Paquimetria óptica:

- A ECC foi medida usando-se um paquímetro óptico (Konan Noncon RoboCA SP - 8000®), tomando-se as medidas de uma zona central de $1 \mathrm{~mm}$. As fotos do endotélio da córnea foram tomadas da mesma localização, com microscópio especular de não-contato, automatizado (Konan Noncon Robo-CA SP - 8000®). Para cada olho foi calculada a média entre três medidas, determinadas pelo mesmo examinador. De acordo com 0 fabricante, a precisão desse método é de cerca de 5 a $10 \mu \mathrm{m}$ (Figura 19).

- Retinografia: fotografias coloridas da retina realizadas com retinógrafo digital Topcon TRC-50DX, câmera Nikon D90 12.3 megapixels, angular de 35;

-OCT obtida pelo aparelho HRA-OCT Heidelberg Spectralis (Heidelberg Engineering, Heidelberg, Alemanha). A avaliação da região macular foi obtida utilizando protocolo de rastreamento padrão $20^{\circ} \times 15^{\circ}$, consistindo de 19 seções horizontais (cada uma a partir de 25 quadros) com distância de $240 \mu \mathrm{m}$ entre cada scan, cobrindo um quadrilátero de $20 \times 15$ graus na retina, centrado na fóvea. O modo de follow-up foi utilizado a fim de minimizar a variabilidade nos novos reexames. Para melhorar a acurácia dos dados da OCT, a delineação automática dos limites interno e externo da retina neurossensorial gerados pelo software do equipamento foram verificados para cada um dos scans. O fechamento do BM foi definido como a reaplicação das bordas do defeito retiniano após a cirurgia, segundo critérios estabelecidos por Imai et al. (1999). O acompanhamento dos casos de MER se deu por meio da espessura foveal central calculada automaticamente pela média da espessura da região macular central em um diâmetro de $1000 \mu \mathrm{m}$ centrado na fovéola pelo software do Spectralis. Nos casos de BM, foi calculada a medida da altura, da base externa e do diâmetro linear mínimo.

- Registro fotográfico do cristalino ou LIO: imagens obtidas com lâmpada de fenda da marca Gilras estilo Haag-Streit com câmera 3ccd Sony acoplada para documentar a incidência e progressão da catarata no grupo submetido apenas à VPP (Figuras 20 e 21). Uma impressão da tabela LOCS III em alta qualidade era usada pelo examinador nesse momento para comparar com o 
cristalino dos pacientes avaliados e então era feita a classificação da catarata.

Figura 20 - Registro fotográfico do cristalino com catarata em paciente do grupo sequencial
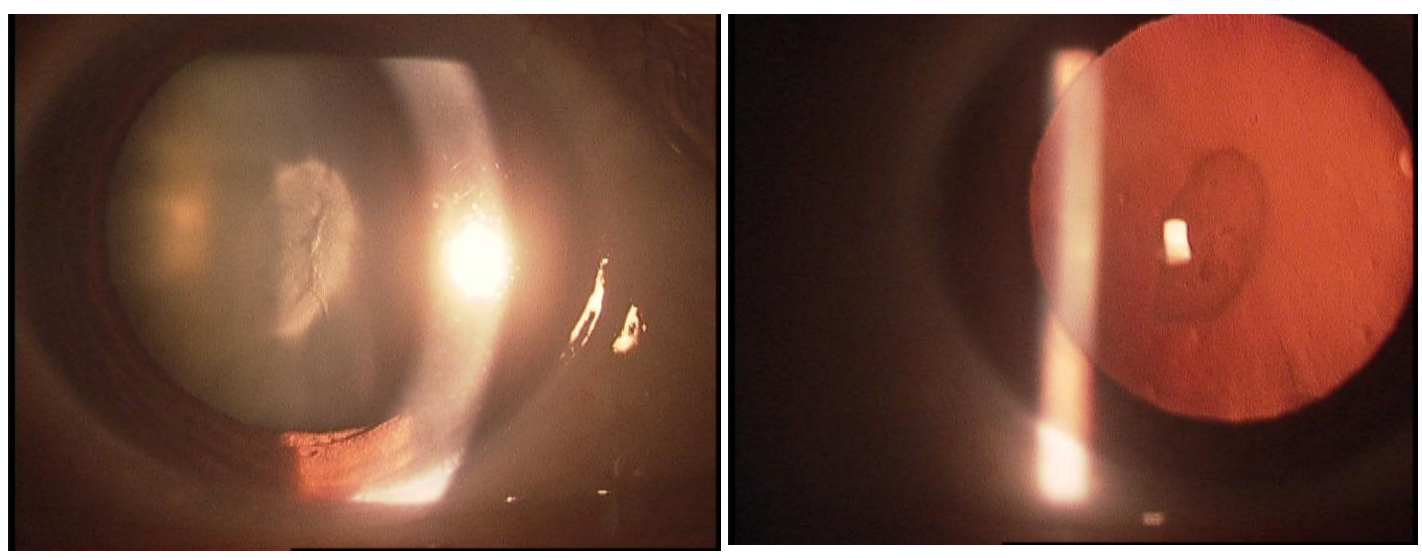

Figura 21 - Evolução da catarata em paciente de grupo sequencial

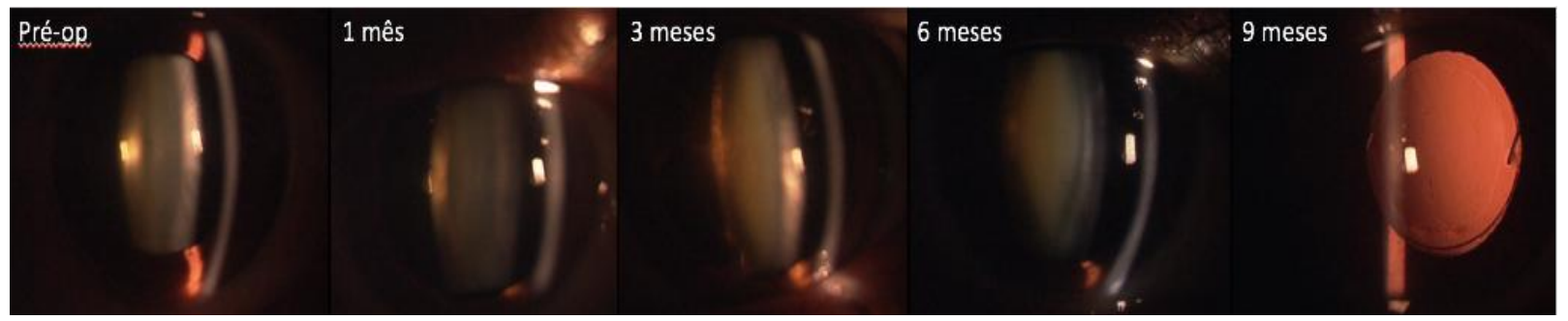

\subsection{Indicação de tratamento e técnica cirúrgica}

Após o exame inicial, os pacientes foram randomizados em dois grupos. Os pacientes do grupo combinado foram submetidos à faco e VPP imediatas, enquanto os do grupo sequencial submeteram-se à VPP, e poderiam realizar a Faco a qualquer momento no pós-operatório se a severidade de catarata fosse $\geq 1$ 
subcapsular ou $\geq 3$ nuclear ou $\geq 3$ cortical (LOCS III), e/ou se o paciente apresentou, na opinião do investigador:

1. Catarata que impediria o exame oftalmológico ou a avaliação da OCT;

2. Diminuição clinicamente significativa da AV atribuível à catarata.

Em ambos os grupos, a medicação pré-operatória consistiu de fenilefrina a $10 \%$ e tropicamida a 1\%. A assepsia pré-operatória das pálpebras e da pele periorbital foi realizada com solução de iodopovidona a $10 \%$ e a conjuntiva foi irrigada com colírio de iodopovidona a 5\% (Ophthalmos®).

Todas as cirurgias foram realizadas por um dos dois cirurgiões de retina e vítreo. A anestesia consistiu em um bloqueio peribulbar de $10 \mathrm{~mL}$ de bupivacaína a $2 \%$ em combinação com sedação endovenosa, administrada por um anestesiologista. A VPP foi realizada com três esclerotomias e instrumentos 23 gauge, sem sutura. A hialoide posterior foi corada com $0,1 \mathrm{ml}$ de triancinolona acetonina e seu descolamento foi tentado em todos os pacientes. O peeling da MLI corada com azul brilhante foi realizado e gás perfluoroctano a 15\% (3 $\mathrm{ml}$ de C3F8 e $20 \mathrm{ml}$ de ar) foi injetado na cavidade vítrea ao final do procedimento. O paciente foi instruído a manter a posição de face para baixo pelo menos por sete dias no pósoperatório nos casos de BM.

A cirurgia de catarata foi realizada pelos mesmos cirurgiões, acima mencionados, através de uma incisão de córnea clara, com uma lâmina de 2,75 mm, capsulorexe curvilínea e contínua, hidrodissecção, hidrodelineação e, em seguida, Faco (máquina Constelation, Alcon) utilizando a técnica "stop and shop", seguida pela aspiração de restos corticais e implante de LIO dobrável três peças (MA60AC, Alcon, Fort Worth, Texas) no saco capsular. Foi realizada sutura com mononylon 10.0 na incisão da córnea clara em pacientes do grupo combinado antes da VPP e removida no final da cirurgia. A sutura de nylon não foi colocada em pacientes de grupo sequencial, por razões éticas. No pós-operatório, todos os pacientes usaram colírio de moxifloxacino a 0,5\% (Vigamox-Alcon) a cada três horas por oito dias e colírio de prednisolona a $0,1 \%$ (Predfort, Allergan) por quatro semanas. Os pacientes em ambos os grupos foram seguidos por um ano após a PPV. 


\subsection{Exames de seguimento e medidas}

Os pacientes foram programados para exames de acompanhamento no préoperatório $\left(T_{0}\right)$, um mês $\left(T_{1}\right)$, três meses $\left(T_{3}\right)$, seis meses $\left(T_{6}\right)$, nove meses $\left(T_{9}\right)$ e doze meses $\left(\mathrm{T}_{12}\right)$ após a VPP. Nessas visitas, a MAVC foi determinada após a refração ETDRS e os pacientes submetidos a exame oftalmológico completo seguindo o plano de trabalho abaixo (Tabela 4):

Tabela 4 - Plano de avaliação e de exames

\begin{tabular}{lcccccc}
\hline & Basal & 1 mês & 3 meses & 6 meses & 9 meses & 12 meses \\
\hline AOG & $\mathbf{X}$ & $\mathbf{X}$ & $\mathbf{X}$ & $\mathbf{X}$ & $\mathbf{X}$ & $\mathbf{X}$ \\
OCT & $\mathbf{X}$ & $\mathbf{X}$ & $\mathbf{X}$ & $\mathbf{X}$ & $\mathbf{X}$ & $\mathbf{X}$ \\
Microscopia Especular & $\mathbf{X}$ & $\mathbf{X}$ & $\mathbf{X}$ & $\mathbf{X}$ & $\mathbf{X}$ & $\mathbf{X}$ \\
Paquimetria & $\mathbf{X}$ & $\mathbf{X}$ & $\mathbf{X}$ & $\mathbf{X}$ & $\mathbf{X}$ & $\mathbf{X}$ \\
Retinografia & $\mathbf{X}$ & $\mathbf{X}$ & $\mathbf{X}$ & $\mathbf{X}$ & $\mathbf{X}$ & $\mathbf{X}$ \\
Foto do cristalino & $\mathbf{X}$ & $\mathbf{X}$ & $\mathbf{X}$ & $\mathbf{X}$ & $\mathbf{X}$ & $\mathbf{X}$
\end{tabular}

AOG: avaliação oftalmológica geral com medida da acuidade visual corrigida, biomicroscopia de segmento anterior e de fundo de olho na lâmpada de fenda, tonometria de aplanação e mapeamento de retina foram realizados em todas as visitas. OCT: Tomografia de coerência óptica.

\subsection{Estimativa do tamanho da amostra}

Considerando a média e o desvio padrão (16\% e 4\%, respectivamente) para a diferença interindividual na DCE encontrada em estudo prévio (VENTURA; WALTI; BOHNKE, 2001), pode-se estimar que, com a amostra de 33 pacientes por grupo, a mínima diferença detectável seria 5\% (considerando-se poder $=80 \%$ ), considerada bem adequada para os objetivos deste estudo. 


\subsection{Análise estatística}

Todos os dados foram analisados com técnicas clássicas de estatística descritiva, utilizando-se gráficos, histogramas e tabelas.

As análises estatísticas foram realizadas utilizando o software JMPß) 10 (SAS Institute Inc. Cary, NC, EUA, 2011). Resultados serão apresentados com os valores clássicos de síntese de dados: média, desvio padrão, erro padrão e intervalo de confiança.

O teste de Kolmogov-Smirnov foi aplicado para testar se os dados apresentavam distribuição normal, quando necessário, constatando-se que para a maioria das variáveis, os testes paramétricos seriam adequados. Além disso, medidas longitudinais, como AV e DCE, foram comparadas durante o seguimento com os valores iniciais dentro de cada grupo, e entre os grupos, usando análise multivariada da variância (MANOVA), considerando os possíveis efeitos dos indivíduos, dos grupos, e do tempo nas variáveis estudadas.

Para verificar a associação das variáveis nominais e qualitativas, como a classificação da patologia e da catarata, foi aplicado o teste qui-quadrado.

Como de praxe, o valor de $\mathrm{P}$ adotado para se considerar estatisticamente significativo foi alpha $<0.05$. 
4. Resultados 
Oitenta e oito pacientes fácicos foram identificados e convidados a participar do estudo durante o período de março de 2016 a março de 2017. Destes, seis não concordaram em participar da pesquisa. Oitenta e dois pacientes (84 olhos, porque dois pacientes participaram dos dois grupos por apresentarem BM bilateral) foram, então, randomizados de acordo com uma sequência gerada por computador em dois grupos. Quarenta e dois pacientes foram alocados no grupo cirurgia combinada (Faco e VPP imediatas) e 42 no grupo cirurgia sequencial (VPP e faco postergada para o segundo tempo). Quatro foram excluídos do estudo: dois por perda de seguimento (falta de duas consultas consecutivas), um paciente por não conseguir realizar os exames e um por apresentar descolamento de retina. Portanto, os dados de 78 pacientes (80 olhos) foram incluídos na análise final (40 pacientes no grupo cirurgia combinada e 40 no grupo cirurgia sequencial).

Os grupos foram comparados (média \pm erro padrão) quanto ao sexo, à idade, presença de hipertensão e/ou diabetes e duração dos sintomas. O relato dos pacientes portadores de BM quanto à duração da baixa visual foi de 11,78 $\pm 2.05 \mathrm{e}$ $12,25 \pm 2.08$ meses nos grupos combinado e sequencial, respectivamente $(p=0.875)$. As características do pré-operatório estão sumarizadas na Tabela 5.

Tabela 5 - Características dos pacientes no pré-operatório nos grupos cirurgia combinada e cirurgia sequencial

\begin{tabular}{|c|c|c|c|c|c|c|c|}
\hline & \multicolumn{2}{|c|}{$\begin{array}{c}\text { Cirurgia combinada (Faco- } \\
\text { VPP) }\end{array}$} & \multicolumn{2}{|c|}{$\begin{array}{c}\text { Cirurgia sequencial (VPP-S- } \\
\text { Faco) }\end{array}$} & \multicolumn{3}{|c|}{$\mathbf{P}$} \\
\hline & BM & MER & BM & MER & BM & MER & BM/MER \\
\hline $\begin{array}{c}\text { Feminino } \\
\text { (número absoluto) }\end{array}$ & 26 & 3 & 25 & 5 & - & & 0,79 \\
\hline $\begin{array}{c}\text { Idade } \\
\text { (média } \pm \mathrm{EP} \text { anos) }\end{array}$ & $66.84 \pm 1.03$ & $71.42 \pm 2.43$ & $64.62 \pm 1.04$ & $68.12 \pm 2.2$ & 0.13 & 0.34 & - \\
\hline $\begin{array}{c}\text { HAS } \\
\text { (número absoluto) }\end{array}$ & 20 & 5 & 19 & 6 & & & 0.91 \\
\hline $\begin{array}{c}\text { Diabéticos } \\
\text { (número absoluto) }\end{array}$ & 7 & 3 & 4 & ZERO & - & - & 0.34 \\
\hline $\begin{array}{l}\text { Tempo de sintomas } \\
\text { (média } \pm \text { EP meses) }\end{array}$ & $11.78 \pm 2.05$ & $29.42 \pm 7.19$ & $12.25 \pm 2.08$ & $15.75 \pm 6.73$ & 0.87 & 0.18 & - \\
\hline
\end{tabular}

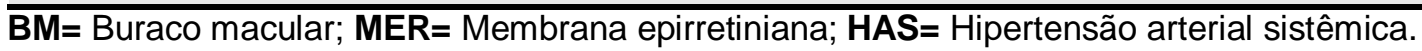


Os grupos também se mostraram homogêneos quanto à distribuição do grau do BM e MER. As características anatômicas do BM e MER (no pré-operatório e aos 12 meses) estão apresentadas nas Tabelas 6 e 7, respectivamente.

Tabela 6 - Características anatômicas do buraco macular nos dois grupos

\begin{tabular}{lcccc}
\hline & $\begin{array}{c}\text { Cirurgia combinada } \\
\text { (Faco-VPP) }\end{array}$ & $\begin{array}{c}\text { Cirurgia sequencial (VPP- } \\
\text { S-Faco) }\end{array}$ & P \\
\hline & 2 & $17 \%$ & $14 \%$ & 0.894 \\
\hline Grau de BM & 3 & $18 \%$ & $20 \%$ & $15 \%$ \\
\hline Taxa de fechamento do BM & $15 \%$ & $75 \%$ & 0.834 \\
\hline Altura do BM & $73 \%$ & $448,06 \pm 11,22 \mu \mathrm{m}$ & $0.65 ;$ \\
\hline Menor diâmetro linear entre & $489,58 \pm 36,57 \mu \mathrm{m}$ & $459,88 \pm 34,79 \mu \mathrm{m})$ & 0.559 \\
\hline as bordas do BM & & & $;$ \\
\hline diâmetro da base do BM & $1094,24 \pm 53,83 \mu \mathrm{m}$ & $1019,75 \pm 62,55 \mu \mathrm{m}$ & 0.369 \\
\hline
\end{tabular}

BM= Buraco macular; Faco: Facoemulsificação; VPP: Vitrectomia via pars plana.

Tabela 7 - Características anatômicas da membrana epirretiniana nos dois grupos no préoperatório e aos 12 meses

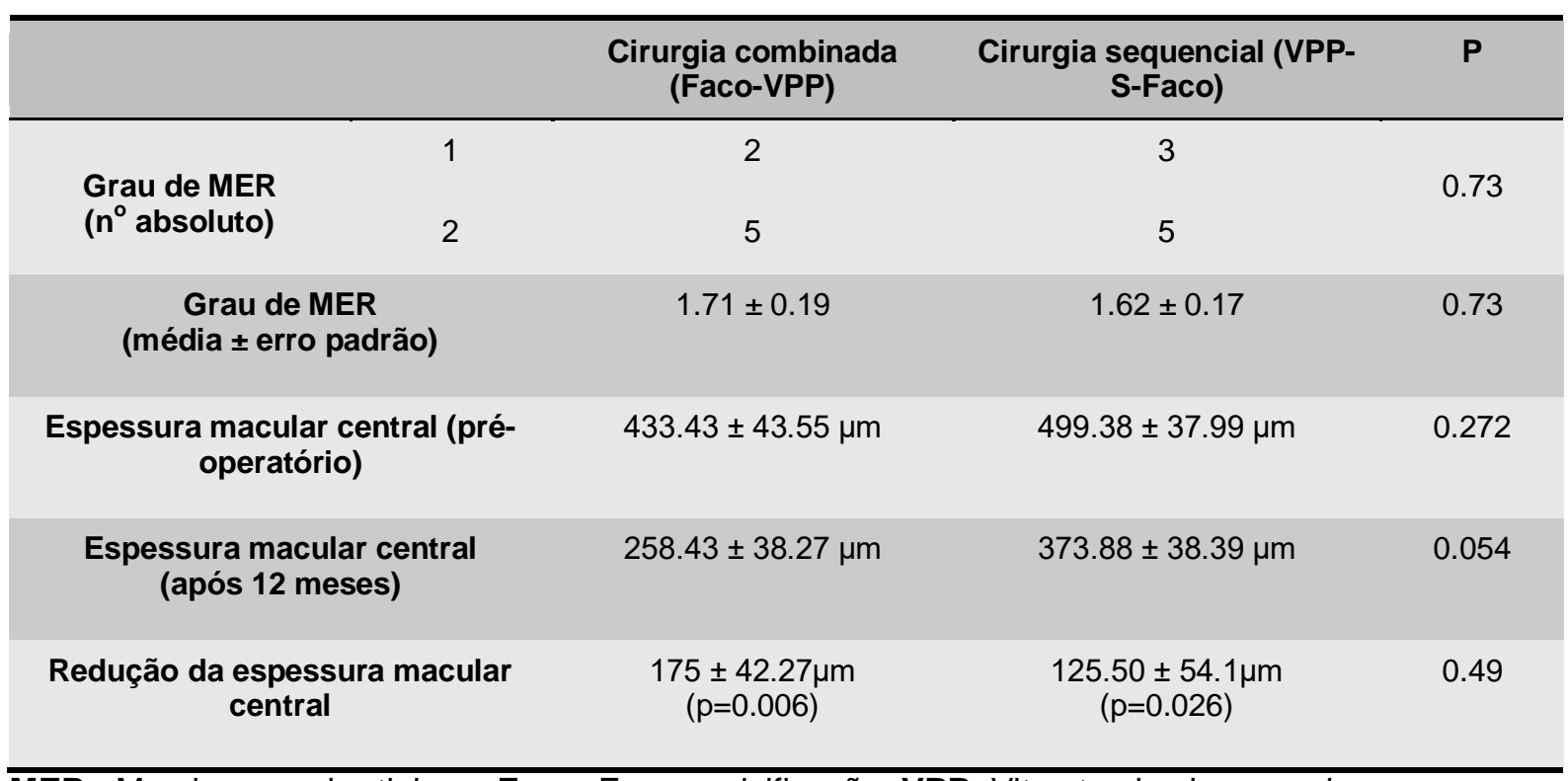

MER= Membrana epirretiniana; Faco: Facoemulsificação; VPP: Vitrectomia via pars plana. 
Em relação à distribuição das patologias (MER e BM), em cada grupo, observou-se que ela foi equivalente, não havendo diferença estatística entre os grupos ( $p=0.775$ ) (Figura 22).

Figura 22 - Distribuição das patologias nos grupos cirurgia combinada e cirurgia sequencial

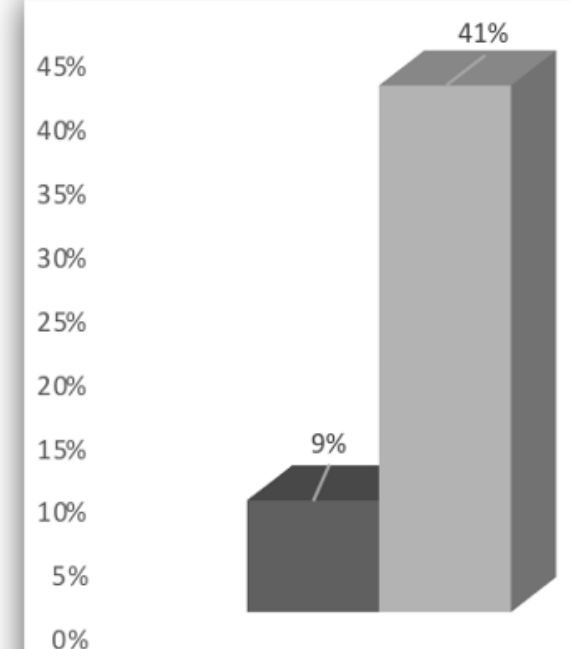

Combina do

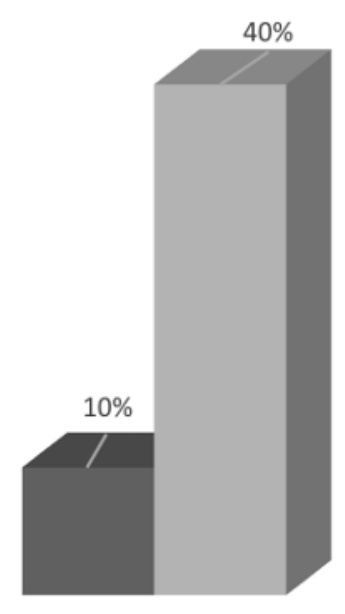

Sequencial
- Membrana Epirretiana

- Buraco Macular

Quanto à classificação da catarata nuclear e cortical no início do estudo e sua distribuição em ambos os grupos, houve diferença estatística no grau de catarata nuclear entre os grupos ( $\mathrm{p}=0.001$ ) (Figura 23); o mesmo não se observou com o grau de catarata cortical, que não apresentou diferença significativa entre os grupos $(p=0.091)$ (Figura 24) 
Figura 23 - Graus de catarata nuclear dos pacientes nos grupos cirurgia combinada e cirurgia sequencial

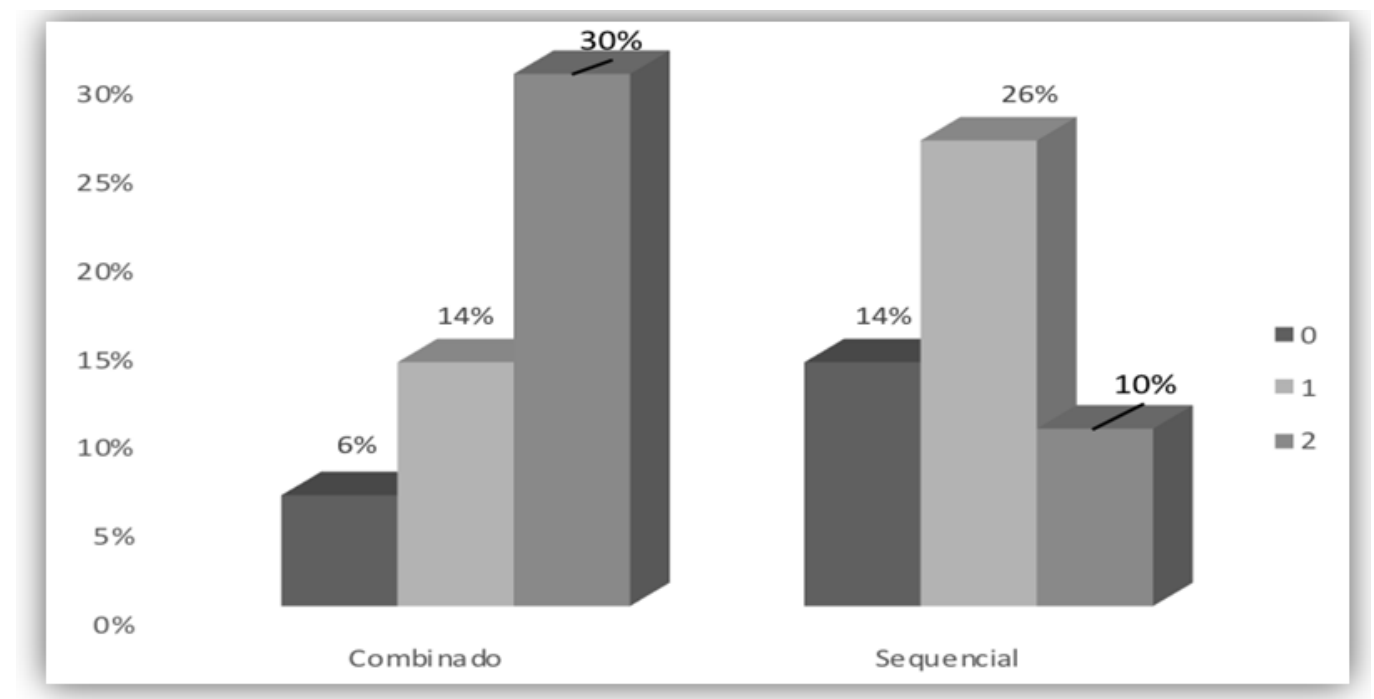

Figura 24 - Graus de catarata cortical dos pacientes nos grupos cirurgia combinada e cirurgia sequencial

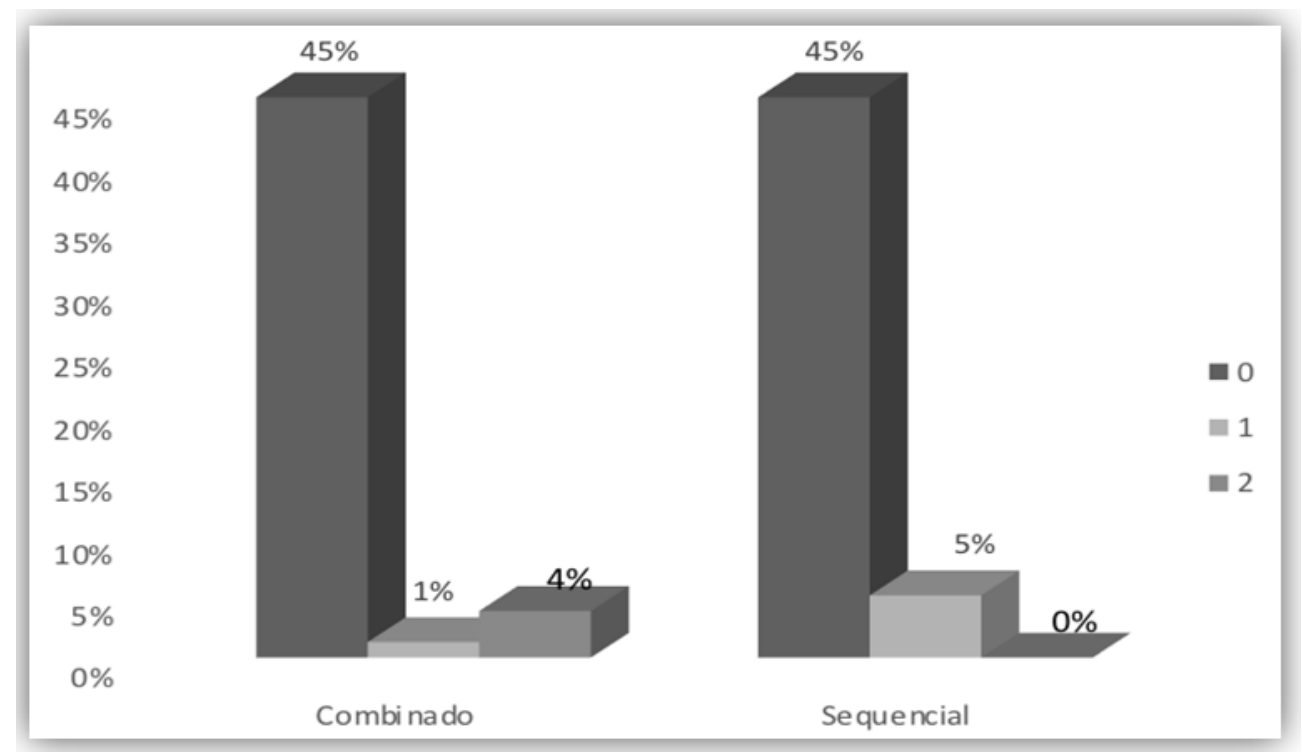




\subsection{Desfecho primário}

\subsubsection{Densidade de células endoteliais}

A média da DCE no pré-operatório e aos 12 meses foi de $2408.70 \pm 56,60$ e $2117.10 \pm 77.74$, respectivamente, no grupo cirurgia combinada, e $2472.85 \pm 56,60$ e $2105.67 \pm 77.74$, respectivamente, no grupo cirurgia sequencial. Diminuição significativa na média da DCE em relação ao pré-operatório foi observada em todas as visitas do estudo no grupo combinado $(p<0.05)$ e após seis meses no grupo sequencial $(p<0.05)$. Não houve diferença significativa na média da DCE entre os grupos em qualquer visita do estudo $(p=0,707)$ (Figura 25).

Figura 25 - Médias e intervalo de confiança 95\% das medidas da densidade de células endoteliais no pré-operatório e durante o seguimento de 12 meses para os dois grupos

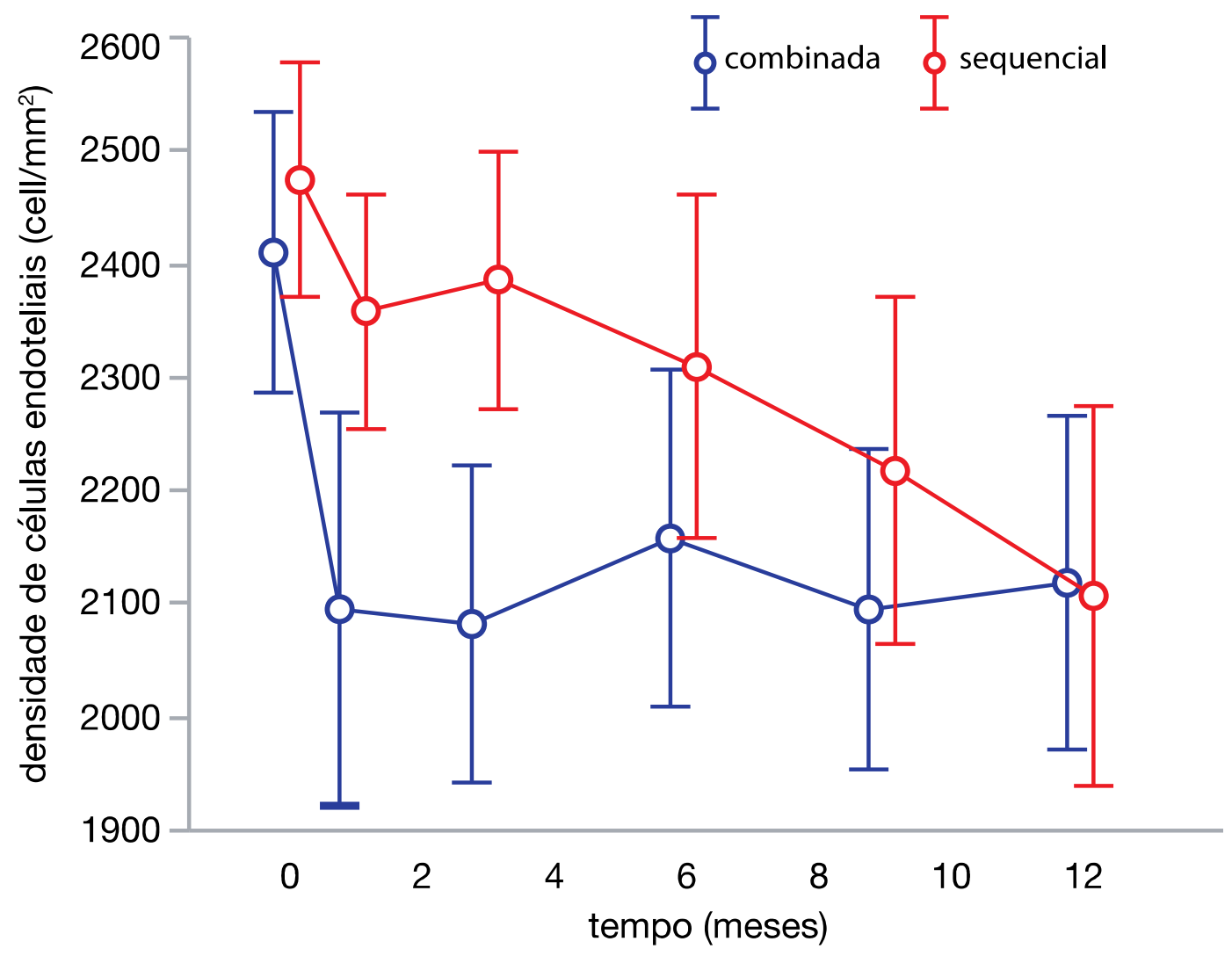




\subsection{Desfechos secundários}

\subsubsection{Paquimetria}

A média da paquimetria no pré-operatório e aos 12 meses foi de $533.93 \pm$ 6.55 e $533.3 \pm 6.51$, respectivamente, no grupo cirurgia combinada e $530.2 \pm 6.55$ e $522.23 \pm 6.51$, respectivamente, no grupo cirurgia sequencial, não havendo diferença estatisticamente significativa em ambos os grupos entre o mês 12 e o baseline (grupo cirurgia combinada: $p=0.910$; grupo cirurgia sequencial: $p=0.151$ ), e nem entre os grupos em qualquer visita do estudo ( $p>0.05$ ) (Figura 26).

Figura 26 - Médias e intervalo de confiança 95\% das medidas da paquimetria no préoperatório e durante o seguimento de 12 meses para os dois grupos

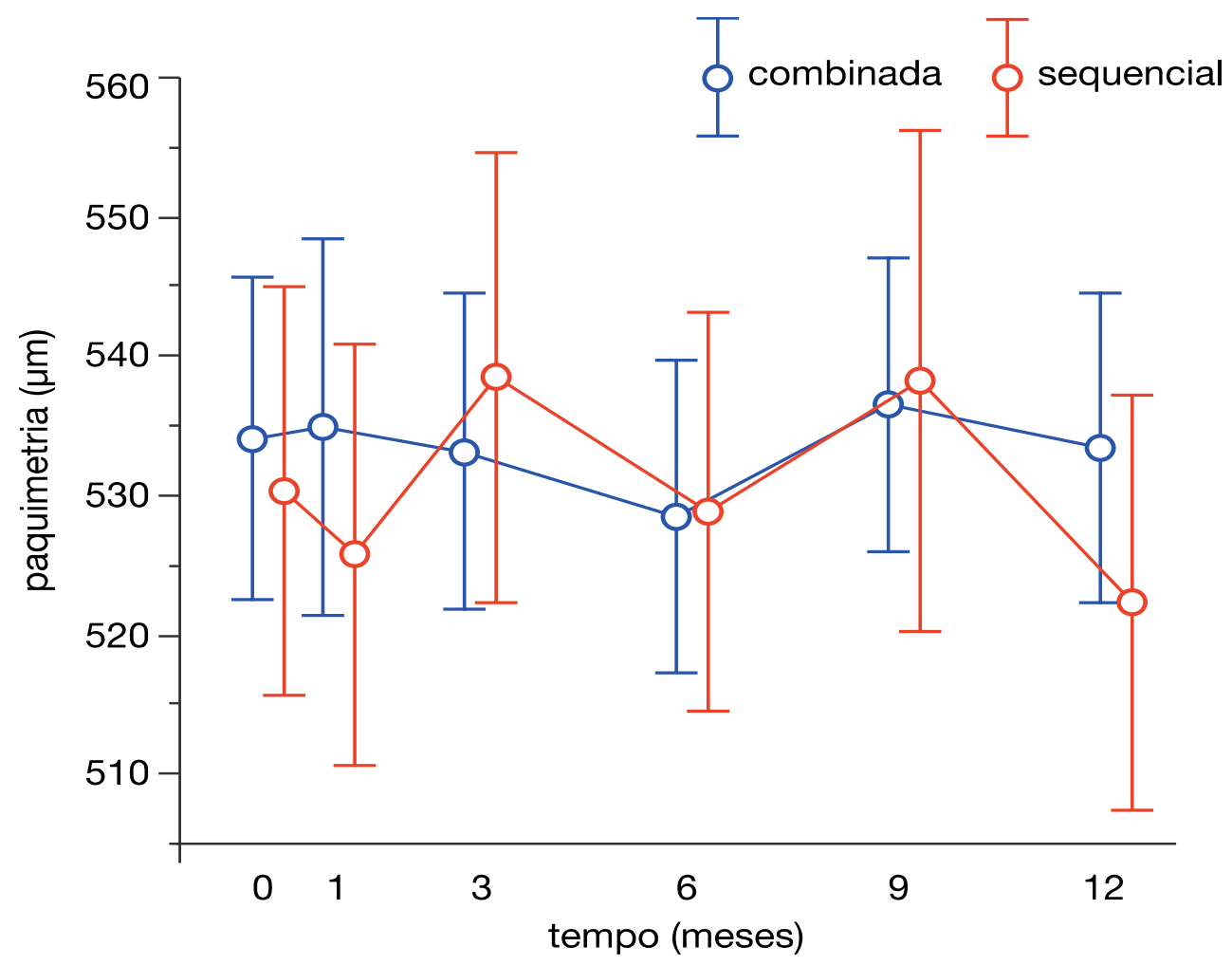




\subsubsection{Coeficiente de variação do tamanho celular (CV)}

A média do CV do tamanho celular se mostrou semelhante nos dois grupos, não havendo diferença significativa entre ambos em qualquer período do estudo ( $p>0.05$ ) (Figura 27). No pré-operatório, a média do CV foi de $36.1 \pm 1.49 \%$ no Grupo cirurgia combinada e $34.6 \pm 1.49 \%$ no Grupo cirurgia sequencial. No mês 12 de pós-operatório, a média do CV foi de $32.18 \pm 1.22 \%$ no Grupo cirurgia combinada e $31.1 \pm 1.22 \%$ no Grupo cirurgia sequencial. Observou-se diminuição significativa na média do CV no mês 12 em relação ao pré-operatório no grupo combinado $(p=0,033)$ e nos meses 9 e 12 em relação ao mês 1 no grupo sequencial ( $p=0,041$ e $p=0,019$, respectivamente).

Figura 27 - Médias e intervalo de confiança 95\% das medidas do coeficiente de variação do tamanho celular no pré-operatório e durante o seguimento de 12 meses para os dois grupos

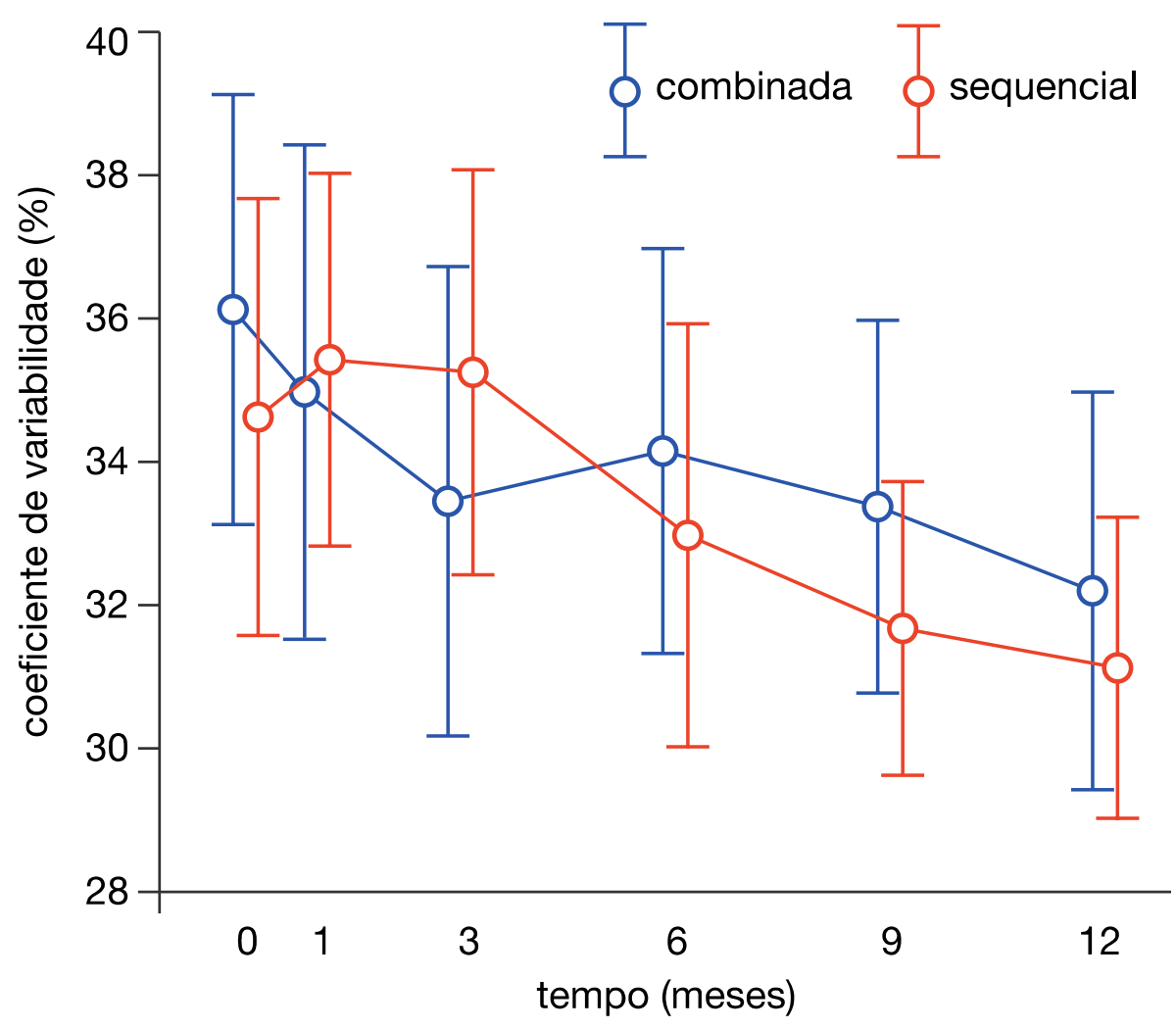




\subsubsection{Melhor acuidade visual corrigida (MAVC)}

A escala utilizada para a medida da MAVC foi a logMAR e os grupos foram analisados comparando separadamente os pacientes com BM e aqueles com MER para a MAVC pré-operatória. No pré-operatório, a média \pm desvio padrão da MAVC logMAR foi $0,92 \pm 0,04$ e $0,90 \pm 0,04$ nos grupos cirurgia combinada e cirurgia sequencial, respectivamente, sem nenhuma diferença significativa entre os grupos ( $p=0.870$ ), quando analisados somente os pacientes com BM (Figura 28). Da mesma forma, quando analisados comparativamente somente aqueles com MER, a média \pm desvio padrão da MAVC pré-operatória foi de $0.72 \pm 0.09$ para grupo cirurgia combinada e $0.68 \pm 0.08$ para grupo cirurgia sequencial, não sendo observada também diferença estatística entre os grupos $(p=0.326)$ (Figura 29).

Figura 28 - Distribuição comparativa da MAVC no pré-operatório entre os grupos nos pacientes com BM

\section{Buraco macular}

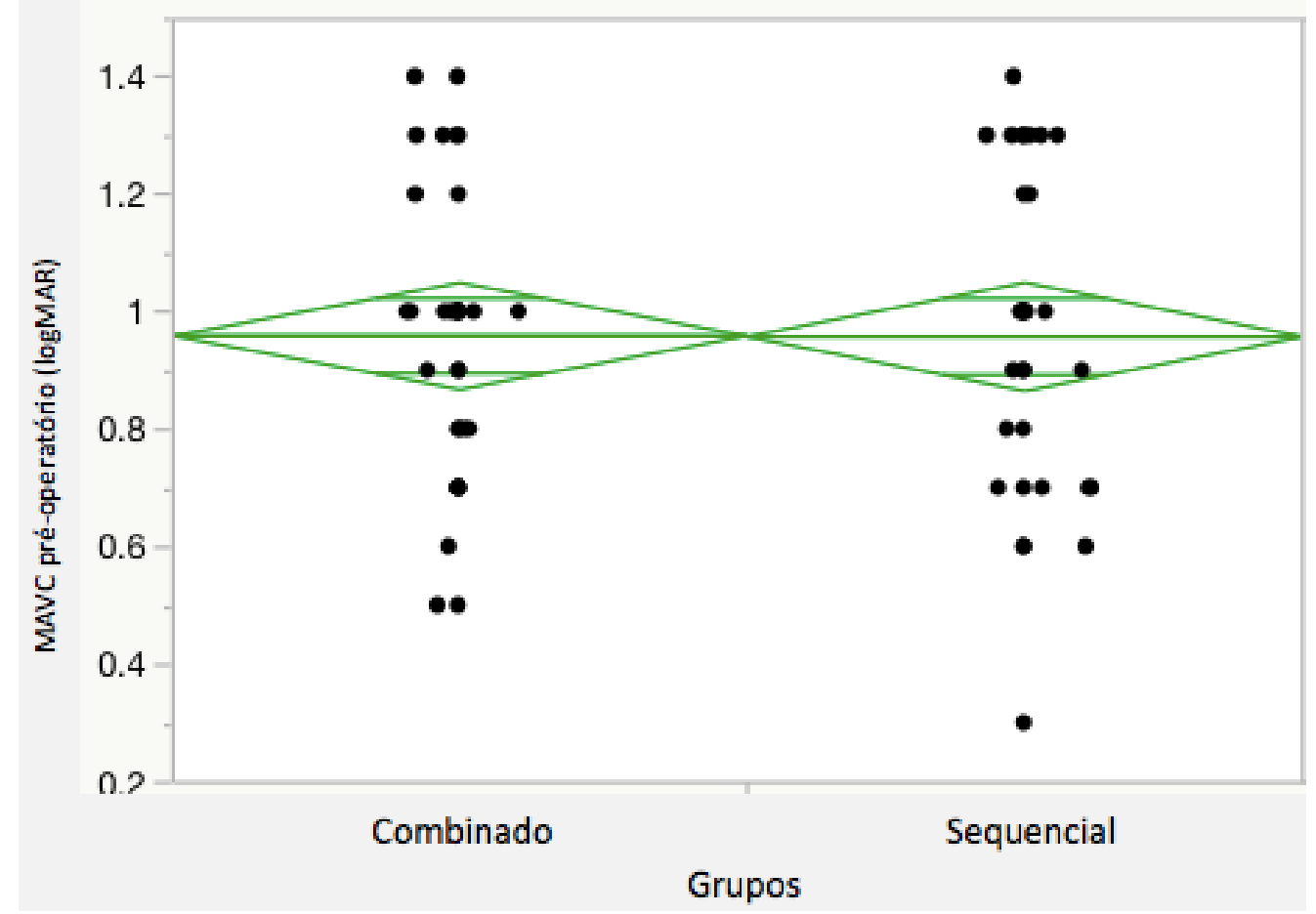


Figura 29 - Distribuição comparativa da MAVC no pré-operatório entre os grupos nos pacientes com MER

\section{Membrana Epirretiniana}

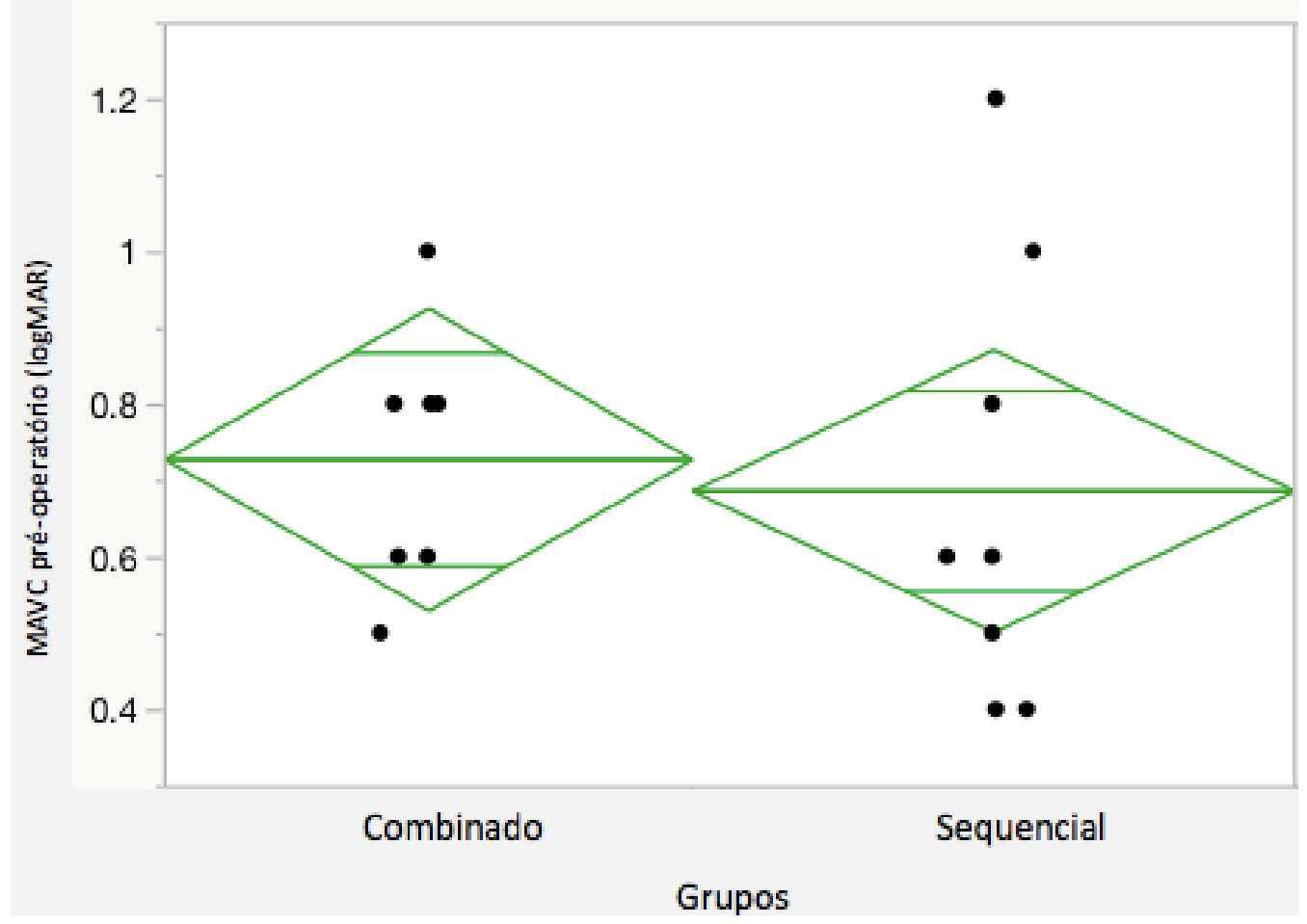

Em relação à MAVC aos 12 meses após a VPP, a média \pm desvio padrão da MAVC logMAR foi de 0,60 $\pm 0,05$ e 0,58 $\pm 0,05$ nos grupos cirurgia combinado e cirurgia sequencial, respectivamente, quando analisados somente os pacientes com $\mathrm{BM}$, e não houve diferença significativa entre os grupos $(p=0.842)$. $E$ quando analisados comparativamente somente aqueles com MER, a média \pm desvio padrão da MAVC final foi de $0.47 \pm 0.13$ para grupo cirurgia combinado e $0.41 \pm 0.14$ para grupo cirurgia sequencial $(p=0.725)$, não sendo observada também diferença estatística entre os grupos quanto à MAVC final. Houve melhora da MAVC final nos dois grupos, independente da patologia macular. No entanto, nos pacientes com BM essa melhora foi significativa $(p<0,0001)$, enquanto naqueles com MER essa melhora não foi estatisticamente significativa $(p=0.239)$ quando comparada com a MAVC no pré-operatório (Figura 30). 
Figura 30 - Evolução da acuidade visual (em logMAR) após 12 meses da vitrectomia divididas pelas patologias BM e MER
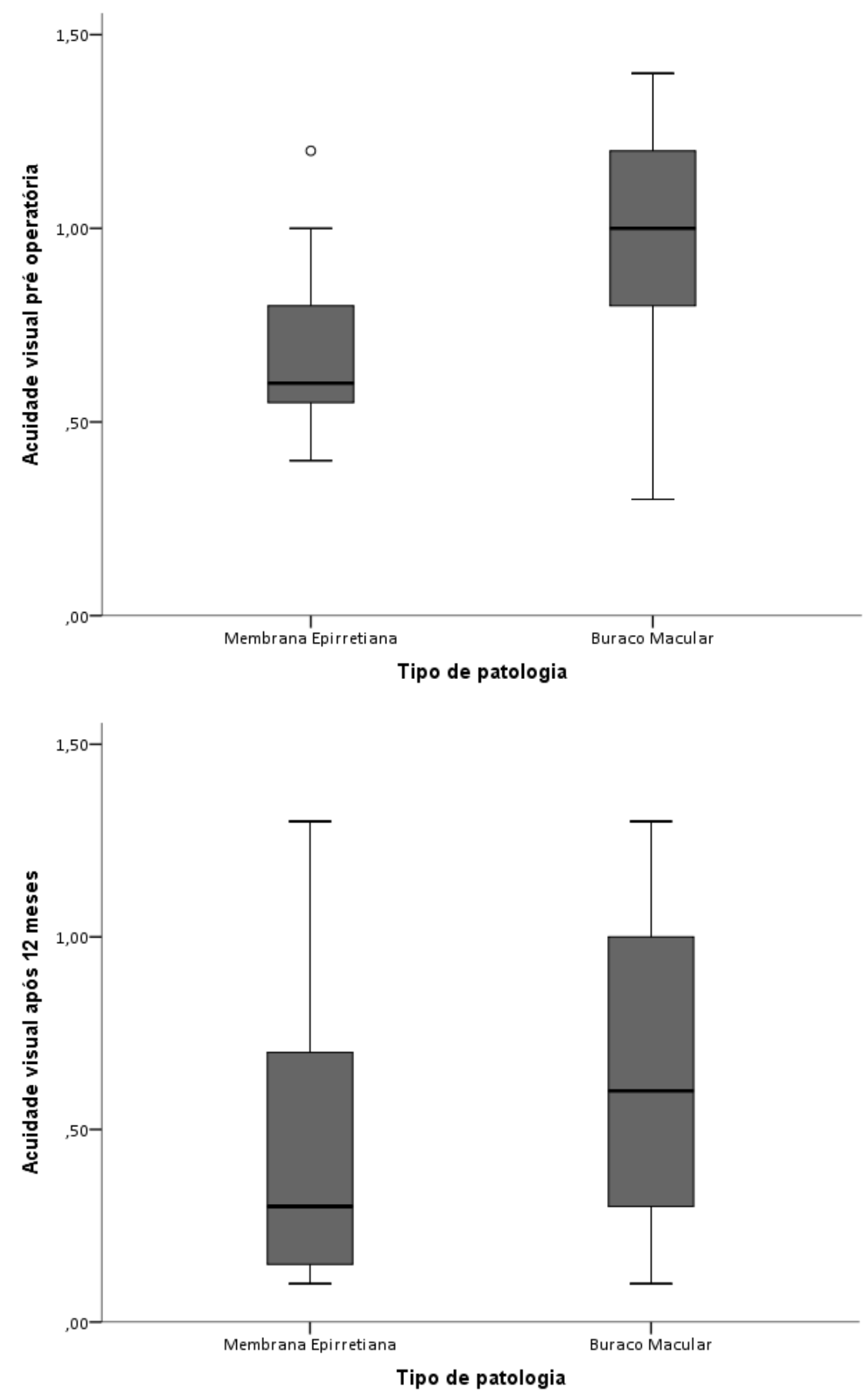
Foi também realizada a comparação entre os dois grupos ao longo do tempo, sem distinção de patologia macular, observando-se melhora significativa da MAVC após a cirurgia em comparação com a linha de base (ANOVA para medidas repetidas) em todas as visitas do estudo de acompanhamento (um, três, seis, nove e doze meses) nos grupos cirurgia combinada e cirurgia sequencial $(p<0,05)$. Observou-se diferença significativa na MAVC entre os grupos somente no sexto mês $(p=0.049)$. Em todas as outras visitas do estudo não se verificou diferença estatística na MAVC entre os dois grupos (Figura 31).

Figura 31 - Evolução da acuidade visual ao longo do tempo nos dois grupos. Os círculos representam as médias e as barras de erro mostram os intervalos de confiança de $95 \%$ das diferenças das acuidades visuais medidas durante o seguimento

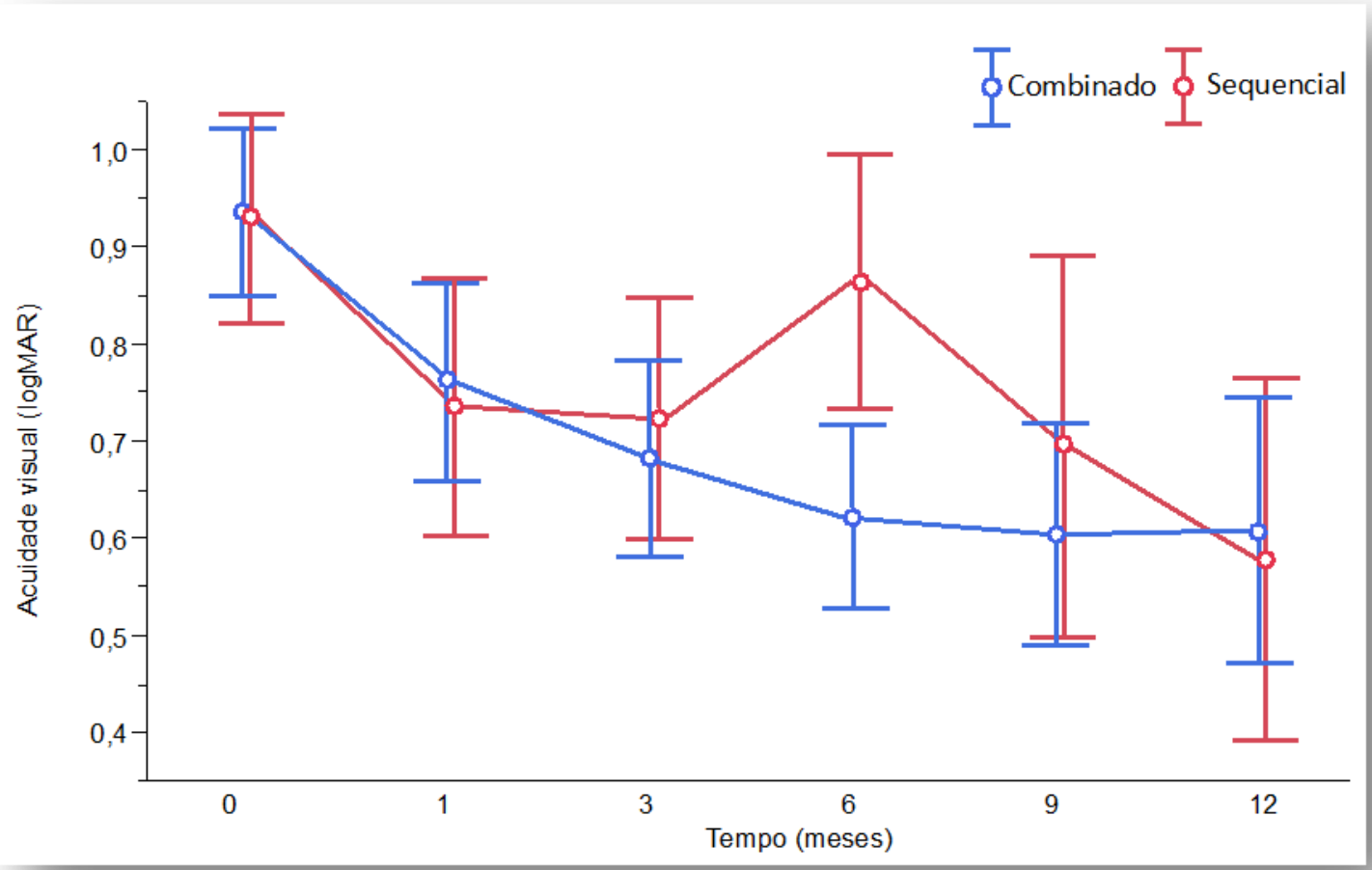

No grupo cirurgia combinada observou-se constante melhora da $\mathrm{AV}$ ao longo do tempo até a última medida do estudo. As médias \pm desvio padrão foram: préoperatório $(0.94 \pm 0.04)$; um mês $(0.76 \pm 0.05)$; três meses $(0.68 \pm 0.05)$; seis meses $(0.62 \pm 0.05)$; nove meses $(0.60 \pm 0.06)$ e 12 meses $(0.61 \pm 0.07)$. Já no grupo 
cirurgia sequencial observou-se melhora da AV até 0 terceiro mês de acompanhamento, seguida por piora no sexto mês e, em seguida, houve retomada da melhora da AV nos meses nove e doze de acompanhamento do estudo. As médias \pm desvio padrão foram: pré-operatório (0.93 \pm 0.05$)$; um mês $(0.74 \pm 0.06)$; três meses $(0.72 \pm 0.06)$; seis meses $(0.87 \pm 0.06)$; nove meses $(0.70 \pm 0.09)$ e 12 meses $(0.58 \pm 0.09)$. Essa piora da média da AV no sexto mês coincidiu com o surgimento da catarata. Ao se compararem os dois grupos (cirurgia combinada versus cirurgia sequencial) em cada visita notou-se diferença estatística entre os grupos somente no sexto mês $(p=0.049)$ (Tabela 8).

Tabela 8 - Comparação da acuidade visual entre o pré operatório e os demais períodos em ambos os grupos

\begin{tabular}{|c|c|c|c|c|c|c|}
\hline & \multicolumn{6}{|c|}{ Acuidade Visual (logMAR) } \\
\hline & Pré-operatório & 1 mês & 3 meses & 6 meses & 9 meses & 12 meses \\
\hline $\begin{array}{c}\text { Grupo } \\
\text { cirurgia } \\
\text { combinada }\end{array}$ & $0.94 \pm 0.04$ & $0.76 \pm 0.05$ & $0.68 \pm 0.05$ & $0.62 \pm 0.05$ & $0.60 \pm 0.06$ & $0.61 \pm 0.07$ \\
\hline $\begin{array}{c}\text { Grupo } \\
\text { cirurgia } \\
\text { sequencial } \\
\text { p-valor }\end{array}$ & $0.93 \pm 0.05$ & $0.74 \pm 0.06$ & $0.72 \pm 0.06$ & $0.87 \pm 0.06$ & $0.70 \pm 0.09$ & $0.58 \pm 0.09$ \\
\hline
\end{tabular}

\subsubsection{Erro refratométrico}

\subsubsection{Refração esférica e astigmatismo}

Em relação ao erro refratométrico foram avaliadas as médias (e erro padrão) da refração esférica e do astigmatismo por grupo e por patologia em cada período do estudo e os resultados foram comparados (Tabelas 9 e 10). 
Tabela 9 - Média e erro padrão da refração esférica por grupo e patologia

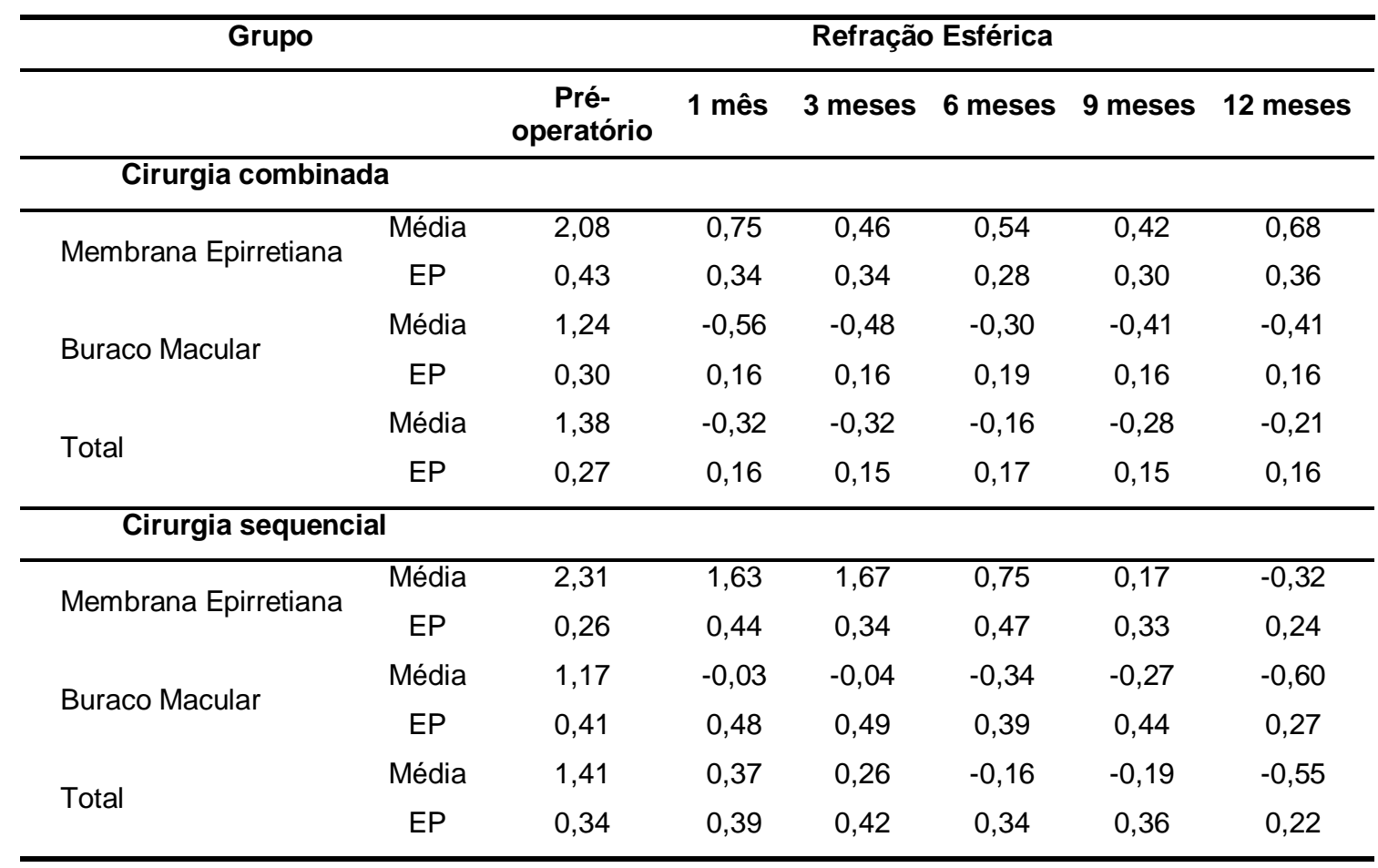

Tabela 10 - Média e erro padrão do astigmatismo por grupo e patologia

\begin{tabular}{|c|c|c|c|c|c|c|c|}
\hline \multicolumn{2}{|l|}{ Grupo } & \multicolumn{6}{|c|}{ Astigmatismo } \\
\hline & & $\begin{array}{c}\text { Pré- } \\
\text { operatório }\end{array}$ & 1 mês & 3 meses & 6 meses & 9 meses & 12 meses \\
\hline \multicolumn{8}{|l|}{ Cirurgia combinada } \\
\hline \multirow{2}{*}{ Membrana Epirretiana } & Média & 1,58 & 2,04 & 1,70 & 1,89 & 1,88 & 1,89 \\
\hline & EP & 0,48 & 0,49 & 0,46 & 0,53 & 0,61 & 0,54 \\
\hline \multirow{2}{*}{ Buraco Macular } & Média & 0,73 & 0,75 & 0,81 & 0,88 & 0,83 & 0,84 \\
\hline & EP & 0,11 & 0,13 & 0,12 & 0,14 & 0,13 & 0,13 \\
\hline \multirow{2}{*}{ Total } & Média & 0,87 & 0,99 & 0,93 & 1,06 & 0,99 & 1,03 \\
\hline & EP & 0,12 & 0,16 & 0,13 & 0,15 & 0,16 & 0,16 \\
\hline \multicolumn{8}{|l|}{ Cirurgia sequencial } \\
\hline \multirow{2}{*}{ Membrana Epirretiana } & Média & 1,44 & 1,50 & 1,25 & 1,21 & 1,00 & 1,25 \\
\hline & EP & 0,30 & 0,47 & 0,24 & 0,37 & 0,28 & 0,36 \\
\hline \multirow{2}{*}{ Buraco Macular } & Média & 0,93 & 1,16 & 1,13 & 1,03 & 0,90 & 0,95 \\
\hline & EP & 0,15 & 0,15 & 0,19 & 0,10 & 0,12 & 0,13 \\
\hline \multirow{2}{*}{ Total } & Média & 1,03 & 1,24 & 1,15 & 1,06 & 0,92 & 1,01 \\
\hline & EP & 0,13 & 0,16 & 0,16 & 0,10 & 0,11 & 0,12 \\
\hline
\end{tabular}




\subsubsection{Análise intragrupos}

Primeiramente, aplicou-se o teste de Kruskall Wallis para comparação das médias do astigmatismo e da refração esférica entre os períodos observados. Dessa forma foram obtidos $p$-valor $=0,826$ para 0 astigmatismo e $p$-valor $<0,001$ para a refração esférica. Assim, é possível afirmar que não foi encontrada diferença entre os graus médios do astigmatismo nos períodos, porém houve diferença significativa entre os graus médios da refração esférica. Utilizou-se também o teste de Wilcoxon com todos os pacientes, de ambos os grupos, para verificar se houve diferença significativa, tanto entre o astigmatismo pré-operatório com o astigmatismo após 12 meses, quanto entre a refração esférica pré-operatória com a refração esférica após 12 meses, constatando-se que o astigmatismo não apresentou diferença significativa entre os valores pré-operatórios e após 12 meses; mas para a refração esférica essa diferença foi significativa (Tabela 11).

Tabela 11 - Teste de Wilcoxon para comparação do astigmatismo e refração esférica entre o pré-operatório e após 12 meses de ambos os grupos

\begin{tabular}{lcc}
\hline \multicolumn{1}{c}{ Teste } & Astigmatismo & Refração esférica \\
\hline Estatística do teste & $-0,46$ & $-5,69$ \\
p-valor & 0,65 & $0,00^{\star}$ \\
\hline
\end{tabular}

Seguindo com as análises, selecionou-se apenas o grupo cirurgia combinada e aplicou-se novamente o teste para verificar se havia diferença significativa, tanto entre o astigmatimo pré-operatório com o astigmatismo após 12 meses, e o mesmo para a refração esférica. Observou-se que o valor do astigmatismo não apresentou diferença significativa, mas para a refração esférica pode-se afirmar que houve diferença significativa entre os períodos (Tabela 12). 
Tabela 12 - Teste de Wilcoxon para comparação do astigmatismo e refração esférica entre o pré-operatório e após 12 meses dos pacientes de grupo cirurgia combinada

\begin{tabular}{ccc}
\hline Teste & Astigmatismo & Refração esférica \\
\hline Estatística do teste & $-0,53$ & $-4,21$ \\
p-valor & 0,59 & $0,00^{*}$ \\
\hline
\end{tabular}

O mesmo foi feito com o grupo cirurgia sequencial, observando-se que 0 astigmatismo não apresentou diferença significativa, mas em relação à refração esférica pode-se afirmar que houve diferença significativa entre os valores préoperatórios e após 12 meses (Tabela 13).

Tabela 13 - Teste de Wilcoxon para comparação do astigmatismo e refração esférica entre o pré-operatório e após 12 meses dos pacientes do grupo cirurgia sequencial

\begin{tabular}{ccc}
\hline Teste & Astigmatismo & Refração esférica \\
\hline Estatística do teste & $-0,39$ & $-3,96$ \\
p-valor & 0,97 & $0,00^{\star}$ \\
\hline
\end{tabular}

Analisou-se, também, se havia diferença significativa entre a refração esférica esperada e a refração esférica após 12 meses nos grupos, sendo encontrada diferença significativa apenas no grupo cirurgia sequencial (Tabelas 14 e 15).

Tabela 14 - Teste de Wilcoxon para comparação da refração esférica esperada e após 12 meses no grupo cirurgia combinada

\begin{tabular}{lc}
\hline \multicolumn{1}{c}{ Teste } & Refração esférica \\
\hline Estatística do teste & $-1,64$ \\
p-valor & $0,10^{\star}$ \\
\hline
\end{tabular}


Tabela 15 - Teste de Wilcoxon para comparação do Refração esférica esperada e após 12 meses no grupo cirurgia sequencial

\begin{tabular}{lc}
\hline \multicolumn{1}{c}{ Teste } & Refração esférica \\
\hline Estatística do teste & $-2,40$ \\
p-valor & $0,02^{\star}$ \\
\hline
\end{tabular}

\subsubsection{Análise entre grupos}

Foi utilizado o teste de Mann Whitney para a comparação das médias do astigmatismo e da refração esférica entre os grupos (Tabelas 16 e 17).

Tabela 16 - Teste Mann Whitney de comparação de médias do astigmatismo entre grupos

\begin{tabular}{lcccccc}
\hline Teste & \multicolumn{7}{c}{ Astigmatismo } \\
\hline & Pré-operatório & $\mathbf{1}$ mês & 3 meses & $\mathbf{6}$ meses & 9 meses & $\mathbf{1 2}$ meses \\
\hline Estatística do teste & $-1,04$ & $-1,74$ & $-1,66$ & $-1,15$ & $-0,28$ & $-0,30$ \\
p-valor & 0,30 & 0,08 & 0,10 & 0,25 & 0,78 & 0,76 \\
\hline
\end{tabular}

Tabela 17 - Teste Mann Whitney de comparação de médias da refração esférica entre grupos

\begin{tabular}{lcccccc}
\hline \multicolumn{1}{c}{ Teste } & \multicolumn{7}{c}{ Refração Esférica } \\
\hline & Pré-operatório & $\mathbf{1}$ mês & $\mathbf{3}$ meses & $\mathbf{6}$ meses & $\mathbf{9}$ meses & $\mathbf{1 2}$ meses \\
Estatística do teste & $-0,78$ & $-2,28$ & $-2,73$ & $-0,32$ & $-0,77$ & $-0,60$ \\
$p$-valor & 0,43 & $0,02^{*}$ & $0,01^{*}$ & 0,75 & 0,44 & 0,55 \\
\hline
\end{tabular}


Notou-se que nos períodos um mês e três meses houve diferença significativa da média da refração esférica, mas não houve diferença significativa da média do astigmatismo entre os grupos em nenhum dos períodos observados (Figuras $32 \mathrm{e}$ 33).

Figura 32 - Evolução da refração esférica nos grupos combinado e sequencial ao longo dos 12 meses do estudo. Houve diferença significativa da média da refração esférica entre os grupos nas visitas de um mês e três meses

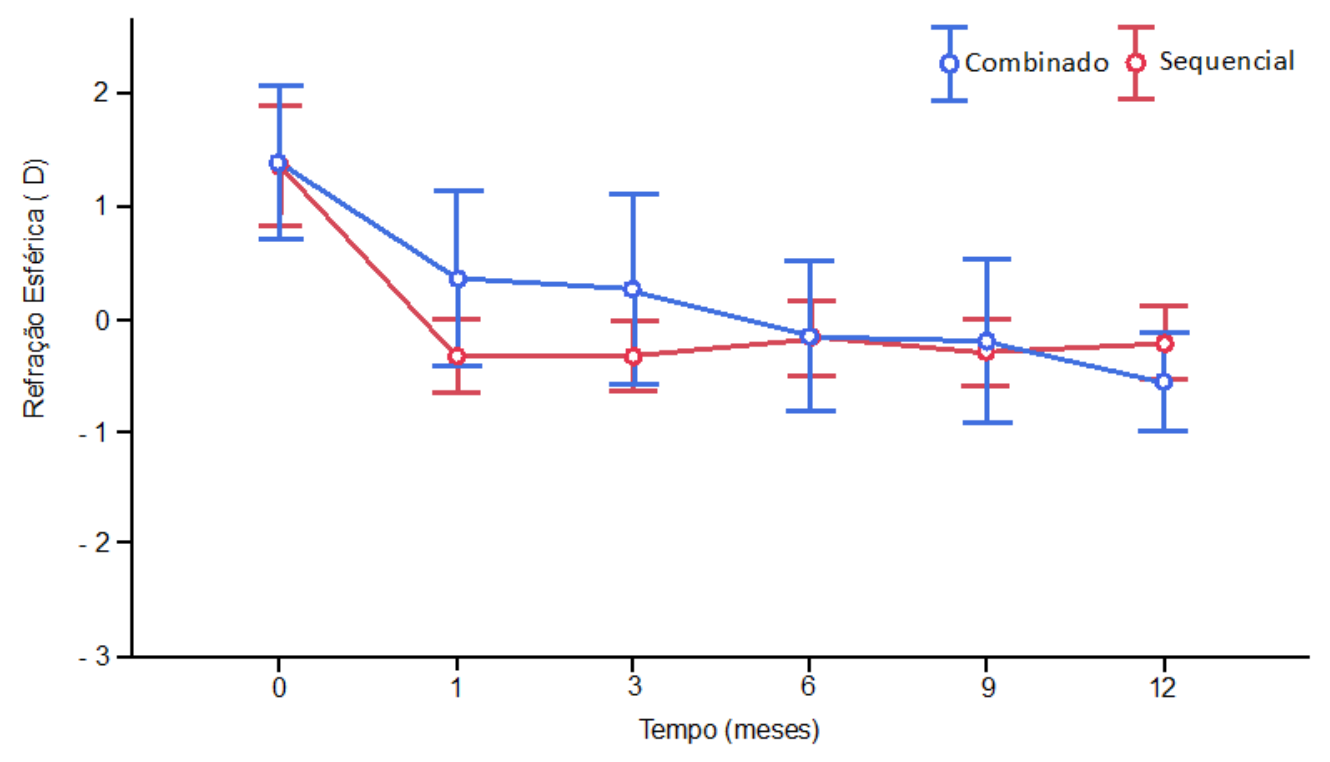


Figura 33 - Evolução do astigmatismo nos grupos combinado e sequencial ao longo dos 12 meses do estudo. Não houve diferença na média do astigmatismo entre os grupos em nenhum dos períodos $(p>0.05)$

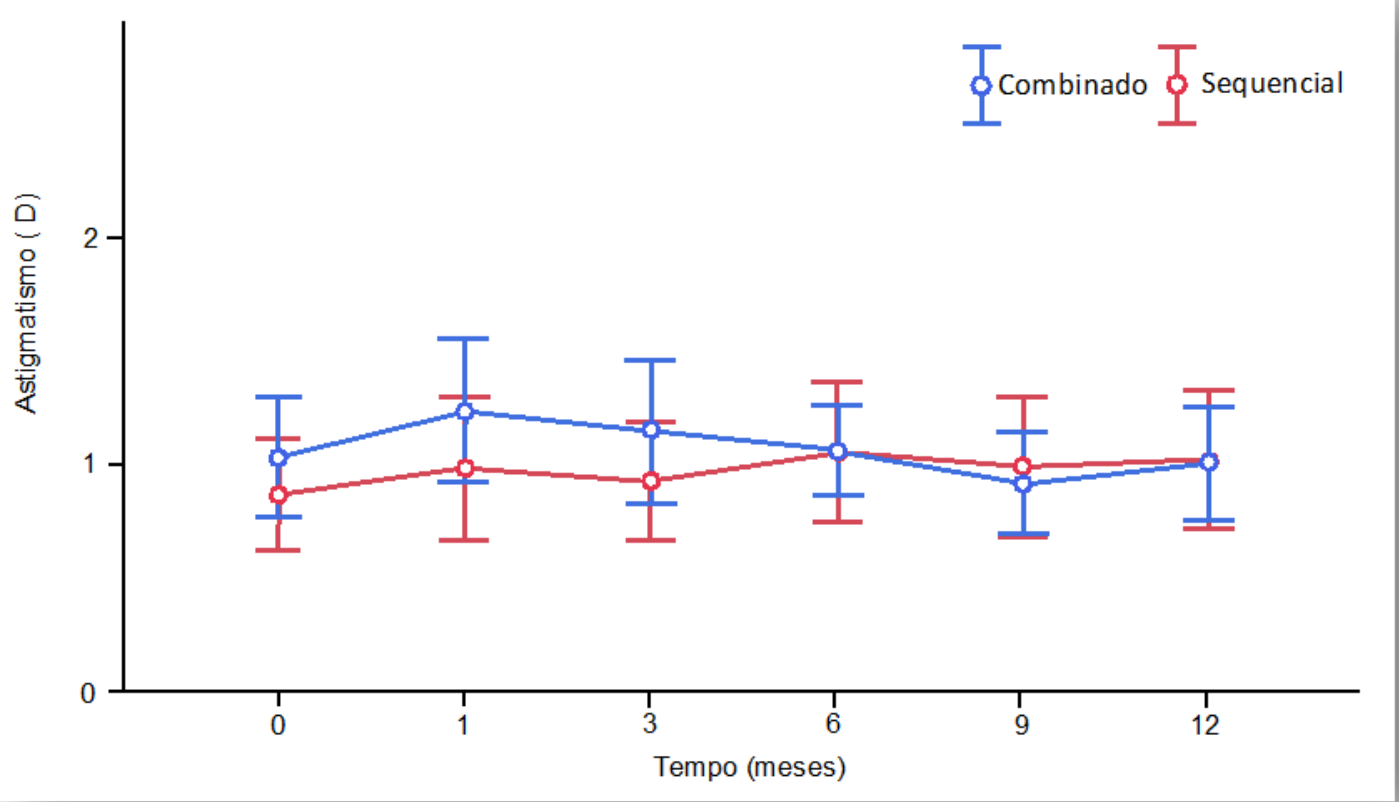

\subsubsection{Equivalente esférico}

Também foram avaliadas as médias (e erro padrão) do equivalente esférico nos dois grupos em cada período do estudo e os resultados foram comparados (Tabela 18).

Tabela 18 - Média e erro padrão do equivalente esférico por grupo e período

\begin{tabular}{llcccccc}
\hline \multicolumn{1}{c}{ Grupo } & & $\begin{array}{c}\text { Equivalente Esférico } \\
\text { operatório }\end{array}$ & $\mathbf{1}$ mês & $\mathbf{3}$ meses & $\mathbf{6}$ meses & $\mathbf{9}$ meses & $\mathbf{1 2}$ meses \\
\hline Cirurgia & Média & 0.91 & -0.78 & -0.72 & -0.69 & -0.72 & -0.68 \\
combinada & EP & 0.3 & 0.28 & 0.32 & 0.27 & 0.27 & 0.19 \\
Cirurgia sequencial & Média & 0.98 & -0.38 & -0.47 & -0.69 & -1.03 & -1.11 \\
\cline { 3 - 8 } p-valor & EP & 0.3 & 0.28 & 0.32 & 0.27 & 0.27 & 0.19 \\
\hline
\end{tabular}


É possível afirmar que não houve diferença significativa da média do equivalente esférico entre os grupos em nenhum dos períodos observados (Figura 34).

Figura 34 - Evolução do equivalente esférico nos grupos cirurgia combinada e cirurgia sequencial

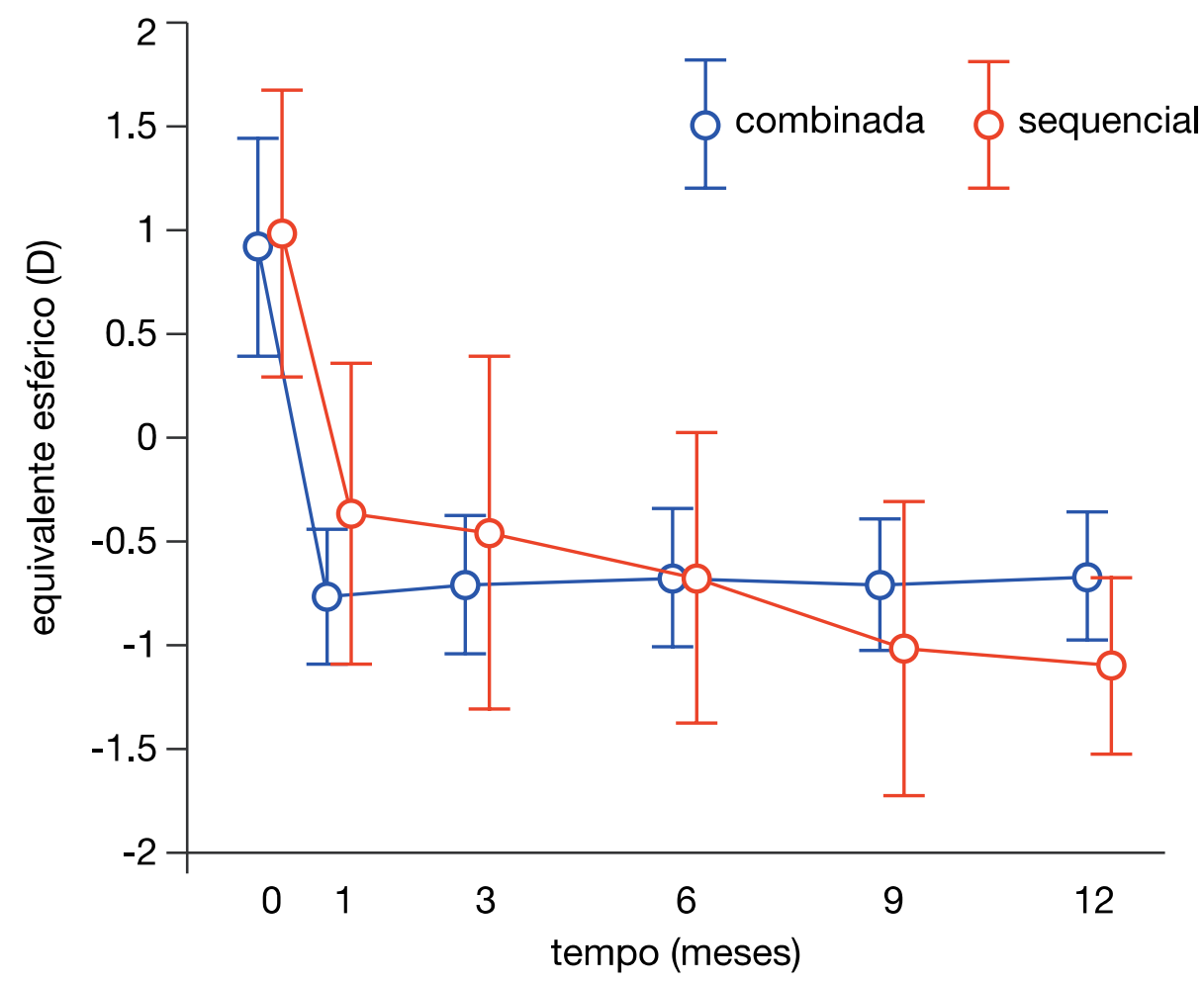

\subsubsection{Ocorrência e progressão da catarata}

A taxa absoluta do desenvolvimento da catarata no grupo cirurgia sequencial foi de $82,5 \%$ em 12 meses. Quando divididos por patologia, essa taxa nos pacientes com MER foi de $83,3 \%$ e naqueles com BM foi de $82,4 \%$. A média \pm erro padrão do tempo em que foi realizado a Faco no grupo cirurgia sequencial foi de 8,52 $\pm 0,46$ meses. Já dividindo por patologia, essa média \pm erro padrão nos pacientes com MER foi de 9,00 $\pm 0,55$ meses e naqueles com BM foi de 8,43 $\pm 0,54$ meses. Quanto ao período da realização da cirurgia de catarata, quando comparadas as duas patologias, não houve diferença estatística $(\mathrm{p}=0.942)$ (Figura 35). 
Figura 35 - Distribuição comparativa do tempo de realização da facoemulsificação entre as duas patologias. A barra em negrito na caixa representa a mediana em meses, o tamanho da caixa representa a dispersão dos valores entre o primeiro e terceiro quartis (mostrando a maior concentração dos dados) e as barras periféricas representam os valores máximos e mínimos em meses

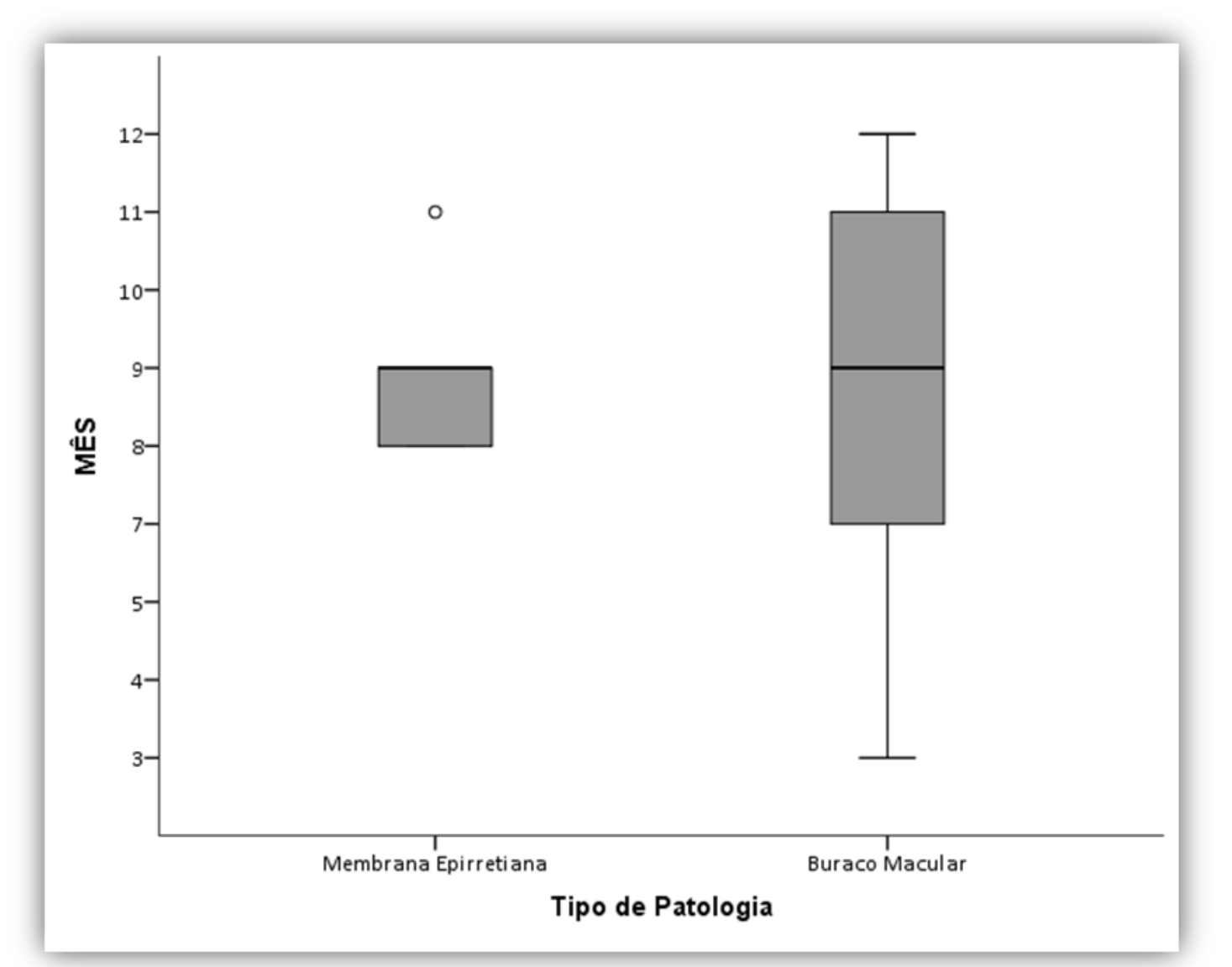

Esse período da realização da cirurgia de catarata no grupo sequencial foi dividido em quatro fases: primeiro trimestre (1-3 meses); segundo trimestre $(>3-6$ meses); terceiro trimestre ( $>6-9$ meses) e quarto trimestre ( $>9-12$ meses). A maior concentração de cirurgias de Faco se deu no terceiro e quarto trimestres com $33 \%$ e $35 \%$ das cirurgias realizadas, respectivamente (Figura 36 ). 
Figura 36 - Distribuição dos períodos, por trimestre, em que foi realizada a cirurgia de facoemulsificação no grupo cirurgia sequencial

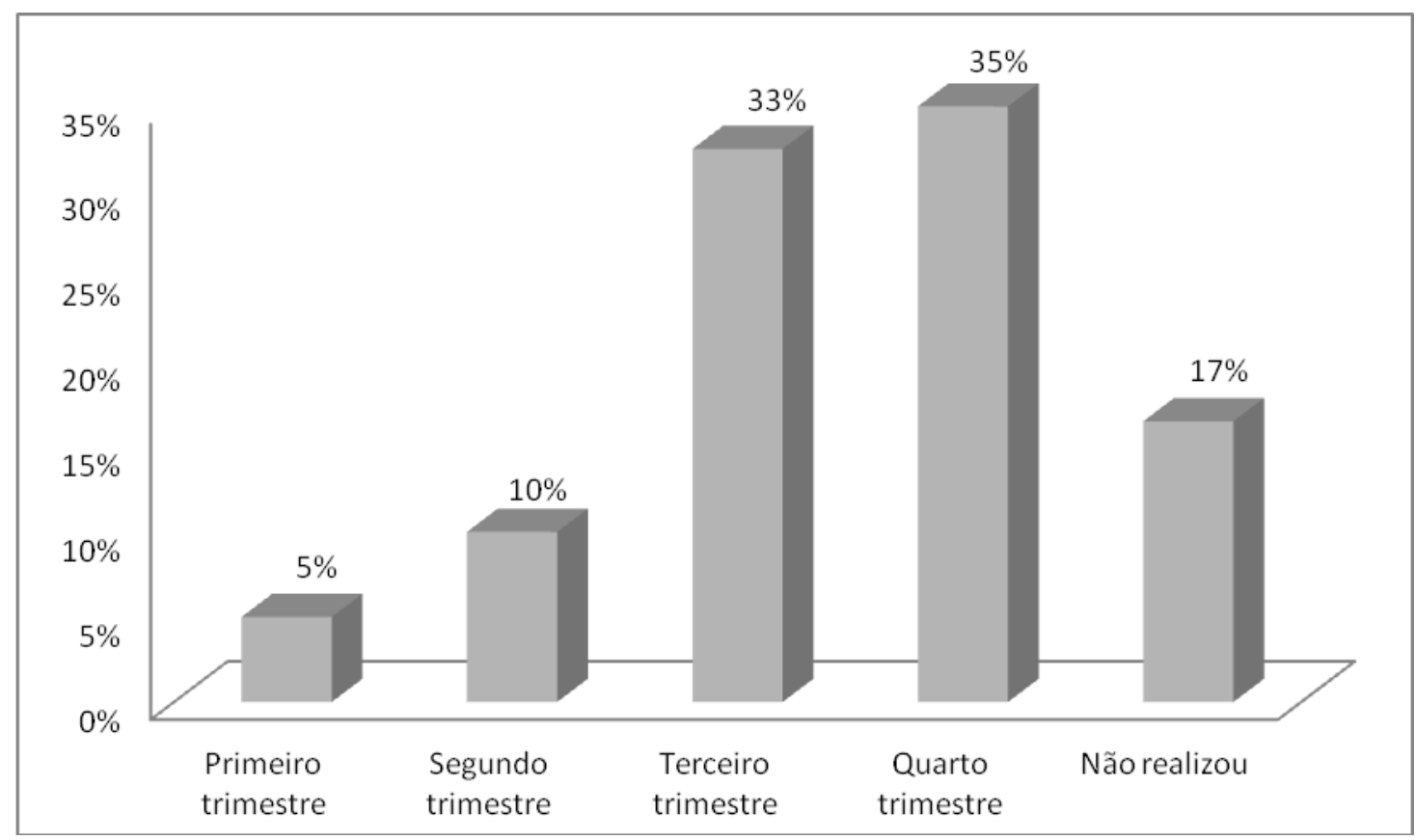

\subsubsection{Eventos adversos}

No grupo cirurgia combinada, um paciente apresentou opacificação da cápsula posterior após seis meses de seguimento, dois pacientes apresentaram corectopia devido a sinéquias posteriores (que ocorreu em três olhos), um paciente com uma LIO inclinada (uma borda da LIO fora e a outra dentro do saco capsular; ambos os hápticos no saco) e um apresentou elevação significativa na PIO (36 $\mathrm{mmHg}$ ) no primeiro dia de pós-operatório, que foi controlada com uso transitório de três medicações tópicas e manitol por via venosa. No grupo cirurgia sequencial, três pacientes desenvolveram hipertensão ocular $(\mathrm{PIO}>21 \mathrm{mmHg}$ ), que foi controlada com utilização transitória de três medicações tópicas, dois pacientes apresentaram ruptura capsular posterior intraoperatória, sendo a LIO posicionada no sulco ciliar e um paciente apresentou uveíte anterior um mês após a cirurgia de Faco, controlada com uso de prednisolona tópica. Esses eventos adversos foram inerentes ao procedimento e estão de acordo com relatos prévios para essas cirurgias (CARIFI et al., 2015; RAO et al., 2013). 


\subsection{Pressão intraocular}

Em relação à PIO pré-operatória, os grupos foram analisados comparando separadamente os pacientes com BM e aqueles com MER.

\subsubsection{Comparação intragrupos}

No grupo cirurgia combinada não houve diferença estatística da PIO ao longo do tempo até a última medida do estudo, quando comparada com a PIO préoperatória ( $p>0.05)$. Já no grupo sequencial, observou-se aumento significativo da PIO no primeiro mês de acompanhamento comparada à PIO pré-operatória $(p=0.001)$, seguido por redução no terceiro e sexto mês, e retomada aos valores basais da PIO nos meses 9 e 12 de acompanhamento do estudo. Com exceção do primeiro mês, nenhuma outra mudança da PIO ao longo do acompanhamento foi significativa quando comparada à PIO pré-operatória ( $p>0.05)$ (Figura 37). 
Figura 37 - Os círculos representam as médias e as barras de erro os intervalos de confiança de $95 \%$ das diferenças das médias de pressão intraocular medidas durante o seguimento, menos a basal, para os dois grupos
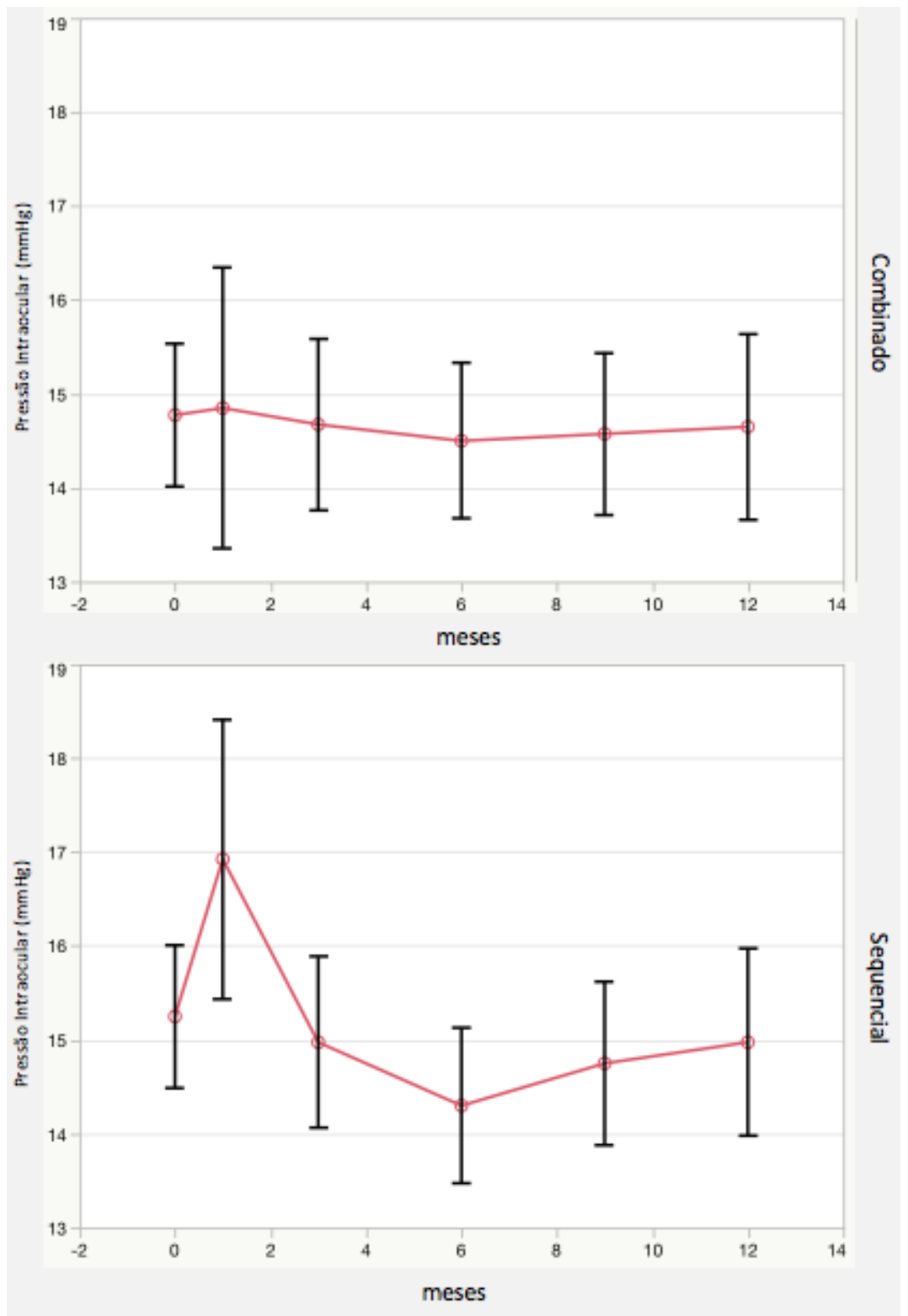


\subsubsection{Comparação entre grupos}

\subsubsection{Pacientes com BM}

Quando analisados os dois grupos somente com os pacientes com BM, a média \pm erro padrão da PIO foi de $14.38 \pm 0.45$ para o grupo cirurgia combinada e $15.15 \pm 0.35$ para o grupo cirurgia sequencial $(p=0.206)$. Não houve, portanto, diferença estatística entre os grupos quanto à $\mathrm{PIO}$ pré-operatória para esta patologia macular (Figura 38).

Figura 38 - Distribuição comparativa da média de pressão intraocular entre os grupos nos pacientes portadores de BM

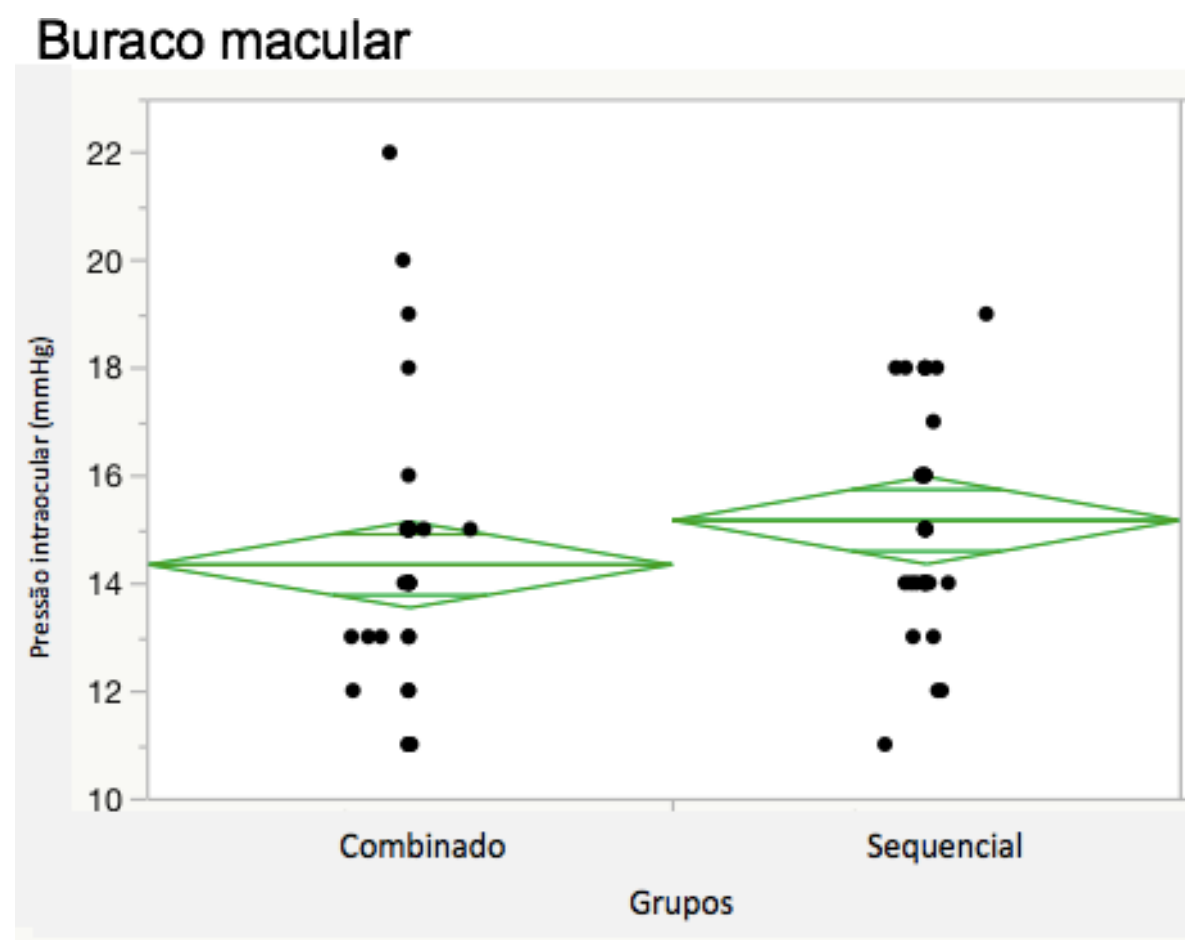

Considerando cada período estudado e avaliando somente os casos com BM, as médias \pm erro padrão da PIO em cada grupo estão dispostas na Tabela 19. 
Tabela 19 - Comparação da pressão intraocular entre o pré-operatório e os demais períodos em ambos os grupos avaliando somente os pacientes com BM

\begin{tabular}{|c|c|c|c|c|c|c|}
\hline & \multicolumn{6}{|c|}{ Pressão intraocular (pacientes com BM) } \\
\hline & Pré-operatório & 1 mês & 3 meses & 6 meses & 9 meses & 12 meses \\
\hline $\begin{array}{l}\text { Grupo cirurgia } \\
\text { combinada }\end{array}$ & $14.38 \pm 0.45$ & $14.03 \pm 0.49$ & $14.31 \pm 0.42$ & $14.09 \pm 0.34$ & $14.25 \pm 0.39$ & $14.44 \pm 0.42$ \\
\hline $\begin{array}{l}\text { Grupo cirurgia } \\
\text { sequencial }\end{array}$ & $15.15 \pm 0.35$ & $17.15 \pm 0.79$ & $15.15 \pm 0.51$ & $14.24 \pm 0.45$ & $14.64 \pm 0.41$ & $15.03 \pm 0.61$ \\
\hline p-valor & $\mathrm{p}=0.096$ & $p=0.001$ & $\mathrm{p}=0.336$ & $\mathrm{p}=0.661$ & $p=0.652$ & $\mathrm{p}=0.393$ \\
\hline
\end{tabular}

BM= Buraco macular.

Nesta patologia, não houve diferença estatística da PIO ao longo do tempo até a última medida do estudo quando comparada com a PIO pré-operatória ( $p>0.05)$. E na comparação das médias \pm erro padrão em cada tempo houve diferença estatística entre os grupos somente no primeiro mês após a VPP.

\subsubsection{Pacientes com MER}

Já quando comparados os grupos somente com os pacientes portadores de MER a média \pm erro padrão da PIO foi de $16.71 \pm 1.19$ para o grupo cirurgia combinada e $15.50 \pm 0.77$ para o grupo cirurgia sequencial $(p=0.046)$. Portanto, quando avaliados apenas os pacientes portadores de MER, também não houve diferença estatística entre os grupos quanto à PIO pré-operatória (Figura 39). 
Figura 39 - Distribuição comparativa da média de pressão intraocular entre os grupos nos pacientes portadores de MER

\section{Membrana Epirretiniana}

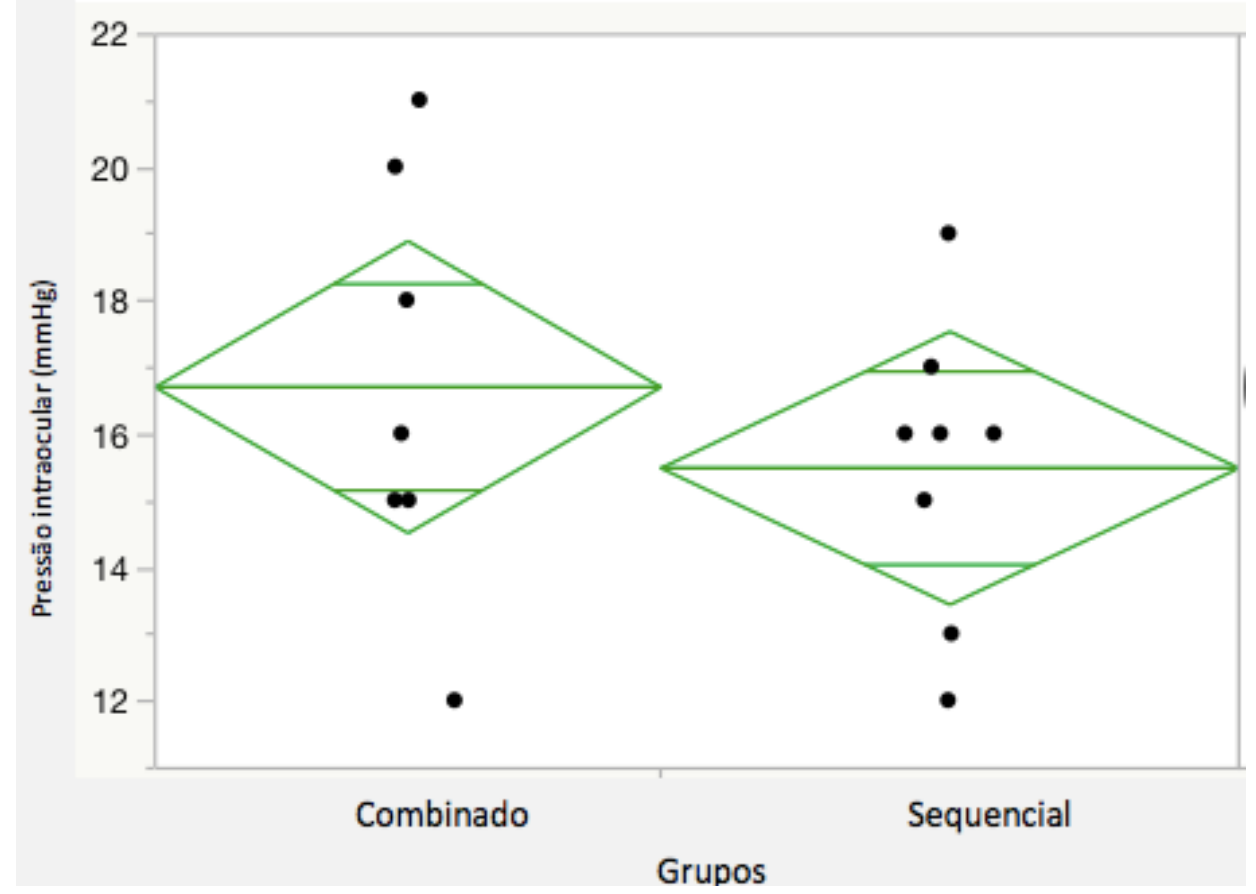

E avaliando somente os casos com MER, considerando cada período estudado, as médias \pm erro padrão da PIO em cada grupo estão dispostas na Tabela 20.

Tabela 20 - Comparação da pressão intraocular entre o pré-operatório e os demais períodos em ambos os grupos avaliando somente os pacientes com MER

\begin{tabular}{|c|c|c|c|c|c|c|}
\hline & \multicolumn{6}{|c|}{ Pressão intraocular (pacientes com MER) } \\
\hline & Pré-operatório & 1 mês & 3 meses & 6 meses & 9 meses & 12 meses \\
\hline $\begin{array}{l}\text { Grupo cirurgia } \\
\text { combinada }\end{array}$ & $16.71 \pm 1.19$ & $18.29 \pm 3.10$ & $16.43 \pm 1.30$ & $16.14 \pm 1.94$ & $16.43 \pm 1.98$ & $16.14 \pm 1.72$ \\
\hline $\begin{array}{l}\text { Grupo cirurgia } \\
\text { sequencial }\end{array}$ & $15.50 \pm 0.77$ & $16.00 \pm 2.33$ & $14.13 \pm 1.21$ & $14.75 \pm 0.64$ & 14. $88 \pm 1.10$ & $14.25 \pm 0.94$ \\
\hline p-valor & $\mathrm{p}=0.613$ & $\mathrm{p}=0.613$ & $\mathrm{p}=0.232$ & $p=0.613$ & $p=0.536$ & $\mathrm{p}=0.281$ \\
\hline
\end{tabular}

MER= Membrana epirretiniana. 
Da mesma forma que nos casos de BM, quando avaliados somente os pacientes com MER também não houve diferença estatística da PIO ao longo do tempo até a última medida do estudo quando comparada com a PIO pré-operatória ( $p>0.05$ ). E analisando a Tabela 20 , na comparação das médias \pm erro padrão em cada tempo também não houve diferença estatística entre os grupos em nenhuma das visitas do estudo.

\subsubsection{BM e MER}

Os grupos, sem distinção de patologia, foram também comparados ao longo do tempo para PIO (ANOVA para medidas repetidas) e, considerando cada período estudado, os valores das médias \pm erro padrão da PIO em cada grupo estão dispostos na Tabela 21, mostrando que houve diferença estatística entre os grupos somente no primeiro mês após VPP.

Tabela 21 - Comparação da pressão intraocular entre o pré-operatório e os demais períodos em ambos os grupos

\begin{tabular}{|c|c|c|c|c|c|c|}
\hline & \multicolumn{6}{|c|}{ Pressão intraocular } \\
\hline & Pré-operatório & 1 mês & 3 meses & 6 meses & 9 meses & 12 meses \\
\hline $\begin{array}{l}\text { Grupo cirurgia } \\
\text { combinada }\end{array}$ & 14. $78 \pm 0.38$ & $14.85 \pm 0.75$ & 14. $68 \pm 0.46$ & $14.5 \pm 0.42$ & $14.58 \pm 0.44$ & $14.65 \pm 0.5$ \\
\hline $\begin{array}{l}\text { Grupo cirurgia } \\
\text { sequencial }\end{array}$ & 15. $25 \pm 0.38$ & $16.93 \pm 0.75$ & $14.98 \pm 0.46$ & 14. $3 \pm 0.42$ & 14. $75 \pm 0.44$ & $14.98 \pm 0.5$ \\
\hline p-valor & $p=0.505$ & $p=0.004$ & $p=0.671$ & $p=0.788$ & $\mathrm{p}=0.801$ & $p=0.646$ \\
\hline
\end{tabular}


Baseado em uma busca no banco de dados PubMed e, de acordo com nosso conhecimento, este é o primeiro estudo prospectivo a comparar os desfechos das alterações da córnea em pacientes fácicos com BM ou MER e sem catarata significativa, submetidos à cirurgia combinada (VPP e Faco) versus VPP e Faco sequencial. Objetivou-se investigar o impacto sobre a contagem e morfologia das células endoteliais e sobre as características biomecânicas da córnea.

Em um estudo semelhante, Hamoudi, Christensen e La Cour (2017) avaliaram diferentes sequências de cirurgia: além da VPP com faco combinada, realizaram também cirurgia sequencial alternando entre VPP e Faco em um segundo tempo e a sequência contrária - Faco como primeiro procedimento. No entanto, somente foram avaliados pacientes portadores de MER com uma amostra pequena (menos de 25 pacientes por grupo). Nesse estudo, o intervalo entre as cirurgias dos dois grupos de cirurgia sequencial foi de 30 dias. No presente estudo, a Faco foi realizada somente após o surgimento da catarata.

Outros autores (DUGAS et al., 2010; MUSELIER et al., 2010; SILVA et al., 2014) também compararam a VPP com faco combinada versus cirurgia sequencial em diferentes situações, mas todos realizaram estudos retrospectivos. Muselier et al. (2010) avaliaram comparativamente as duas técnicas em relação aos resultados funcionais (MAVC) e anatômicos (taxa de fechamento do BM) durante o seguimento de 12 meses. Dugas et al. (2010) desenvolveram um estudo semelhante, mas avaliando apenas pacientes com MER idiopática, submetidos à cirurgia combinada (VPP e Faco) versus VPP e Faco sequencial, e os resultados funcionais (MAVC) e anatômicos (diminuição da espessura macular) obtidos. SILVA et al. (2014) estudaram somente pacientes portadores de retinopatia diabética, submetidos à VPP e Faco combinada versus VPP sem Faco sequencial. Foi realizado um estudo retrospectivo observacional que utilizou os registros dos prontuários dos pacientes no período de quatro anos após os procedimentos (VPP e faco combinada ou VPP). Nenhum desses autores avaliou as alterações funcionais e anatômicas da córnea causadas pelos procedimentos cirúrgicos realizados. 


\subsection{Densidade de células endoteliais}

No estudo atual, perda significativa de células endoteliais foi detectada a partir de primeiro mês após a cirurgia combinada e após seis meses no grupo VPP e faco sequencial $(p<0.05)$. A diminuição na DCE no grupo faco sequencial ocorreu mais tarde, à medida que mais pacientes foram submetidos à Faco durante o seguimento, ou seja, como esperado, a DCE diminuiu significativamente apenas após a cirurgia de catarata, e não após a VPP.

A redução da DCE em um ano não diferiu entre os dois grupos e essa redução em cada grupo foi semelhante àquela relatada após a Faco isolada por Lucena et al. (2010). Foi encontrada redução na DCE de 12 a 15\%, corroborando com estudos anteriores, embora a redução varie de $4 \%$ a $23 \%$ em diferentes estudos (HAMOUDI; CHRISTENSEN; LA COUR, 2017; REUSCHEL et al., 2015; STORR-PAULSEN et al., 2007). Destes, o único que avaliou a redução da DCE em cirurgia combinada e sequencial foi o de Hamoudi, Christensen e La Cour (2017), que observaram redução de 15 a 20\%. Além disso, o índice morfológico do endotélio corneano (CV) mudou em todos os grupos, mas sem diferença significativa entre eles.

O número de células endoteliais que necessita ser contado em cada imagem para obtenção de precisão máxima é bastante controverso na literatura: alguns autores estão satisfeitos com 30 células (BENETZ et al., 1999), enquanto outros acreditam que são necessárias 75 (DOUGHTY; MULLER; ZAMAN, 2000). O objetivo do presente estudo era ter pelo menos 45 células em cada imagem analisada para melhorar a precisão. Devido à variabilidade na DCE e no CV, determinada a partir das imagens (REUSCHEL et al., 2015), foi obtida média de três medidas (ou seja, três fotografias em cada exame). Utilizou-se a contagem manual, que é mais precisa do que a contagem automatizada. Há controvérsias quanto ao tempo necessário de pós-operatório para avaliar a DCE, mas geralmente são considerados três meses para perda, reorganização celular e estabilização (BOURNE et al., 2004). 


\subsection{Paquimetria}

Alguns consideram a paquimetria um indicador útil da função das células endoteliais (LUNDBERG; JONSSON; BEHNDIG, 2005; SUZUKI et al., 2006). O aumento transitório observado na paquimetria com subsequente diminuição progressiva foi descrito anteriormente em cirurgia de catarata (ARIBABA et al., 2015), VPP (WATANABE et al., 2012) e cirurgia combinada (WATANABE et al., 2015). O presente estudo, em conjunto com outros, avaliou as células endoteliais com microscopia especular de não-contato na córnea central, com um alcance de $<1 \mathrm{~mm}^{2}$ por foto. Assim, não se levou em consideração as diferenças regionais e não se avaliou a função total das células endoteliais (AZEN et al., 1983). O mapeamento da espessura da córnea, usando o software de paquimetria, obtido por meio de uma câmera Scheimpflug (no Pentacam), pode avaliar toda a córnea e estimar o CV (HAYASHI, K.; NAKAO; HAYASHI, F, 1994).

A paquimetria revela alterações em curto prazo após a cirurgia. Neste estudo, a primeira reavaliação foi realizada com um mês, quando normalmente o edema de córnea induzido pelo trauma cirúrgico já regrediu. Apenas traumas intensos ou em córneas previamente doentes podem levar ao aumento persistente, o que não foi o caso do presente estudo (SALVI et al., 2007; VALBON et al., 2012; VENTURA; WALTI; BOHNKE, 2001). Em outras palavras, este estudo concluiu que não há dano importante em ambas as estratégias cirúrgicas que leve ao aumento significativo da espessura da córnea em pacientes com BM e MER.

Não foi encontrada diferença estatisticamente significativa na ECC em ambos os grupos entre o mês 12 e o baseline, nem entre os grupos em qualquer visita do estudo ( $p>0.05$ ), embora um aumento da ECC de até $10 \mu \mathrm{m}$ esteja dentro do intervalo do erro de medição da repetibilidade do dispositivo Pentacam (NAM et al., 2010) e, portanto, seria, provavelmente, um achado sem importância clínica.

\subsection{Coeficiente de variabilidade (CV)}

É prática comum que a DCE seja usada para avaliar o estado da córnea após a Faco, mas não pode refletir a dinâmica do processo de cicatrização do trauma. $A$ 
mudança na morfologia tem uma relação mais próxima com a dinâmica do processo de recuperação da córnea. Sabe-se que ao contrário do epitélio da córnea que facilmente se regenera após um trauma, a regeneração das células do endotélio ainda não está bem definida. Como resposta imediata à cirurgia, leva ao aumento no tamanho das células para cobrir a superfície posterior da córnea, a fim de preencher o espaço. Isso leva ao aumento no CV do tamanho celular e à diminuição no percentual de hexagonalidade. Após o período de rearranjo, essas alterações diminuem e tendem a estabilizar cerca de três meses após a Faco e o CV e percentual de hexagonalidade tendem a retornar aos valores pré-operatórios. Gradualmente, as células retornam à estabilidade para manter a função fisiológica da córnea (SCHULTZ et al., 1986; TANG et al., 2017). Outra possibilidade de regeneração endotelial está em estudo e poderá vir através da injeção de células endoteliais corneais suplementada com inibidor de rho-proteína quinase asssociada - ROCK (KOIZUME et al., 2014).

No presente estudo observou-se certa desorganização nos primeiros meses e remodelamento com estabilização depois, conforme já verificado em estudos anteriores (BOURNE et al., 2004; DIAZ-VALE et al., 1998; KRAFF; SANDERS; LIEBERMAN, 1980; SCHULTZ et al., 1986). A média do CV do tamanho celular se mostrou semelhante nos dois grupos, não havendo diferença significativa entre ambos em qualquer período do estudo. No entanto, diferente de estudos anteriores (INOUE, et al., 2002; LIU et al., 2014; SCHULTZ et al., 1986), foi observada diminuição significativa na média do CV no mês 12 em relação ao pré-operatório no grupo combinado $(p=0,033)$, quando esta deveria ter retornado aos valores basais ou ter aumentado em relação ao baseline.

Não foi encontrada correlação clara entre alterações na DCE, CV e ECC. No entanto, a utilidade do CV ainda não está estabelecida (SUZUKI et al., 2006), e a DCE ainda é o parâmetro amplamente aceito na avaliação do dano cirúrgico ao endotélio corneano e da invasividade da cirurgia (WATANABE et al., 2015). 


\subsection{Melhor Acuidade Visual Corrigida (MAVC)}

Neste estudo, não houve diferença entre os dois grupos em relação à média da MAVC após um ano de acompanhamento. Outros autores também relataram que a cirurgia combinada VPP e Faco está associada a resultados semelhantes de MAVC quando comparada à VPP sozinha nos olhos com BM e catarata (KOTECHA et al., 2000; LAHEY et al., 2002; THEOCHARIS et al., 2005). MUSELIER et al. (2010) relataram resultados semelhantes de AV em 12 meses pós-VPP em olhos com BM tratados com VPP combinada com faco versus VPP e cirurgia de faco sequencial $(0,50 \pm 0,38$ e 0,58 $\pm 0,38$, respectivamente; $p=0.36)$.

É importante observar que o presente estudo não foi delineado para detectar diferenças intergrupos menores que 0,15 logMAR ou seis letras ETDRS. No entanto, alguns autores têm relatado melhora após a VPP para BM, variando de 0,30 (12 letras ETDRS) para 0,37 (15 letras ETDRS) logMAR, valores muito superiores a 0,15 logMAR ou seis letras ETDRS (DAY et al., 2016; ROGERS et al., 2007). Em outras palavras, a variação esperada na MAVC é muito maior do que a diferença que pôde ser detectada com o tamanho da amostra do presente estudo.

A MAVC no baseline (considerando as duas patologias) foi de $0.94 \pm 0.04$ logMAR no grupo cirurgia combinada e $0.93 \pm 0.05$ no grupo cirurgia sequencial (aproximadamente 20/160 Snellen), semelhante aos achados de estudos retrospectivos, nos quais a AV inicial foi de 20/200 ou pior (POLLACK et al., 2004; ROGERS et al., 2007). No mês 12, a média da MAVC foi significativamente melhor em relação ao baseline em ambos os grupos (0.61 logMAR no grupo cirurgia combinada e 0.58 logMAR no grupo cirurgia sequencial), correspondendo ao ganho de 0,33 logMAR e 0,35 logMAR nos grupos cirurgia combinada e cirurgia sequencial, respectivamente; representando aproximadamente 15 letras ETDRS, sem diferença estatisticamente significativa entre os grupos cirurgia combinada e cirurgia sequencial.

Nos olhos submetidos apenas à VPP, inicialmente, a tendência para a piora da visão a partir do terceiro mês foi, provavelmente, devida ao desenvolvimento de catarata nos olhos fácicos desse grupo, sendo observada diferença significativa na MAVC entre os dois grupos no sexto mês (os valores de MAVC observados aos seis 
meses foram de 0,62 e 0,87 logMAR nos grupos combinado e sequencial, respectivamente). Os resultados visuais no grupo VPP e faco sequencial demonstraram melhora subsequente gradual na MAVC, que coincidiu com o momento da extração da catarata (Figura 36), com tempo médio da VPP até a cirurgia de catarata de 8,52 $\pm 0,46$ meses. Após a cirurgia de catarata no grupo cirurgia sequencial, a MAVC passou a apresentar melhora significativa e, ao fim do estudo, evidenciou valores semelhantes ao grupo de cirurgia combinada. Estes resultados corroboram o estudo realizado com membrana macular epirretiniana idiopática, comparando procedimentos consecutivos e combinados (DUGAS et al., 2010).

No presente estudo, o tempo médio de recuperação dos pacientes no grupo combinado foi seis meses menor que o do grupo cirurgia sequencial, possivelmente devido à progressão da catarata após a cirurgia vítrea. Este resultado foi semelhante ao de Muselier et al. (2010), que mostraram menor tempo de recuperação para o grupo de cirurgia combinada em termos de melhora da AV após a cirurgia para BM.

Os grupos foram também analisados comparando separadamente os pacientes com BM e aqueles com MER para a MAVC pré e pós-operatória, considerando que a distribuição de pacientes com BM e MER nos dois grupos foi semelhante.

Fazendo a análise utilizando somente os casos com BM, percebeu-se que a MAVC pré-operatória foi de 0.92 logMAR para o grupo cirurgia combinada e 0.90 logMAR para o grupo cirurgia sequencial, chegando ao final de 12 meses aos valores de 0.60 e 0.58 logMAR nos grupos cirurgia combinada e cirurgia sequencial, respectivamente. Esta melhora equivale ao ganho de aproximadamente 15 letras na tabela ETDRS. Rogers et al. (2007) também obtiveram melhora na AV de 0,37 logMAR (15 letras ETDRS) para casos de BM. Já Muselier et al. (2010) em seu estudo retrospectivo de cirurgia combinada versus sequencial para BM, encontraram melhora na MAVC de 0,39 logMAR no grupo cirurgia combinado e 0.42 logMAR para o grupo cirurgia sequencial ao final de 12 meses, correspondendo ao ganho de 20 letras ETDRS. Esses achados respaldam os do presente estudo que evidenciaram melhora de 15 letras ETDRS ao final de 12 meses da VPP. 
Quando analisados somente os casos com MER, a média da MAVC préoperatória foi de 0.73 logMAR para grupo cirurgia combinado e 0.69 logMAR para grupo cirurgia sequencial, e melhorou para 0.47 logMAR no grupo combinado e 0.41 logMAR no grupo sequencial, sem diferença estatística entre os grupos. Dugas et al. (2010), em seu estudo retrospectivo não randomizado, compararam cirurgia combinada e sequencial para MER. Nesse estudo, a AV para longe melhorou nos dois grupos, passando de 0,61 no grupo combinado e 0,56 no grupo sequencial para 0,25 e 0,26 nos grupos combinado e sequencial, respectivamente. Essa melhora foi significativa e não houve diferença estatística entre os grupos. No presente estudo, diferente dos achados de Dugas et al. (2010), o número de pacientes com MER avaliados foi muito pequeno, o que poderia explicar a melhora não significativa da AV após 12 meses da VPP. Ou seja, neste estudo houve melhora da MAVC final nos dois grupos, independente da patologia macular. No entanto, nos pacientes com BM essa melhora foi significativa $(p<0,0001)$, enquanto naqueles com MER a melhora não foi estatisticamente significativa $(p=0.239)$ quando comparada com a MAVC no pré-operatório.

Os dados sobre a estabilidade do fechamento do BM e a AV, em longo prazo, dos olhos com sucesso no resultado cirúrgico são encorajadores. A melhora da AV também parece estável após a remoção da catarata. A MAVC melhorou média de 15 letras ETDRS ao final de 12 meses e a literatura mostra resultados semelhantes de outros autores que relataram que VPP e Faco combinada ou sequencial estão associados à melhora da MAVC em olhos com BM ou MER e catarata significativa associada. Alexandrakis et al. (1999), em sua pesquisa de cirurgia combinada para MER, obtiveram melhora de duas ou mais linhas de Snellen em $88 \%$ dos casos. Dugas et al. (2010) revelaram melhora da AV após procedimento combinado e sequencial em $85,8 \%$ dos casos.

É importante reconhecer a progressão da catarata esclerótica nuclear após a cirurgia do BM ou MER na técnica sequencial, porque a catarata geralmente causa deterioração da AV após melhora inicial e reduz os benefícios visuais da VPP para BMs e MERs em um ano, ou mais, após a cirurgia. A diminuição da AV nesses olhos pode ser atribuída erroneamente à mácula e não à catarata. Muitos pacientes submetidos à cirurgia por BM, principalmente aqueles com mais de 50 anos, não 
atingem sua melhor AV no pós-operatório até a remoção da catarata, uma vez que esta progride no momento em que a mácula se recupera completamente após a VPP.

\subsection{Erro refratométrico}

O resultado refrativo médio (equivalente esférico) de $-0,68 \pm 0,19 \mathrm{D}$ no grupo combinado e -1,11 \pm 0,19 D no grupo sequencial é semelhante ao relatado por Kim et al. (2015), que compararam os resultados refrativos da facovitrectomia combinada para MER com a cirurgia de catarata isolada e encontraram desvio míope semelhante.

$\mathrm{Na}$ facovitrectomia combinada, alguns autores acreditam que erros refrativos pós-operatórios surjam de patologia macular concomitante, como espessamento macular devido à MER. Kovács et al. (2007) sugerem que a miopização resulta da subestimação do comprimento axial devido à mácula mais espessa, por meio da ultrassonografia A-scan. Em contrapartida, Manvikar, Allen e Steel (2009) relataram que não há tendência à mudança míope na estimativa da potência da LIO usando o IOLMaster, enquanto Falkner-Radler, Benesch e Binder (2008) observaram que houve alteração refrativa miópica após a facovitrectomia combinada, apesar do cálculo do poder da LIO realizado no IOLMaster. Esses estudos sugerem a retina mais espessa no pré-operatório ou deslocamento anterior da LIO pelo preenchimento completo de gás obtido após a facocovitrectomia como mecanismos potenciais de miopização.

O ultrassom A-scan mede a distância entre a superfície anterior da córnea e a MLI, enquanto o IOL-Master mede a distância entre a superfície anterior da córnea e o EPR e depois calibra para corresponder à medida do A-scan. Verhulst e Vrijghem (2001) observaram que a diferença média no comprimento axial entre o ultrassom e a biometria óptica foi de 0,2 mm, e o IOLMaster resultou na medição de um comprimento axial mais longo, levantando-se a hipótese de que um erro na medição do comprimento axial devido à MER poderia causar desvio miópico no cálculo da LIO com A-scan. No presente estudo, o comprimento axial foi medido somente pelo A-scan nos dois grupos, de forma que não foi possível fazer essa comparação. 
O IOLMaster mede o comprimento axial até o EPR e, portanto, não deve ser afetado pelo espessamento da retina devido à presença de MER. No entanto, Kim et al. (2015) mostraram que houve um grau semelhante de erro de previsão de refração obtido ao usar o IOLMaster, em comparação com o A-scan. Estudos sobre o posicionamento da LIO relataram que, durante a primeira semana pós-operatória, a LIO avança levemente para a frente, o que é neutralizado por um ligeiro movimento para trás em três meses (KIM et al., 2015; PETTERNEL et al., 2004). Falkner-Radler, Benesch e Binder (2008) e Kim et al. (2015) referiram que, comparados com pacientes de cirurgia de catarata isolada, os pacientes do grupo da cirurgia combinada apresentaram desvio míope pós-operatório na média do erro refracional e CA mais profunda no cálculo da LIO com o IOLMaster.

Houve muitas tentativas de reduzir o erro de previsão refrativa no pósoperatório após a realização de cirurgia combinada de catarata e VPP. Um estudo realizado por Patel, Rahman e Kumarasamy (2007) sugeriu que uma leve hipermetropia residual poderia compensar a sobrecorreção miópica). Kovács et al. (2007) tentaram determinar a ametropia planejada ajustada substituindo o comprimento axial total e a potência da LIO implantada na fórmula SRK/T. Esse comprimento axial total foi determinado em cada caso, adicionando a diferença entre o valor normal da espessura macular e os resultados das varreduras da OCT ao comprimento axial do A-scan. Da mesma forma, Sun e Choi (2011) propuseram uma correlação entre a refração pós-operatória e a refração predita calculada usando um comprimento axial ajustado com alteração da espessura macular com base no olho contralateral. Para aplicar esse cálculo, prospectivamente, a pacientes com planejamento de espessura macular aumentado para serem submetidos à facovitrectomia combinada, eles subtraíram a espessura macular do olho normal contralateral da espessura macular do olho afetado e adicionaram esse número ao comprimento axial medido por A-scan. Embora essas várias tentativas de compensar a hipercorreção míope usando o comprimento axial medido com A-scan ajustado tenham se mostrado parcialmente eficazes na compensação do desvio míope, a espessura macular, em muitos pacientes, não diminui completamente para um valor normal após a cirurgia; e cada paciente mostra uma alteração pósoperatória diferente da espessura macular central. Todos esses autores advogam 
que para uma avaliação mais precisa da espessura macular central e do comprimento axial e, dessa forma, maximizar os resultados refrativos no pósoperatório, pode ser melhor realizar a VPP primeiro e depois a cirurgia de catarata, com base no cálculo da LIO obtido após a VPP, de maneira sequencial. No entanto, todos esses estudos foram realizados em pacientes portadores de MER, e o presente estudo apresentou uma quantidade bem maior de pacientes com BM nos dois grupos e, mesmo no grupo sequencial, em que o cálculo da LIO foi realizado em um olho já vitrectomizado e com a patologia retiniana já tratada, observou-se também hipercorreção miópica. Esta análise mostrou erro de predição refrativa persistente no pós-operatório, em ambos os grupos.

Alguns estudos sugerem que a miopização pode ser resultado do aumento pós-operatório do comprimento axial causado pelo afinamento da esclera, ou alongamento nos locais de esclerotomia, ou ao redor dos mesmos após a VPP (FALKNER-RADLER; BENESCH; BINDER, 2008; JEOUNG; CHUNG; YU, 2007). Neste estudo não foi realizada essa avaliação com medidas do comprimento axial pré e pós-operatório mas Kim et al. (2015) mostraram que não houve alteração significativa no comprimento medido pelo IOLMaster após a cirurgia combinada. Portanto, seria difícil considerar os pequenos aumentos no comprimento axial no pós-operatório como causa potencial para um desvio míope após Faco e VPP na estimativa da potência da LIO. Os mesmos autores especularam que o desvio míopico pelo cálculo do IOLMaster pode resultar de um valor K2 no pós-operatório significativamente mais alto do que o valor basal de K2 no grupo da cirurgia combinada. Ou seja, pensaram que seria possível que uma alteração no valor de $\mathrm{K}$ após a cirurgia também pudesse contribuir para o erro de previsão de refração pósoperatória, mesmo com o uso do IOLMaster. Também houve autores relatando que, após a VPP, o gel vítreo é substituído pelo aquoso e o índice de refração diminui ligeiramente, resultando em desvio míope (BYRNE et al., 2008; MEHDIZADEH; NOWROOZZADEH, 2009). Teoricamente, o desvio míope nos olhos vitrectomizados pode ser de até $-0.5 \mathrm{D}$. Considerando que neste estudo o erro refrativo médio foi de $-0,68 \mathrm{D}$ no grupo combinado e $-1,11 \mathrm{D}$ no grupo sequencial, especulou-se que a VPP em si também poderia desempenhar um papel na causa da miopização após a cirurgia combinada ou sequencial. Pode-se considerar que estes resultados são 
compatíveis com a literatura encontrada, uma vez que o cálculo biométrico planejou uma hipercorreção para -0.5 D, ou seja, não houve diferença significativa entre o equivalente esférico esperado e o obtido ao final do seguimento. Atualmente, não existem fórmulas disponíveis para olhos vitrectomizados ou facovitrectomia, e uma nova geração de fórmulas pode precisar ser desenvolvida no futuro.

Como o uso de incisões sem sutura de pequeno calibre é conhecido por reduzir o astigmatismo induzido cirurgicamente e a VPP não causou alteração significativa no astigmatismo no pós-operatório no presente estudo nos dois grupos, pode-se assumir que a realização de VPP sem sutura, combinada ou não com Faco, não causaria alteração astigmática significativa.

Muitas tentativas de corrigir o desvio miópico após a facovitrectomia combinada, existentes na literatura, foram baseadas no cálculo da LIO usando medidas de comprimento axial com A-scan. A sequência da cirurgia, o tempo entre as cirurgias, o uso do IOLMaster associado ao A-scan bem como o ajuste com base em um olho contralateral saudável podem precisar ser levados em conta para melhorar os resultados da refração nos casos considerados para facovitrectomia combinada ou sequencial.

Em conclusão, tanto a cirurgia combinada como a sequencial resultaram em erro refrativo miópico aos 12 meses, sem diferença significativa entre os grupos. A hipercorreção miópica nos cálculos da LIO com A-scan pode ser atribuída à subestimação do comprimento axial devido à MER ou, nos casos de BM, à combinação de fatores como alterações nos valores de $\mathrm{K}$, profundidade da CA e índice de refração devido a remoção de gel vítreo. Portanto, para melhorar a precisão da estimativa do poder da LIO nos olhos com catarata e MER ou BM, pode ser necessário considerar uma cirurgia sequencial para a patologia retiniana e a catarata.

\subsection{Ocorrência e progressão da catarata}

Nos pacientes fácicos, a progressão da catarata é uma complicação pósoperatória comum da VPP com alta incidência em variados estudos (70 a 84\%), e esses pacientes precisam de um segundo procedimento cirúrgico dentro de 
aproximadamente dois anos após a VPP (CHERFAN et al., 1991; THOMPSON, 2004; YORGUN et al., 2016).

Neste estudo, a taxa absoluta do desenvolvimento da catarata no grupo cirurgia sequencial foi de 82,5\% em 12 meses. Em pacientes submetidos à VPP por retinopatia diabética proliferativa, a incidência de catarata após a cirurgia é menor do que na presente pesquisa (entre 65 e 70\% em 12 meses), mas parte dessa diferença pode estar relacionada à menor idade média dos pacientes submetidos à VPP por complicações da retinopatia diabética (HUTTON; PESICKA; FULLER, 1987; NOVAK et al., 1984). Separando as patologias, a presente amostra apresentou taxa de progressão da esclerose nuclear nos pacientes com MER semelhante à encontrada naqueles com $\mathrm{BM}(83,3 \%$ e $82,4 \%$, respectivamente), sem diferença estatisticamente significativa entre ambas. No entanto, a literatura mostra que a esclerose nuclear progride mais rapidamente nos olhos submetidos à VPP por BM do que naqueles tratados para MER. Thompson et al. (1995) referiram que a catarata progrediu em $75 \%$ dos olhos operados por BM em um ano e em $95 \%$ dos olhos seguidos por dois anos após a cirurgia. Já o estudo de Cherfan et al. (1991) observaram que aproximadamente $43 \%$ dos pacientes operados por MER apresentaram progressão da esclerose nuclear em um ano e $70 \%$ em dois anos após a cirurgia de VPP. Os achados deste estudo podem ter se mostrados um pouco díspares em relação a estudos anteriores para essa variável devido ao pequeno número de pacientes submetidos à VPP para MER, que pode ter levado a um viés com relação à verdadeira percentagem de pacientes que desenvolvem catarata após VPP para tratamento de MER. Outra possível explicação seria o fato de os pacientes com MER no grupo sequencial serem um pouco mais velhos que os pacientes com BM. A idade média dos pacientes com BM foi de 64 anos em comparação aos 68 anos daqueles com MER. Pacientes mais velhos podem estar predispostos à progressão mais rápida da esclerose nuclear, embora a diferença de quatro anos não seja grande.

Quanto ao período de aparecimento da esclerose nuclear, com a consequente realização da cirurgia de catarata, a média \pm erro padrão do tempo em que foi realizada a Faco nesse grupo foi de 8,52 \pm 0,46 meses, o que já foi observado em estudos anteriores (ERÇALIK et al., 2017). Quando comparadas as 
duas patologias (BM e MER), não houve diferença estatística quanto ao tempo entre a VPP e a realização da Faco, e a maior concentração de cirurgias se deu no terceiro e quarto trimestres com $33 \%$ e $35 \%$ das cirurgias realizadas, respectivamente.

\subsection{Eventos adversos}

Tanto a Faco em um olho vitrectomizado quanto a VPP combinada têm sido consideradas tecnicamente desafiadoras, e as complicações pós-catarata na cirurgia combinada ou sequencial são relatadas como sendo mais comuns do que aquelas na cirurgia de catarata isolada. No entanto, houve poucos relatos diretamente comparando as complicações relacionadas à Faco entre os procedimentos sequenciais e combinados da cirurgia de VPP e catarata para BM e/ou MER (DUGAS et al., 2010; MUSELIER et al., 2010).

A Faco combinada com a VPP normalmente envolve um tempo cirúrgico mais longo do que a VPP isolada somada à Faco sequencial. No presente estudo, a duração média da cirurgia no grupo combinado foi de 76,13 $\pm 20,58$ minutos e no grupo sequencial foi de $62,85 \pm 14,80$ minutos. Esse aumento do tempo cirúrgico poderia, teoricamente, levar a mais inflamações e complicações pós-operatórias, como sinéquias posteriores, captura pupilar, hipertensão ocular ou opacificação da cápsula posterior (LAHEY; FRANCIS; KEARNEY, 2003; LEE et al., 2012). No entanto, neste estudo, as taxas de complicações para essas entidades não diferiram significativamente entre os grupos combinado e sequencial, novamente sugerindo que não há grande diferença no risco associado a esses procedimentos cirúrgicos.

Já a extração da catarata após a VPP pode ser dificultada por causa da perda do suporte vítreo (TREUMER et al., 2006). São descritas na literatura variações anormais da profundidade da CA, miose intraoperatória, zônulas instáveis e cápsula posterior flácida durante a aspiração cortical, mas esses problemas técnicos não resultaram em complicações graves no presente estudo, em que somente dois pacientes no grupo sequencial apresentaram ruptura capsular intraoperatória com a LIO sendo posicionada no sulco. De fato, a extração de catarata foi realizada após o tempo médio de 8,52 meses. Isso indica que a opacificação do cristalino da maioria 
desses pacientes não era tão densa, o que provavelmente minimizou os problemas técnicos atribuíveis à extração secundária de catarata. Os dois olhos que apresentaram ruptura capsular foram submetidos à Faco 11 meses após a VPP (superior à média de 8,5 meses do restante do grupo) e apresentavam grau mais elevado de densidade nuclear (grau 2). Nos dois grupos nenhuma complicação grave foi observada. A elevação transitória da PIO foi a complicação pós-operatória precoce mais frequente, ocorrendo em um paciente do grupo cirurgia combinado e em três pacientes do grupo cirurgia sequencial. Todos os casos foram controlados com sucesso com medicação tópica e, no paciente do grupo combinado foi associado manitol por via venosa. Os mecanismos que levam a esse aumento transitório na PIO estão descritos no item 5.8.

Poderia-se postular que o endotélio da córnea estaria em maior risco durante uma cirurgia combinada do que somente na Faco, devido à maior complexidade e duração do procedimento. Alguns autores têm descrito a ocorrência de perda de transparência da córnea devido a edema e dobras na membrana de Descemet durante o procedimento ou no pós-operatório imediato (RIVAS-AGUIÑO et al., 2009). Em todos os casos do grupo combinado a córnea permaneceu suficientemente clara durante toda a cirurgia do segmento posterior, e não foram observadas diferenças significativas entre os dois grupos quanto às características morfológicas do endotélio corneano em nenhuma das visitas durante o seguimento.

Fibrina da CA ocorreu em três olhos do grupo cirurgia combinada. Os fatores que predispõem à reação da fibrina nas cirurgias vitreoretinianas incluem múltiplos procedimentos cirúrgicos, como retinopexia, fotocoagulação excessiva por endolaser, retinotomia extensa, presença de retinopatia diabética, hemorragia vítrea e uso de óleo de silicone (CHUNG, T. Y.; CHUNG, H.; LEE, 2002; TREUMER et al, 2006). A fibrina da CA no presente estudo foi resolvida com anti-inflamatórios não esteroides e intensificação dos esteroides tópicos. Exceto pela sinéquia posterior encontrada nos mesmos três casos, não houve membranas organizadas de fibrina ou complicações anteriores no pós-operatório no grupo combinado. No grupo sequencial um paciente apresentou uveíte anterior.

De acordo com relatos da literatura as taxas de deslocamento da lente, trauma da íris e deiscência zonular durante a Faco não diferem entre os grupos de 
cirurgia combinada e sequencial, mas os autores referem ser a ruptura da cápsula posterior a complicação mais comum nos grupos de cirurgia sequencial quando comparada à cirurgia combinada (AHFAT; YUEN; GROENEWALD, 2003; CHEUNG; HERO, 2005), corroborando os achados deste estudo, que mostraram a ocorrência de ruptura capsular somente no grupo sequencial.

Em conclusão, a Faco em um olho vitrectomizado apresentou maior ocorrência de ruptura capsular do que na VPP combinada. Este resultado pode ter sido causado por uma catarata com núcleo mais duro em um olho vitrectomizado. Por outro lado, percentagem maior de exsudação fibrinosa na CA foi encontrada no grupo de cirurgia combinada. Apesar dos números relativos aos eventos adversos, acima mencionados, o presente estudo não possui poder para detectar diferenças relacionadas às complicações, acima citadas, entre os grupos.

\subsection{Pressão intraocular}

Após a VPP, é frequente ocorrer elevação transitória ou sustentada da PIO, com incidência variando entre 20 e $28 \%$ na maioria dos estudos (CAMPBELL et al., 1977; GHARTEY et al., 1980; WEINBERG; PEYMAN; HUAMONTE, 1976). Vários mecanismos explicam essa elevação aguda da pressão pós-VPP, como o glaucoma eritroclástico, inflamatório e neovascular. Além disso, intervenções terapêuticas específicas, comumente usadas em conjunto com a cirurgia de VPP, como introflexão escleral, endofotocoagulação ou uso de gases expansíveis, podem também estar associados à elevação da PIO.

A presença de glaucoma preexistente ou a ocorrência de complicações pósoperatórias, como formação de fibrina, hemorragia ou descolamento de coroide também podem aumentar o risco de elevação da PIO. No entanto, a contribuição relativa de cada um desses fatores não é clara. No entanto, nesses estudos, a indicação para cirurgia em um grande número das populações avaliadas foi retinopatia diabética. É provável que a incidência de elevação sustentada da PIO por glaucoma neovascular seja menor em uma população com menos olhos diabéticos. Han et al. (1989) relataram elevação aguda da PIO após 48h acima de $30 \mathrm{mmHg}$ em $35,6 \%$ dos 222 pacientes após VPP para diversas patologias retinianas como: 
descolamento de retina, hemorragia vítrea, retinopatia diabética e trauma ocular. Já o aumento persistente da PIO não é comum após VPP. Passemard et al. (2010) descreveram aumento persistente da PIO em 5,6\% dos casos após VPP, demonstrando sua baixa incidência.

A facectomia combinada à VPP também pode predispor o olho ao glaucoma transitório, pelo aumento da inflamação, congestão uveal, devida ao aumento da manipulação do olho ou obstrução da malha trabecular pelas partículas do cristalino, dispersão do pigmento uveal pela faco-fragmentação ultrassônica ou por uso de materiais viscoelásticos.

A introflexão escleral ou a endofotocoagulação intraoperatória parecem aumentar o risco de elevação da PIO pós-VPP de forma significativa e independente. Em muitos casos, isso provavelmente se deve à capacidade inerente de cada uma dessas modalidades de causar PIO elevada por congestão do corpo ciliar ou descolamento de coroide com fechamento secundário do ângulo. Estima-se que o glaucoma de ângulo fechado ocorra em 6 a 22\% dos olhos submetidos à panfotocoagulação e $3,6 \%$ dos olhos submetidos à introflexão escleral com implantes (HAN et al., 1989).

Em se tratando da cirurgia combinada, ou facovitrectomia, a literatura demonstra que a PIO elevada tem sido relatada como a complicação pós-operatória precoce mais frequente, com incidência variando de 4,4\% a 23,8\% (DEMETRIADES et al., 2003; JUN; PAVLOVIC; JACOBI, 2001). Isso foi semelhante aos resultados do presente estudo, em que a incidência de PIO elevada após cirurgia combinada aos 30 dias de pós-operatório foi de 5,0\% dos casos (dois pacientes apresentaram PIO maior do que $21 \mathrm{mmHg}$ no pós-operatório de um mês, sendo um caso de BM e outro de MER). No grupo sequencial, cinco pacientes apresentaram PIO maior do que 21 $\mathrm{mmHg}$ no pós-operatório de um mês, sendo quatro casos de BM e um caso de MER, o que representa $12,5 \%$ dos casos. Houve diferença significativa entre os grupos combinado e sequencial somente no primeiro mês de pós-operatório, com média de 14,6 e 16,93 mmHg, respectivamente. Esta média de valor da PIO está de acordo com os achados da literatura, em que a média da PIO foi de $16 \mathrm{mmHg}$ após um mês da VPP (CHEN, 1998). 
Foi observada incidência mais baixa de elevação da PIO no grupo cirurgia combinada em relação ao grupo cirurgia sequencial, mesmo que teoricamente esse grupo gerasse mais processo inflamatório, em virtude do maior tempo cirúrgico e maior resposta ao trauma, devido aos dois procedimentos de VPP combinado com a extração do cristalino. Isso difere um pouco dos relatos da literatura: Chung, T. Y., Chung, H. e Lee (2002) encontraram aumento da PIO no pós-operatório em 55,8\% após cirurgia combinada. Em estudo de 513 casos de cirurgia combinada, Mueller et al. (2004) observaram elevação da PIO no pós-operatório em 37,7\% dos olhos, com variação de 22 a 30 mmHg; e em 15,4\% dos olhos, com variação de 31 a 40 mmHg. A menor proporção de olhos diabéticos neste estudo também pode explicar essas diferenças, inclusive o fato de não se observar aumento sustentado da PIO após a VPP.

Avaliando somente os casos de BM que apresentaram aumento da PIO 30 dias após a cirurgia em cada grupo, percebeu-se que 3,0\% do grupo combinado e $12,5 \%$ do grupo sequencial tiveram aumento da PIO. Avaliando somente os casos de MER com aumento da PIO após um mês da VPP em cada grupo, observou-se que $14,2 \%$ do grupo combinado e $12,5 \%$ do grupo sequencial demonstraram aumento da PIO, ou seja, sem diferença estatística entre ambos. Pode-se notar que foram os casos de BM que contribuíram para essa diferença da PIO após um mês entre os grupos. Fujikawa et al. (2014) descreveram aumento da PIO após VPP em olhos com BM, mas não naqueles com MER.

É bem descrito na literatura o efeito da Faco na redução da PIO. Jahn (1997) comparou a diferença de PIO entre olhos pseudofácicos e olhos fácicos ao longo do tempo e observou que a PIO média de olhos pseudofácicos era $2 \mathrm{mmHg}$ mais baixa que a dos olhos fácicos contralaterais. O mecanismo exato não é claro, mas a facectomia aumenta significativamente o fluxo de humor aquoso (SIEGFRIED et al., 2010). Portanto, a não realização da facectomia no grupo sequencial no primeiro mês pode justificar a diferença da média de $2,33 \mathrm{mmHg}$ entre os grupos. Essa hipótese fica fortalecida pelo fato de os achados deste estudo demonstrarem que não houve diferença significativa na variação da PIO após 12 meses entre os grupos, independente das patologias (BM ou MER), ou seja, após a facectomia nos pacientes do grupo sequencial. 


\subsection{Custos}

A maioria dos estudos disponíveis já demonstrou que a combinação da VPP com Faco e implante LIO (faco/LIO) é um tratamento seguro para vários tipos de doenças da retina que ocorrem concomitante com a catarata. O principal benefício de uma abordagem combinada ou "facovitrectomia" é que ela evita a necessidade de retorno à sala de cirurgia para tratar a catarata, o que geralmente ocorre logo após a VPP.

As análises do presente estudo sugerem que a combinação de faco/LIO e VPP ou "facovitrectomia" pode oferecer uma economia significativa de custos em comparação com a abordagem sequencial dos procedimentos. Essa economia de custos parece ser o resultado de taxas reduzidas de cirurgiões, centro cirúrgico e anestesiologia com a facovitrectomia.

Relatos na literatura já demonstraram que procedimentos combinados diminuem o custo total da cirurgia e melhoram o desempenho funcional para 0 paciente, cuja recuperação da AV é mais rápida (KOTECHA et al., 2000; LAHEY et al., 2002). De fato, usando o sistema de gerenciamento da tabela de procedimentos, medicamentos e OPM (órteses, próteses e materiais) do Sistema Único de Saúde brasileiro (SUS) (www.datasus.gov.br) comparou-se o custo desses procedimentos cirúrgicos para o hospital. Nas cirurgias sequenciais de BM/MER e facectomia, o custo foi de $R \$ 771,60$ (\$143.70) para Faco com implante de lente dobrável e $\mathrm{R} \$ 1.862,63$ (\$347.61) para a VPP, totalizando $\mathrm{R} \$ 2.634,23$ (\$491.40). Já na cirurgia combinada, o custo total foi de $\mathrm{R} \$ 1.991,27$ (\$371.60). Portanto, a cirurgia combinada foi menos dispendiosa do que a cirurgia sequencial no SUS, que paga diretamente ao hospital.

Essas estimativas são um tanto arbitrárias porque essa análise de custos não leva em consideração fatores indiretos de custos como: exames oftalmológicos, acompanhamento, a quantidade de consultas pós-operatórias e transportes, que são relevantes para o cálculo do custo total. Embora também não tenha sido incluída na presente análise, o tempo de recuperação e, portanto, o tempo do afastamento do trabalho provavelmente são reduzidos com a facovitrectomia. Essas limitações para 
estas estimativas enviesam esta análise e isso sugere que o custo-benefício da facovitrectomia é provavelmente bem mais robusto.

Deve-se enfatizar que os custos do presente estudo foram analisados da perspectiva do pagador, a saber, o SUS. Os custos reais para um paciente podem variar de acordo com o tipo de seguro médico.

Certamente, a decisão de fazer VPP combinada versus sequencial e faco/LIO depende de muitos fatores, incluindo a proficiência do cirurgião, as características do caso clínico e as preferências do paciente. No entanto, há inúmeros benefícios da cirurgia combinada que incluem mais rápida recuperação visual, minimizando a morbidade do paciente e evitando um segundo procedimento, e a redução do risco cirúrgico e das visitas dos pacientes à clínica e à sala de operações e do custo geral. A cirurgia combinada deve, portanto, tornar-se parte da política pública de saúde, diminuindo o custo total dos procedimentos.

\subsection{Síntese}

Houve algumas limitações para este estudo: as cirurgias foram realizadas por dois cirurgiões e não houve um controle em relação ao número de cirurgias por grupo, por cirurgião; e não se registrou sistematicamente a quantidade de energia ultrassônica usada e tempo cirúrgico. Sugere-se considerar essas questões em estudos futuros. Essas limitações são parcialmente mitigadas pelo uso de formulários padronizados de coleta de dados, um prontuário personalizado, projetado especificamente para avaliar os resultados, todas as medições de MAVC realizadas por oftalmologistas habilitados e variabilidade cirúrgica reduzida devido ao número limitado de cirurgiões e um único centro cirúrgico.

Defende-se a realização de cirurgia de catarata simultaneamente com VPP. Ao contrário, se a VPP for realizada primeiro, haverá desenvolvimento de catarata em $82,5 \%$ dos pacientes dentro de um ano de seguimento, e isto os privará de melhora na AV após seis meses da cirurgia, um dado importante a ser apresentado a estes na escolha da técnica cirúrgica a ser empregada no tratamento de sua doença ocular. 
A facovitrectomia é realizada rotineiramente em algumas áreas. Às vezes, a VPP combinada à Faco é realizada em pacientes com apenas catarata leve para melhorar a visualização durante a VPP, ou porque se espera que a catarata se desenvolva logo após a mesma. Certamente, se a facovitrectomia fosse realizada em um paciente sem uma catarata visualmente significativa, o procedimento faco/LIO seria cobrado em conjunto e a economia de custos para o paciente ou para o plano de saúde seria maior. Certas limitações da facovitrectomia podem incluir perda de acomodação em pacientes pré-présbitas e uveíte fibrinosa com sinéquia posterior. No entanto, os possíveis benefícios da cirurgia combinada incluem a oportunidade de remoção cirúrgica intraoperatória do cristalino com melhora da visibilidade da mácula durante a remoção da membrana limitante (nos casos com catarata), melhor retirada da base vítrea sem os riscos de toque do cristalino e redução das visitas dos pacientes à clínica. A cirurgia combinada pode ser significativamente menos onerosa para o paciente.

Concluindo, a combinação de VPP e Faco como único procedimento cirúrgico em pacientes com MER ou BM, quando indicada, resultou em alterações da córnea semelhantes, além de resultados visuais e taxas de complicações comparáveis à VPP seguida de Faco a posteriori. No geral, estes achados sugerem que, para pacientes com catarata e doença vitreorretiniana coexistente que necessitam de VPP, a facovitrectomia combinada pode ser uma opção terapêutica apropriada sem risco substancial aumentado e com bons resultados visuais.

Até onde se sabe, este é o primeiro estudo prospectivo comparando as alterações morfológicas do endotélio da córnea nas duas técnicas mencionadas em pacientes com BM ou MER. 
6. Conclusões 
Após análise dos resultados, concluiu-se que:

- Houve redução significativa e semelhante na DCE em ambos os grupos em relação ao baseline, ao final de 12 meses de seguimento. No grupo cirurgia combinada esta perda foi maior na primeira visita pós-operatória, intensificando a semelhança entre os grupos somente após o sexto mês quando aumentou significativamente a realização de faco no grupo cirurgia sequencial.

- Não foi encontrada diferença estatisticamente significativa na ECC (paquimetria) em ambos os grupos entre o mês 12 e o baseline, nem entre os grupos em qualquer visita do estudo.

- A média do CV do tamanho celular se mostrou semelhante nos dois grupos em qualquer período do estudo, não sendo influenciada pela técnica utilizada (combinada ou sequencial).

- Comparando os dois grupos, houve melhora significativa da AV ao final de 12 meses de acompanhamento no grupo cirurgia combinada e no grupo cirurgia sequencial, independente da patologia macular (BM ou MER), sem diferença estatisticamente significativa entre os grupos. No sexto mês houve diferença entre os grupos, coincidindo com a progressão da catarata no grupo sequencial.

- Tanto a VPP + faco imediata como a VPP com faco postergada resultaram em variação no equivalente esférico semelhante após 12 meses.

- A incidência de catarata no grupo cirurgia sequencial foi de 82,5\% após 12 meses de seguimento.

- Com relação aos eventos adversos, a Faco na cirurgia sequencial apresentou maior taxa de ruptura capsular posterior do que na VPP 
combinada. Por outro lado, maior porcentagem de exsudação fibrinosa na CA e sinéquias posteriores foi encontrada no grupo de cirurgia combinada.

- Não houve diferença significativa na variação da PIO após 12 meses entre os grupos, independente das patologias BM ou MER. Somente na visita do primeiro mês a média da PIO no grupo sequencial foi mais alta. 


\section{Referências Bibliográficas ${ }^{1}$}

${ }^{1}$ Elaboradas de acordo com as Diretrizes para Apresentação de Dissertações e Teses da USP: Documento Eletrônico e Impresso - Parte I (ABNT) 3를 ed. São Paulo: SIBi/USP, 2016. 
AABERG, T. M, BLAIR, C. J; GASS, J. D. Macular holes. Am J Ophthalmol. v. 69, p. 555-562, 1970.

ABIB, F. C. Behavior of corneal endothelial density over a lifetime. J Cataract Refract Surg. v. 27, p. 1574-1578, 2001.

AGARWAL, A. Normal macula. In: Gass' atlas of macular diseases. $5^{\text {th }}$ ed. Elsevier Saunders. v. 1, chapter 1, p. 2-16, 2012.

AHFAT, F. G.; YUEN, C.H.; GROENEWALD, C. P. Phacoemulsification and intraocular lens implantation following pars plana vitrectomy: a prospective study. Eye. v. 17, p.16-20, 2003.

ALEXANDRAKIS, G. et al. Combined cataract surgery, intraocular lens insertion, and vitrectomy in eyes with idiopathic epiretinal membrane. Ophthalmic Surg Lasers. v. 30, n. 4, p. 327-8, 1999.

AREVALO, J. F.; FERNANDEZ, C. F.; MENDOZA, A. J. Normal Anatomy of the Macula. In: Age-related Macular Degeneration: A Comprehensive Textbook. Lippincott Williams \& Wilkins. chapter 1, p. 1-12, 2006.

ARIBABA, O.T. et al. Central corneal thickness changes following manual small incision cataract surgery. Clin Ophthalmol. v. 9, p. 151-155, 2015.

AZEN, S.P. et al. Effects of the shearing posterior chamber intraocular lens on the corneal endothelium. Am J Ophthalmol. v. 95, p. 798-802, 1983.

BANACH, M. J. et al. Clinical course and surgical treatment of macular epiretinal membranes in young subjects. Ophthalmology. v. 108, n. 1, p. 23-6, 2001.

BATES, A. K.; HIORNS, R. W.; CHENG, H. Modelling of changes in the corneal endothelium after cataract surgery and penetrating keratoplasty. Br J Ophthalmol. v. 76, p. 32-35, 1992.

BECHMANN, M. et al. Central corneal thickness measurement with a retinal optical coherence tomography device versus standard ultrasonic pachymetry. Cornea. v. 20, p. 50-54, 2001.

BEHNDIG, A. et al. Corneal endothelial integrity in mice lacking extracellular superoxide dismutase. Invest Ophthalmol Vis Sci. v. 42, p. 2784-2788, 2001.

BENETZ, B. A. et al. Comparison of corneal endothelial image analysis by Konan SP8000 noncontact and Bio-Optics Bambi systems. Cornea v. 18, p. 67-72, 1999.

BENSON, W. E. et al. Surgical management of macular holes: A report by the Ophthalmology. v. 108, n. 7, p. 1328-35, 2001.

BIRÓ, Z.; KOVACS, B. Results of cataract surgery in previously vitrectomized eyes. J 
Cataract Refract Surg. v.28, p.1003-1006, 2002.

BLANKS, J. C. Morphology and topography of the retina. In: RYAN, S. J. Retina. 3rd Ed. St Louis, MO: Mosby, 2001. v. 1, p. 32-53.

BLATT, H. L. et al. Endothelial cell density in relation to morphology. Invest Ophthalmol Vis Sci. v. 18, p. 856-859, 1979.

BOLLINGER, K. E.; LANGSTON, R. H. S. What can patients expect from cataract surgery? Cleve Clin J Med. v. 75, n. 3, p. 193-6, 199-200, 2008.

BOURNE, R. R. et al. Effect of cataract surgery on the corneal endothelium: modern phacoemulsification compared with extra-capsular cataract surgery. Ophthalmology. v. 111, p. $679-685,2004$.

BOURNE, W.; NELSON, B. A.; HODGE, M. S. Continued endothelial cell loss ten years after lens implantation. Ophthalmology. v. 101, p. 1014-1023, 1994.

BOVELLE, R. et al. Corneal thickness measurements with the Topcon SP-2000P specular microscope and an ultrasound pachymeter. Arch Ophthalmol. v. 117, p. 868-870, 1999.

BRIGHTBILL, F. S.; MYERS, F. L.; BRESNICK, G. H. Postvitrectomy keratopathy. Am J Ophthalmol. v. 85, p. 651-5, 1978.

BRITO, P. N. et al. Possible role for fundus autofluorescence as a predictive factor for visual acuity recovery after epiretinal membrane surgery. Retina. v. 34, n. 2, p. 273-80, 2014.

BROOKS, H. L. Jr. Macular hole surgery with and without internal limiting membrane peeling. Ophthalmology. v. 107, n. 10, p. 939-48, 2000. Discussion 1948-9.

BUETTNER H, BOURNE WM. Effect of trans pars plana surgery on the corneal endothelium. Dev Ophthalmol. v. 2, p. 28-34, 1981.

BYRNE, S. et al. Refractive change following pseudophakic vitrectomy. BMC Ophthalmol. v. 8, p.19, 2008.

CAMPARINI, M. et al. ETDRS-fast: implementing psychophysical adaptive methods to standardized visual acuity measurement with ETDRS charts. Invest Ophthalmol Vis Sci. v. 42, p. 1226-1231, 2001.

CAMPBELL, D.G. et al. Glaucoma occurring after closed vitrectomy. Am J Ophthalmol. v. 83, p. 63-9, 1977. 
CARIFI, G. et al. Complications and outcomes of phacoemulsification cataract surgery complicated by anterior capsule tear. Am J Ophthalmol. v. 159, p. 463-469, 2015.

CHANG, M. A. et al. Outcome of phacoemulsification after pars plana vitrectomy. Ophthalmology. v.109, p.948- 954, 2002.

CHEN, C. J. Glaucoma after macular hole surgery. Ophthalmology. v. 105, n. 1, p. 94-9, 1998. Discussion 99-100.

CHENG, H. et al. Positive correlation of corneal thickness and endothelial cell loss. Serial measurements after cataract surgery. Arch Ophthalmol. v. 106, p. 920-922, 1988.

CHENG L. et al. Duration of vitrectomy and postoperative cataract in the vitrectomy for macular hole study. Am J Ophthalmol. v. 132, p. 881-887, 2001.

CHERFAN, G. M. et al. Nuclear sclerotic cataract after vitrectomy for idiopathic epiretinal membranes causing macular pucker. Am J Ophthalmol. v.111, p. 434438, 1991.

CHEUNG, C.M.; HERO, M. Stabilization of anterior chamber depth during phacoemulsification cataract surgery in vitrectomized eyes. J Cataract Refract Surg. v. 31, p. 2055-2057, 2005.

CHEW, E. Y. et al. Clinical course of macular holes. The Eye Disease CaseControl Study. Arch Ophthalmol. v.117: 242-246, 1999.

CHUNG, T. Y.; CHUNG, H.; LEE, J. H. Combined surgery and sequential surgery comprising phacoemulsification, pars plana vitrectomy, and intraocular lens implantation: comparison of clinical outcomes. J Cataract Refract Surg. v. 28, p. 2001-2005, 2002.

CHYLACK Jr., L. T. et al. The Lens Opacities Classification System III. The Longitudinal Study of Cataract Study Group. Arch Ophthalmol. v.111, n. 6, p.831836, 1993.

DAY, A. C. et al. United Kingdom National Ophthalmology Database Study of Cataract Surgery: Report 3: Pseudophakic Retinal Detachment. Ophthalmology. v. 123, n. 8, p. 1711-1715, 2016.

DE BUSTROS, S. et al. Nuclear sclerosis after vitrectomy for idiopathic epiretinal membranes. Am J Ophthalmol. v. 105, p.160-164, 1988.

DEMETRIADES, A.M. et al. Combined phacoemulsification, intraocular lens implantation, and vitrectomy for eyes with coexisting cataract and vitreoretinal pathology. Am J Ophthalmol. v.135, p. 291-296, 2003. 
DÍAZ-VALLE, D. et al. Endothelial damage with cataract surgery techniques. J Cataract Refract Surg. v. 24, n. 7, p.951-955, 1998.

DICK, H. B. et al. Long-term endothelial cell loss following phacoemulsification through a temporal clear corneal incision. J Cataract Refract Surg. v. 22, p. 63-71, 1996.

DOUGHTY, M. J.; MULLER, A.; ZAMAN, M. L. Assessment of the reliability of human corneal endothelial cell-density estimates using a noncontact specular microscope. Cornea v. 19, p. 148-158, 2000.

DUA, H.S.; FARAJ, L.A.; SAID, D.G. et al. Human corneal anatomy redefined: a novel pre-Descemet's layer (Dua's layer). Ophthalmology. v. 120, p. 1778-1785, 2013.

DUGAS, B. et al. Idiopathic epiretinal macular membrane and cataract extraction: combined versus consecutive surgery. Am J Ophthalmol. v. 149, p. 302-306, 2010.

DUKER, J. S. et al. The International Vitreomacular Traction Study Group Classification of Vitreomacular Adhesion, Traction, and Macular Hole. Ophthalmology. v.120, p. 2611-2619, 2013.

EHLERS, $\mathrm{N}$. et al. Central corneal thickness in newborns and children. Acta Ophthalmol. v. 54, p. 285-290, 1976.

ELVIRA, J. C.; HUESO, J. R.; TOLDOS, J. Endothelial cell loss in phacoemulsification. J Cataract Refract Surg. v. 25, p. 640-642, 1999.

ERÇALIK, N. Y. et al. Comparison of intra and postoperative complications of phaco between sequential and combined procedures of 23-gauge vitrectomy and phaco. Saudi J Ophthalmol. v. 31, p. 238-242, 2017.

EZRA, E. et al. Immunocytochemical characterization of macular hole opercula. Arch Ophthalmol. v. 119, p. 223-231, 2001.

FALKNER-RADLER, C. I.; BENESCH, T.; BINDER, S. Accuracy of preoperative biometry in vitrectomy combined with cataract surgery for patients with epiretinal membranes and macular holes: results of a prospective controlled clinical trial. $\mathbf{J}$ Cataract Refract Surg. v. 34, p.1754-1760, 2008.

FOULKS, G. N. et al. Factors related to corneal epithelial complications after closed vitrectomy in diabetes. Arch Ophthalmol. v.97, p. 1076-8, 1979.

FRASER-BELL, S. et al. Five-year cumulative incidence and progression of epiretinal membranes: the Blue Mountains Eye Study. Ophthalmology. v. 110, n. 1, p. 34-40, 2003. 
FRIBERG, T. R.; DORAN, D. L.; LAZENBY, F. L. The Effect of Vitreous and Retinal Surgery on Corneal Endothelial Cell Density. Ophthalmology. v. 91, n. 10, p. 11661169, 1984.

FUJIKAWA, M. et al. Long-term intraocular pressure changes after vitrectomy for epiretinal membrane and macular hole. Graefes Arch Clin Exp Ophthalmol. v. 252, n. 3, p. 389-93, 2014.

GASS, D. M. Stereoscopic atlas of macular diseases: diagnosis and treatment. 2nd ed. St. Louis: Mosby; 1987.

GASS, J. D. Idiopathic senile macular hole. Its early stages and pathogenesis. Arch Ophthalmol. v. 106, p. 629-639, 1988.

GASS, J. D. Reappraisal of biomicroscopic classification of stages of development of a macular hole. Am J Ophthalmol. v. 119, p. 752-759, 1995.

GAUDRIC, A. et al. Macular Hole Formation New Data Provided by Optical Coherence Tomography. Arch Ophthalmol. v. 117, p. 744-751, 1999.

GHARTEY, K. N. et al. Closed vitreous surgery. XVII. Results and complications of pars plana vitrectomy. Arch Ophthalmol. v. 98, p. 1248-1252, 1980.

HAMOUDI, H.; CHRISTENSEN, U.C.; LA COUR, M. Corneal endothelial cell loss and corneal biomechanical characteristics after two-step sequential or combined phaco-vitrectomy surgery for idiopathic epiretinal membrane. Acta Ophthalmol. v. 95, p. 493-497, 2017.

HAN, D. P. et al. Mechanisms of intraocular pressure elevation after pars plana vitrectomy. Ophthalmology. v. 96, n. 9, p. 1357-1362, 1989.

HAYASHI, K.; NAKAO, F.; HAYASHI, F. Corneal topographic analysis of superolateral incision cataract surgery. J Cataract Refract Surg. v. 20, p. 392-399, 1994.

HAYASHI, K. Risk factors for corneal endothelial injury during phacoemulsification. $\mathbf{J}$ Cataract Refract Surg. v. 22, p. 1079-1084, 1996.

HENKIND, P. et al. Development of macular vessels in monkey and cat. $\mathbf{B r} \mathbf{J}$ Ophthalmol. v. 59, p. 703-709, 1975.

HERSE, P.; YAO, W. Variation of corneal thickness with age in young New Zealanders. Acta Ophthalmol. v. 71, p. 360-364, 1993.

HOON, M. et al. Functional Architecture of the Retina: Development and Disease. Prog Retin Eye Res. v. 42, p.44-84, 2014.

HSUAN, J.D. et al. Posterior subcapsular and nuclear cataract after vitrectomy. J Cataract Refract Surg. v. 27, p. 437-444, 2001. 
HUTTON, W. L.; PESICKA, G. A.; FULLER, D. G. Cataract extraction in the diabetic eye after vitrectomy. Am. J. Ophthalmol. v. 104, p. 1-4, 1987.

IMAI, M. et al. Optical coherence tomography of successfully repaired idiopathic macular holes. Am J Ophthalmol. v. 128, n. 5, p. 621-7, 1999.

INOUE, K. et al. Corneal endothelial cell morphology in patients undergoing cataract surgery. Cornea. v. 21, p. 360-363, 2002.

ISAGER, P. et al. Comparison of endothelial cell density estimated by contact and non-contact specular microscopy. Acta Ophthalmol Scand, v. 78, p. 42-44, 2000.

JACKSON, T. L. et al. Pars plana vitrectomy for vitreomacular traction syndrome a systematic review and metaanalysis of safety and efficacy. Retina. v. 33, p. 20122017, 2013.

JAHN, C. E. Reduced intraocular pressure after phacoemulsification and posterior chamber intraocular lens implantation. J Cataract Refract Surg. v. 23, n. 8, p. 12601264, 1997.

JENSEN, O. M.; LARSEN, M. Objective assessment of photoreceptor displacement and metamorphopsia: a study of macular holes. Arch Ophthalmol. v. 116, p. 13031306, 1998.

JEOUNG, J. W.; CHUNG, H.; YU, H. G. Factors influencing refractive out- comes after combined phacoemulsification and pars plana vitrectomy: results of a prospective study. J Cataract Refract Surg. v. 33, p. 108-14, 2007.

JOHNSON, M. W. Perifoveal vitreous detachment and its macular complications. Trans Am Ophthalmol Soc. v. 103, p. 537-567, 2005.

JOHNSON, M. W. Posterior vitreous detachment: evolution and complications of its early stages. Am J Ophthalmol. v. 149, p. 371-382, 2010.

JOHNSON, R. N.; GASS JD. Idiopathic macular holes. Observations, stages of formation, and implications for surgical intervention. Ophthalmology. v. 95, p. 917924, 1988.

JOLBERT, I.; STAPLETON, F. The corneal stroma during contact lens wear. Cont Lens Anterior Eye. v. 28, p. 3-12, 2005.

JOYCE, N. C. Cell cycle status in human corneal endothelium. Exp Eye Res. v. 81, p. 629-638, 2005.

JUN, Z.; PAVLOVIC, S.; JACOBI, K.W. Results of combined vitreoretinal surgery and phacoemulsification with intraocular lens implantation. Clin Experiment Ophthalmol. v.29, p. 307-311, 2001. 
KELLY, N. E.; WENDEL, R. T. Vitreous surgery for idiopathic macular holes: results of a pilot study. Arch Ophthalmol. v. 109, n. 5, p. 654-9, 1991.

$\mathrm{KIM}, \mathrm{M}$. et al. Intraocular lens power estimation in combined phacoemulsification and pars plana vitrectomy in eyes with epiretinal membranes: A case-control study. Yonsei Med J. v. 56, p. 805-811, 2015.

KISS, B. et al. Corneal endothelial cell protection with a dispersive viscoelastic material and a irrigating solution during phacoemulsification. Low-cost versus expensive combination. J Cataract Refract Surg. v. 29, p. 733-740, 2003.

KLEIN, R.; et al. Inter-observer variation in refraction and visual acuity measurement using a standardized protocol. Ophthalmology. v. 90, p.1357-1359, 1983.

KOHLHAAS, M. et al. Changes in corneal thickness and endothelial cell density after cataract extraction using phacoemulsification. Ophthalmology. v. 94, p. 515-518, 1997.

KOHLHAAS, $M$. et al. Endothelial cell loss secondary to two different phacoemulsification techniques. Ophthalmic Surg Lasers. v. 29, p. 890-895, 1998.

KOIZUMI, $H$. et al. Three-dimensional evaluation of vitreomacular traction and epiretinal membrane using spectral-domain optical coherence tomography. Am J Ophthalmol. v.145, p. 509-517, 2008.

KOTECHA, A.V. et al. Pars plana vitrectomy for macular holes combined with cataract extraction and lens implantation. Ophthalmic Surg Lasers. v. 31, p. 387393, 2000.

KOVÁCS, I. et al. Intraocular lens power calculation for combined cataract surgery, vitrectomy and peeling of epiretinal membranes for macular oedema. Acta Ophthalmol Scand. v. 85, p. 88-91, 2007.

KRAFF, M. C, SANDERS, D. R.; LIEBERMAN, H. L. Specular microscopy in cataract and intraocular lens patients (a report of 564 cases). Arch Ophthalmol. v. 98, p. 1782-1784, 1980.

KWITKO, S. Endotélio e cirurgia da catarata. In: Padilha M. Catarata. Rio de Janeiro: Cultura Médica. chapter 8, p. 93-100, 2003.

KUMAGAI, K. et al. Percentage of fellow eyes that develop full-thickness macular hole in patients with unilateral macular hole. Arch Ophthalmol. v.130, p.393-394, 2012.

LAHEY, J. M. et al. Combining phacoemulsification with vitrectomy for treatment of macular holes. Br J Ophthalmol. v. 86, p. 876-878, 2002.

LAHEY, J. M.; FRANCIS, R. R.; KEARNEY, J. J. Combining phacoemulsification with 
pars plana vitrectomy in patients with proliferative diabetic retinopathy: a series of 223 cases. Ophthalmology. v. 110, p.1335-1339, 2003.

LAING, R. A. et al. Changes in the corneal endothelium as a function of age. Exp. Eye Res. v. 22, p. 587-94, 1976.

LAING, R. A.; SANDSTROM, M.; LEIBOWITZ, H. M. Clinical specular microscopy. I. Optical principles. Arch Ophthalmol. v. 97, p. 1714-1719, 1979.

LE GOFF, M. M.; BISHOP, P. N. Adult vitreous structure and postnatal changes. Eye. v. 22, p. 1214-1222, 2008.

LEE, J. Y. et al. Comparison of intraoperative complications of phacoemulsification between sequential and combined procedures of pars plana vitrectomy and cataract surgery. Retina. v. 32, p. 2026-2033, 2012.

LEE, S. J.; LEE, C. S.; KOH, H. J. Posterior vitreomacular adhesion and risk of exudative age-related macular degeneration: paired eye study. Am J Ophthalmol. v. 147, p.621-626, 2009.

LEWIS, M. et al. Bilaterality of idiopathic macular holes. Graefes Arch Clin Exp Ophthalmol. v. 234, n. 4, p. 241-5, 1996.

LIU, J. et al. Study on corneal endothelial cells after phacoemulsication. Int Eye Sci. v.14, p. 2247-2249, 2014.

LUCENA, D. R. Estudo comparativo do Ringer Lactato versus BSS Plus para cirurgia de catarata por facoemulsificação. 2009. 82f. Dissertação (Mestrado) Faculdade de Medicina de Ribeirão Preto da Universidade de São Paulo. Ribeirão Preto-SP. 2009.

LUCENA, D. R. et al. Comparison of corneal changes after phacoemulsification using BSS Plus versus Lactated Ringer's irrigating solution: a prospective randomised trial. Br J Ophthalmol. v.95, p. 485-489, 2010.

LÜKE, J. et al. Morphological and functional outcome after brilliant blue g-assisted macular hole surgery. Ophthalmologica. v. 230, n. 2, p. 81-6, 2013.

LUNDBERG, B.; BEHNDIG, A. Intracameral mydriatics in phacoemulsification cataract surgery. J Cataract Refract Surg. v. 29, p. 2366-2371, 2003.

LUNDBERG, B.; JONSSON, M.; BEHNDIG, A. Postoperative corneal swelling correlates strongly to corneal endothelial cell loss after phacoemulsification cataract surgery. Am J Ophthalmol. v. 139, p. 1035-1041, 2005.

MAKITIE, J.; ANNAS, A.; KOSKENVUO, M. Corneal endothelial cells in mono and dizygotic twins. Invest Ophthalmol Vis Sci. v. 24, p. 1029-1032, 1983. 
MANVIKAR, S. R.; ALLEN, D.; STEEL, D. H. Optical biometry in combined phacovitrectomy. J Cataract Refract Surg. v.35, p. 64-69, 2009.

MATSUDA, M.; YEE, R. W.; EDELHAUSER, H. F. Comparison of the corneal endothelium in an American and a Japanese population. Arch Ophthalmol. v. 103, p. 68-70, 1985.

MAURICE, D. M. Cellular membrane activity in the corneal endothelium of the intact eye. Experientia. v. 24, p. 1094-1095, 1968.

McCANNEL, C. A. et al. Population based incidence of macular holes. Ophthalmology. v.116, p. 1366-1369, 2009.

McCAREY, B. E.; EDELHAUSER, H. F.; LYNN, M. J. Review of corneal endothelial specular microscopy for FDA clinical trials of refractive procedures, surgical devices, and new intraocular drugs and solutions. Cornea. v. 27, p. 1-16, 2008.

MEHDIZADEH M.; NOWROOZZADEH, M. H. Postoperative induced myopia in patients with combined vitrectomy and cataract surgery. J Cataract Refract Surg. v. 35, p.798-9, 2009.

MISHIMA, S. Clinical investigations on the corneal endothelium. Ophthalmology. v. 89, p. 525-530, 1982.

MÓDIS Jr., L.; LANGENBUCHER, A.; SEITZ, B. Corneal endothelial cell density and pachymetry measured by contact and noncontact specular microscopy. J Cataract Refract Surg. v. 28, p. 1763-1769, 2002.

MUELLER, A.J. et al. Combined anterior and posterior segment surgery. Ophthalmologe. v. 101, p. 667-74, 2004.

MUSELIER A.; et al. Macular hole surgery and cataract extraction: Combined vs consecutive surgery. Am J Ophthalmol. v. 150, n. 3, p. 387-391, 2010.

NADAL, J.; DELAS, B.; PIÑERO, A. Vitrectomy without face-down posturing for idiopathic macular holes. Retina. v. 32, n. 5, p. 918-21, 2012.

NAM, S. M. et al. Accuracy of RTVue optical coherence tomography, Pentacam, and ultrasonic pachymetry for the measure- ment of central corneal thickness. Ophthalmology. v. 117, p. 2096-2103, 2010.

NOVAK, M. A., et al. The crystalline lens after vitrectomy for diabetic retinopathy. Ophthalmology. v. 91, p. 1480, 1984.

NUSSBAUM, J. J.; PRUETT, R. C.; DELORI, F. C. Historic perspectives: macular yellow pigment; the first 200 years. Retina. v. 1, p. 296-310, 1981.

OGURA, Y. et al. Quantitative analysis of lens changes after vitrectomy by 
fluorophotometry. Am J Ophthalmol. v. 111, p. 179-183, 1991.

OHNO, K. et al. Comparison of recording systems and analysis methods in specular microscopy. Cornea, v. 18, p. 416-423, 1999.

OKAMOTO, F. et al. Vision-related quality of life and visual function after vitrectomy for various vitreoretinal disorders. Invest Ophthalmol Vis Sci. V. 51. p. 744-751, 2010.

OLSEN, T. Variations in endothelial morphology of normal corneas and after cataract extraction. A specular microscopic study. Acta Ophthalmol, v. 57, n. 6, p. 10141019, 1979.

OLSEN, T.; ERIKSEN, J. S. Corneal thickness and endothelial damage after intraocular lens implantation. Acta Ophthalmol. v. 58, p. 773-786, 1980.

PASSEMARD, M. et al. Long-term Outcome of Idiopathic Macular Hole Surgery. Am J Ophthalmol. v. 149, n. 1, p. 120-126, 2010.

PATEL, D.; RAHMAN, R.; KUMARASAMY, M. Accuracy of intraocular lens power estimation in eyes having phacovitrectomy for macular holes. J Cataract Refract Surg. v. 33, p. 1760-1762, 2007.

PETTERNEL, V. et al. Effect of optic edge design and haptic angulation on postoperative intraocular lens position change. J Cataract Refract Surg. v. 30, p.527, 2004.

POLLACK, A. et al. Results of combined surgery by phacoemulsification and vitrectomy. Isr Med Assoc J. v. 6, n. 3, p. 143-6, 2004.

POLSE, K. A. et al. Age differences in corneal hydration control. Invest Ophthalmol Vis Sci. 30, p. 392-399, 1989.

PORTELINHA, W.; BELFORT Jr., R. Central and peripheral corneal thickness in newborns. Acta Ophthalmol. v. 69, p. 247-250, 1991.

RAO, G. N. et al. Endothelial cell morphology and corneal deturgescence. Ann Ophthalmol. v. 11, p. 885-899, 1979.

RAO, X. et al. Outcomes of outpatient fluid-gas exchange for open macular hole after vitrectomy. Am J Ophthalmol. v. 156, n. 2, p. 326-333.e1, 2013.

REUSCHEL, A. et al. Influence of anterior chamber depth, anterior chamber volume, axial length, and lens density on postoperative endothelial cell loss. Graefe's Arch Clin Exp Ophthalmol. v. 253, p. 745-752, 2015.

RIVAS-AGUIÑO, P. et al. Pars plana vitrectomy, phacoemulsification, and intraocular lens implantation for the management of cataract and proliferative diabetic 
retinopathy: comparison of a combined versus two-step surgical approach. Arch Soc Esp Oftalmol. v. 84, p. 31-38, 2009.

ROBINETT, D. A.; KAHN, J. H. The physical examination of the eye. Emerg Med Clin North Am. v. 26, p. 1-16, 2008.

ROGERS, S. et al. Combined phacovitrectomy for macular hole: Long-term results. Ophthalmic Surg Lasers Imaging. v. 38, n. 6, p. 452-456, 2007.

ROPER-HALL, M. J.; WILSON, R. S. Reduction in endothelial cell density following cataract extraction and intraocular lens implantation. Br J Ophthalmol. v. 66, p. 516517, 1982.

SALVI, S. M. et al. Central corneal thickness changes after phacoemulsification cataract surgery. J Cataract Refract Surg. v. 33, p. 1426-1428, 2007.

SASSANI, J. W. et al. Electron microscopic study of corneal epithelial-endothelial interactions in organ culture. Ophthalmology. v. 91, p. 553-557, 1984.

SAWA, M. et al. Assessment of nuclear sclerosis after nonvitrectomizing vitreous surgery. Am J Ophthalmol. v. 132, p. 356-362, 2001.

SCHULTZ, O. et al. Response of the corneal endothelium to cataract surgery. Arch Ophthalmol. v. 104, p. 1164-1169, 1986.

SCHULZE, S. et al. Vitreomacular traction and exudative age-related macular degeneration. Acta Ophthalmol. v. 86, p. 470-481, 2008.

SEBAG, J. Ageing of the vitreous. Eye. v. 1, p. 254-262, 1987.

SEBAG, J. Anatomy and pathology of the vitreo-retinal interface. Eye. v. 6, p. 541552, 1992.

SIEGFRIED, C. J. et al. Oxygen distribution in the human eye: Relevance to the etiology of open-angle glaucoma after vitrectomy. Invest Ophthalmol Vis Sci. v. 51, n. 11, p. 5731-8, 2010.

SILVA, P. S. et al. Visual outcomes from pars plana vitrectomy versus combined pars plana vitrectomy, phacoemulsification, and intraocular lens implantation in patients with diabetes. Retina, v. 34, p.1960-1968, 2014.

SPITERI CORNISH, K. et al. Vitrectomy with internal limiting membrane peeling versus no peeling for idiopathic full-thickness macular hole. Ophthalmology. v. 121, n. 3, p. 649-55, 2014.

STEEL, D. H. W.; LOTERY, A. J. Idiopathic vitreomacular traction and macular hole: a comprehensive review of pathophysiology, diagnosis, and treatment. Eye. v. 27, p. S1-S21, 2013. 
STORR-PAULSEN, A. et al. The influence of viscoelas- tic substances on the corneal endothelial cell population during cataract surgery: a prospective study of cohesive and dispersive viscoelastics. Acta Ophthalmol Scand. v. 85, p.183-187, 2007.

SUDA, T. Mosaic pattern changes in human cornea1 endothelium with age. Jpn. J. Ophthalmol. v. 28, p. 331-338, 1984.

SUN, H. J.; CHOI, K. S. Improving intraocular lens power prediction in combined phacoemulsification and vitrectomy in eyes with macular oedema. Acta Ophthalmol. v. 89, p. $575-578,2011$.

SUZUKI, H. etal. Phacoemulsification Associated Corneal Damage Evaluated by Corneal Volume. Am J Ophthalmol. v. 142, p. 525-528, 2006.

TANG, Y. et al. Clinical evaluation of corneal changes after phacoemulsification in diabetic and non-diabetic cataract patients, a systematic review and meta-analysis.

Sci Rep. v. 7, 14128, 2017.

TANNER, V. et al. Optical coherence tomography of the vitreoretinal interface in macular hole formation. Br J Ophthalmol. v. 85, p. 1092-1097, 2001.

THEOCHARIS, I. P. et al. Combined phacoemulsification and pars plana vitrectomy for macular hole treatment. Acta Ophthalmol Scand. v. 83, p.172-175, 2005.

THOMPSON, J. T. et al. Progression of nuclear sclerosis and long-term visual results of vitrectomy with transforming growth factor beta-2 for macular holes. Am $\mathbf{J}$ Ophthalmol. v.119, p.48-54, 1995.

THOMPSON, J. T. The role of patient age and intraocular gases in cataract progression following vitrectomy for macular holes and epiretinal membranes. Trans Am Ophthalmol Soc. v.101, p. 479-492, 2003.

THOMPSON, J. T. The role of patient age and intraocular gas use in cataract progression after vitrectomy for macular holes and epiretinal membranes. Am $\mathbf{J}$ Ophthalmol. v. 137, p. 250-257, 2004.

TREUMER, F. et al. Pars plana vitrectomy, phacoemulsification and intraocular lens implantation. Comparison of clinical complications in a combined versus two-step surgical approach. Graefe's Arch Clin Exp Ophthalmol. v. 244, p. 808-815, 2006.

TSUBOTA, K.; YAMADA, M.; NAOI, S. Specular microscopic observation of human corneal epithelial abnormalities. Ophthalmology. v. 98, p. 184-191, 1991.

UCHINO E, UEMURA A, OHBA N. Initial stages of posterior vitreous detachment in healthy eyes of older persons evaluated by optical coherence tomography. Arch Ophthalmol. v. 119, p.1475-1479, 2001.

VALBON, B. F. et al. Central corneal thickness and biomechanical changes after clear corneal phacoemulsification. J Refract Surg. v.28, p. 215-219, 2012. 
VALLE, D. et al. Endothelial damage with cataract surgery techniques. J Cataract Refract Surg. v. 24, p. 951-955, 1998.

VENTURA, A. C. S.; WALTI, R.; BOHNKE, M. Corneal thickness and endothelial density before and after cataract surgery. Br J Ophthalmol. v. 85, p. 18-20, 2001.

VERHULST, E.; VRIJGHEM, J. C. Accuracy of intraocular lens power calculations using the Zeiss IOL master. A prospective study. Bull Soc Belge Ophtalmol. p. 6165, 2001.

WALTMAN, S. R. et al. Intraocular irrigating solutions for clinical vitrectomy. Ophthalmic Surg. v. 6, n. 4, p. 90-94, 1975.

WARING, G. O. et al. The corneal endothelium. Normal and pathologic structure and function. Ophthalmology. v. 89, p. 531-590, 1982.

WATANABE, A. et al. Changes in corneal thickness following vitreous surgery. Clin Ophthalmol v. 6, p. 1293-1296, 2012.

WATANABE, A. et al. Changes in corneal thickness following combined cataract and vitreous surgery. BMC Res Notes. v. 8, p. 674, 2015.

WATSKY, M. A. et al. Corneal endothelial junctions and the effect of ouabain. Invest Ophthalmol Vis Sci, v. 31, p. 933-941, 1990.

WEINBERG, R. S.; PEYMAN, G. A.; HUAMONTE, F. U. Elevation of intraocular pressure after pars plana vitrectomy. Albrecht von Graefes Arch Klin Exp Ophthalmol. v.200, p.157-161, 1976.

WORST, J. G. Cisternal systems of the fully developed vitreous body in the young adult. Trans Ophthalmol Soc UK. v. 97, p. 550-554,1977.

YAGI, F.; TAKAGI, S.; TOMITA, G. Combined idiopathic macular hole vitrectomy with phacoemulsification without face-down positioning. J Ophthalmol. v. 2012, p. 571748, 2012.

YAGOUBI, M I. et al. Effects of irrigation solutions on corneal endothelial function. Br J Ophthalmol, v. 78, p. 302-306, 1994.

YEE, R. W. et al. Changes in the normal corneal endothelial cellular pattern as a function of age. Curr. Eye Res. v.4, p. 671-8, 1985.

YORGUN, M. A. et al. Clinical outcomes of 25-gauge vitrectomy surgery for vitreoretinal diseases: comparison of vitrectomy alone and phaco-vitrectomy. Int $\mathbf{J}$ Ophthalmol. v 9, p. 1163-1169, 2016. 


\section{COMPROVANTE DE APROVAÇÃO DO COMITÊ DE ÉTICA}

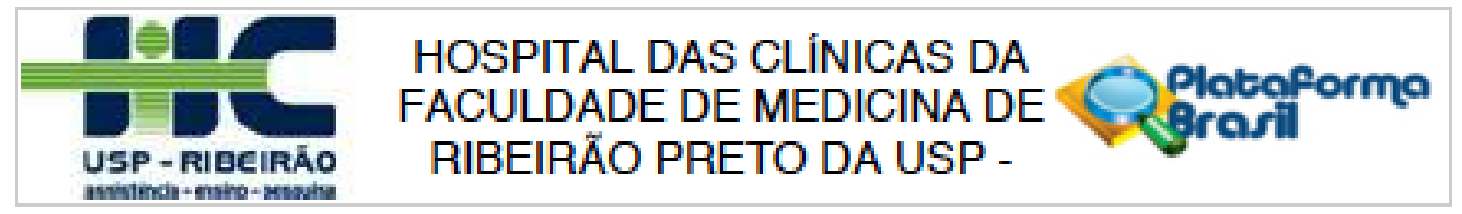

Coninuaplo do Paracer: 1.238 .000

Os procedimentos do estudo foram descritos.

O orçamento do estudo está apresentado de forma adequada.

O cronograma está adequado.

Recomendaçōes:

O pesquisador responsável encaminhou adequadamente as pendéncias solicitadas no parecer anterior, constante no Projeto de pesquisa Versho dezembro 2015,modificado 30-12-2015; e os TCLEs Versfio dezembro de 2015-modificado 30-12-2015;

Termo de Consentimento Livre e Esclarecido Versâo dezembro de 2015-modificado 30-12-2015.

Conclusōes ou Pendéncias e Lista de Inadequaçōes:

Diante do exposto $\theta$ à luz da Resoluçåo CNS 466/2012, o projeto de pesquisa Versâo dezembro 2015,modificado 30-12-2015, assim como $\propto$ Termos de Consentimento Livre e Esclarecidos Versto dezembro de 2015-modificado 30-12-2015, podem ser enquadrados na categoria APROVADO.

Consideraçöes Finais a critério do CEP:

Projeto Aprovado: Tendo em vista a legislaçâo vigente, devem ser encaminhados ao CEP, relatorios parciais anuais referentes ao andamento da pesquisa $\theta$ relatório final ao término do trabalho. Qualquer modificaçlio do projeto original deve ser apresentada a este CEP em nova verstoo, de forma objetiva e com justificativas, para nova apreciaçå.

Este parecer foi elaborado baseado nos documentos abaixo relacionados:

\begin{tabular}{|c|c|c|c|c|}
\hline Tipo Documento & Arquivo & Postagem & Autor & Situachio \\
\hline $\begin{array}{l}\text { Informaçes Basicas } \\
\text { do Projeto }\end{array}$ & $\begin{array}{l}\text { PB_INFORMACCOES_BASICAS_DO_P } \\
\text { RO_ETO_549945.pdf }\end{array}$ & $\begin{array}{c}30 / 12 / 2015 \\
13: 41: 04\end{array}$ & & Aceito \\
\hline Outros & CARTA.doc $x$ & $\begin{array}{c}30 / 12 / 2015 \\
13: 40: 28\end{array}$ & KARLOS ITALO & Aceito \\
\hline $\begin{array}{l}\text { TCLE / Termos de } \\
\text { Assentimento / } \\
\text { Justificativa de } \\
\text { Ausencia }\end{array}$ & $\begin{array}{l}\text { tcle_versao_dezembro_2015_membran } \\
\text { a_epirretiniana docx }\end{array}$ & $\begin{array}{c}30 / 12 / 2015 \\
13.36-25\end{array}$ & KARLOS ITALO & Aceito \\
\hline $\begin{array}{l}\text { TCLE / Termos de } \\
\text { Assentimento / } \\
\text { Justificativa de } \\
\text { Ausencia }\end{array}$ & $\begin{array}{l}\text { tcle_versao_dezembro_2015_buraco_m } \\
\text { acular.docx }\end{array}$ & $\begin{array}{c}30 / 12 / 2015 \\
13: 36: 04\end{array}$ & KARLOS ITALO & Aceito \\
\hline Cronograma & $\begin{array}{l}\text { Cronograma_versao_dezembro_2015.d } \\
\text { ocx }\end{array}$ & $\begin{array}{c}30 / 12 / 2015 \\
13.35: 39\end{array}$ & KARLOS ITALO & Aceito \\
\hline
\end{tabular}

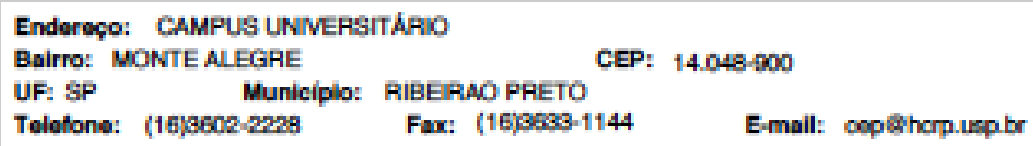




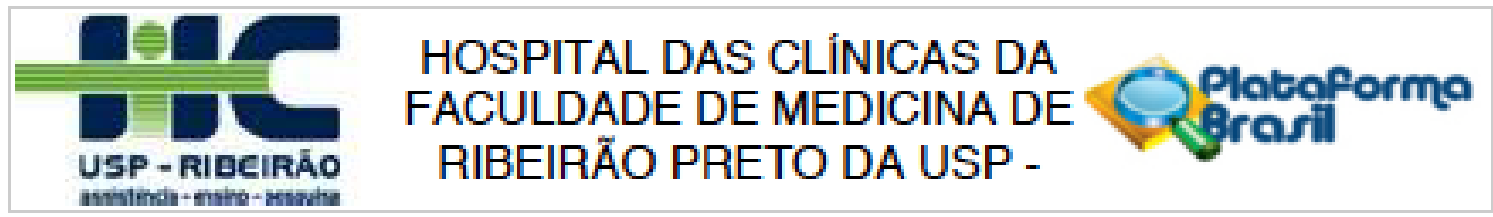

Continuacilo do Parecer: 1.839 .000

\begin{tabular}{|c|c|c|c|c|}
\hline \begin{tabular}{|l|} 
Projeto Detalhado / \\
Brochura \\
Investigador
\end{tabular} & \begin{tabular}{|l} 
Projeto_detalhado_versao_dezembro_2 \\
015.docx
\end{tabular} & $\begin{array}{c}30 / 12 / 2015 \\
13.35: 20\end{array}$ & KARLOS ITALO & Acento \\
\hline Orçamento & Orcamento.doc $x$ & $\begin{array}{c}04 / 10 / 2015 \\
18: 24: 58\end{array}$ & KARLOS ITALO & Aceito \\
\hline Outros & digitalizar0001.jpg & $\begin{array}{l}15 / 08 / 2015 \\
17: 15: 18\end{array}$ & & Aceito \\
\hline Folha de Rosto & follha de rosto-Karlos Italo.pdf & $\begin{array}{l}15 / 08 / 2015 \\
17: 12: 19\end{array}$ & & Aceito \\
\hline
\end{tabular}

Situaçāo do Parecer:

Aprovado

Necessita Apreciaçāo da CONEP:

Nalo

RIBEIRAO PRETO, 02 de Março de 2016

Assinado por:

MARCIA GUIMARĀES VILLANOVA

(Coordenador) 
9. Apêndice 


\title{
TERMO DE CONSENTIMENTO LIVRE E ESCLARECIDO
}

\author{
Título: Estudo comparativo da vitrectomia posterior via pars plana associada ou não a \\ cirurgia de facoemulsificação para o tratamento de membrana epirretiniana e \\ buraco macular
}

\author{
Responsáveis: David da Rocha Lucena
}

Prof. Dr. Rodrigo Jorge

Convidamos o Sr.(a) que é portador de uma patologia denominada membrana epirretiniana ou buraco macular intitulado para participar de uma pesquisa cujo título é "Estudo comparativo da vitrectomia posterior via pars plana associada ou não a facoemulsificação para o tratamento de membrana epirretiniana e buraco macular."

O objetivo desta pesquisa é verificar se há diferença ou não entre a cirurgia de vitrectomia e a cirurgia de catarata sendo realizadas no mesmo momento ou em tempos separados. Neste último caso, primeiro será realizada a cirurgia de vitrectomia e depois, se necessário, a cirurgia de catarata.

O buraco de mácula é uma interrupção das camadas da retina na área central da visão. Essa interrupção é devida a alterações do gel vítreo e retina que ocorrem com o envelhecimento. O diagnóstico é feito com o exame detalhado da área central da retina, a mácula, utilizando recursos como o exame de fundo de olho pelo oftalmologista. As principais queixas das pessoas que apresentam essa doença são embaçamento da visão, mancha escura ou falha na área central da visão e distorção das imagens. O tratamento do buraco macular é com cirurgia (vitrectomia) e depende do estágio da mesma e da duração das queixas.

A vitrectomia é a cirurgia do olho mais comumente utilizada no tratamento das doenças da retina e vítreo. Na vitrectomia, são empregados instrumentos microcirúrgicos (como pinças e microguilhotinas) através de pequenas aberturas realizadas nos olhos acometidos por buraco macular. Durante a vitrectomia, o vítreo, a substância gelatinosa que preenche o segmento posterior do olho, é removido. Para substituir o vítreo removido, um gás especial é utilizado para preencher o olho e ajudar no fechamento do buraco de mácula. Essa cirurgia é geralmente realizada sem internação hospitalar sob anestesia local mais sedação. Durante um mês após a cirurgia é comum uma mancha preta na visão, pois se trata do gás especial usado na cirurgia. Após esse período, o gás é reabsorvido.

Sabe-se que praticamente $100 \%$ dos pacientes desenvolvem catarata a partir do primeiro dia até o quinto ano de seguimento após a cirurgia de vitrectomia. Quando o paciente possui catarata importante, não há dúvida que é preciso retirar-se a catarata durante a vitrectomia. Mesmo porque, sem retirar a catarata, é impossível se enxergar o fundo de olho e a retina. No entanto, quando não há catarata importante, a conduta não é bem estabelecida. Alguns cirurgiões preferem remover o cristalino (nome da lente natural que existe dentro de nosso olho e onde dá a catarata) mesmo sem catarata e realizar a cirurgia da retina (chamada vitrectomia) no mesmo ato operatório (mesmo dia: cirurgia simultânea), enquanto outros preferem apenas realizar a cirurgia da retina, e operar a catarata quando a mesma piorar, meses ou anos após (cirurgia sequencial). Outro dado importante é que, algumas vezes, dependendo do machucado causado pela cirurgia da retina (vitrectomia), a cirurgia de catarata realizada meses ou anos depois pode ser mais difícil tecnicamente. 
$\mathrm{Na}$ cirurgia de catarata, emprega-se um instrumento microcirúrgico especial cuja ponteira de titânio vibra em frequência ultrassônica, sendo capaz de liquefazer e aspirar a catarata. A função da ponteira é controlada por aparelho, denominado facoemulsificador. Este procedimento é realizado através de pequenas aberturas na córnea, o vidro do nosso olho. Ao término da remoção da catarata, é implantada uma lente intraocular para reabilitar a visão. A cirurgia de catarata é normalmente realizada como um procedimento ambulatorial (sem internação hospitalar) sob anestesia local (anestésico aplicado ao redor do olho) mais sedação.

Caso aceite participar da pesquisa, será sorteado se o Sr. (a) realizará a cirurgia de vitrectomia junto com a cirurgia de catarata ou apenas a vitrectomia no primeiro momento. Neste caso, a cirurgia de catarata será realizada a partir do momento em que esta seja notada pelo médico e esteja causando diminuição da visão ou impedindo a realização dos exames do fundo do olho e assim que o Sr. (a) desejar.

Não há previsão para ressarcimento dos pacientes participantes da pesquisa para cobrir despesas como transporte ou refeição.

Os riscos que envolvem o seu tratamento são: aumento da pressão intraocular (pressão interna do olho), inflamação ocular, infecção ocular, hemorragia dentro do gel vítreo, catarata - lente natural do olho opacificada (suja) nos casos que for realizado apenas a vitrectomia, descolamento de retina, edema de córnea, afacia (impossibilidade de implante de lente intraocular), persistência do problema da membrana epirretiniana ou buraco macular, rotura retiniana, descolamento de coroide. Para resolver as complicações podem ser necessárias medicações específicas e/ou cirurgias adicionais que serão abordadas pelo setor de Oftalmologia do Hospital das Clínicas da Faculdade de Medicina de Ribeirão Preto (HCFMRP).

Os benefícios esperados do tratamento são: restaurar o máximo possível a arquitetura normal da retina, diminuir as queixas como embaçamento da visão e distorção das imagens.

Para que o estudo tenha sucesso, o Sr. (a) deverá comparecer ao HCRPFMRP para consultas oftalmológicas, no primeiro e sétimo dias após a cirurgia e posteriormente com 1 , 3, 6, 9 e 12 meses de pós-operatório, como ocorre de rotina com os pacientes tratados com problemas semelhantes ao seu pelo setor de retina e vítreo do HCRPFMRP. do estudo.

Estão garantidas todas as informações que o Sr. (a) queira, antes durante e depois

A sua participação neste estudo é voluntária, tendo a liberdade de recusar participar. Caso o Sr. (a) aceite participar, poderá retirar seu consentimento a qualquer momento. Este fato não implicará na interrupção de seu atendimento, que está assegurado.

As informações relacionadas ao estudo poderão ser inspecionadas pelos médicos que executam a pesquisa e pelas autoridades legais, no entanto, se qualquer informação for divulgada em relatório ou publicação, isto será feito sob forma codificada, para que a confidencialidade seja mantida.

O Sr. (a) terá a garantia de que qualquer problema decorrente do estudo será tratado no próprio Hospital das Clínicas da Faculdade de Medicina Ribeirão Preto.

Quando os resultados forem publicados, não aparecerá seu nome, e sim um código.

Em qualquer etapa do estudo, você terá acesso aos profissionais responsáveis pela pesquisa para esclarecimento de dúvidas. O principal investigador é o Dr. Karlos Ítalo Souza Viana (CRM-SP 171214), que pode ser encontrado no endereço Avenida Bandeirantes 3900, Ribeirão Preto - São Paulo - Brasil, telefone cel (16)982511000, fixos (16) 3602-2523 ou (16) 3602-2323 e e-mail: karlositalo@gmail.com Se você tiver alguma consideração ou dúvida sobre a ética da pesquisa, entre em contato com o Comitê de Ética em Pesquisa (CEP) do Hospital das Clínicas da Faculdade de medicina de Ribeirão Preto/USP - Campus Universitário s/n - Monte Alegre-Ribeirão Preto/SP,Brasil,14048-900 tel: (16) 3602-2228; email:cep@hcrp.usp.br 
Fui suficientemente informado a respeito do estudo

Eu discuti as informações acima com o Pesquisador Responsável Karlos Ítalo Souza Viana, sobre a minha decisão em participar nesse estudo. Ficaram claro para mim os objetivos, os procedimentos, os potenciais desconfortos e riscos e as garantias. Concordo voluntariamente em participar deste estudo, assino este termo de consentimento e recebo uma via rubricada pelo pesquisador.

Nome Completo (participante):

Assinatura do participante / representante legal

Data

Nome Completo (pesquisador):

Assinatura do responsável pelo estudo

Data 1

DADOS DE IDENTIFICAÇÃO (OU ETIQUETA INSTITUCIONAL DE IDENTIFICAÇÃO) DO PARTICIPANTE DA PESQUISA OU RESPNSÁVEL

1. NOME:

DOCUMENTO DE IDENTIDADE $N^{\circ}$ : SEXO: M( ） $\mathrm{F}(\quad)$

DATA DE NASCIMENTO:

ENDEREÇO: $\mathrm{N}^{\circ}$ APTO

BAIRRO CIDADE

CEP: TELEFONE: DDD ( )

2. LEGAL RESPONSÁVEL

NATUREZA (grau de parentesco, tutor, curador e etc.)

SEXO: M( ) $\mathrm{F}($ )

DATA DE NASCIMENTO:

ENDEREÇO:

$\mathrm{N}^{\circ}$ APTO

BAIRRO CIDADE

CEP: TELEFONE:DDD ( ) 


\title{
TERMO DE CONSENTIMENTO LIVRE E ESCLARECIDO
}

\author{
Título: Estudo comparativo da vitrectomia posterior via pars plana associada ou não a \\ cirurgia de facoemulsificação para o tratamento de membrana epirretiniana e \\ buraco macular.
}

\author{
Responsáveis: David da Rocha Lucena \\ Prof. Dr. Rodrigo Jorge
}

Convidamos o Sr.(a) que é portador de uma patologia denominada membrana epirretiniana ou buraco macular intitulado para participar de uma pesquisa cujo título é "Estudo comparativo da vitrectomia posterior via pars plana associada ou não a facoemulsificação para o tratamento de membrana epirretiniana e buraco macular."

O objetivo desta pesquisa é verificar se há diferença ou não entre a cirurgia de vitrectomia e a cirurgia de catarata sendo realizadas no mesmo momento ou em tempos separados. Neste último caso, primeiro será realizada a cirurgia de vitrectomia e depois, se necessário, a cirurgia de catarata.

A membrana epirretiniana é uma fina camada de tecido cicatricial que cresce sobre a superfície da área central da retina(camada do olho que processa a visão), sendo causada por alterações do vítreo (substância gelatinosa que preenche o olho) e retina que ocorrem com o envelhecimento. À medida que a membrana epirretiniana se desenvolve, ocorre enrugamento da superfície da retina e alteração da visão. O diagnóstico é feito com o exame detalhado da área central da retina, a mácula, utilizando recursos como o exame de fundo de olho pelo oftalmologista. As principais queixas das pessoas que apresentam essa doença são embaçamento da visão e distorção das imagens. O tratamento da membrana epirretiniana é com cirurgia (vitrectomia) e depende do estágio da mesma e da duração das queixas.

A vitrectomia é a cirurgia do olho mais comumente utilizada no tratamento das doenças da retina e vítreo. Na vitrectomia, são empregados instrumentos microcirúrgicos (como pinças e microguilhotinas) através de pequenas aberturas realizadas nos olhos acometidos pela membrana epirretiniana. Durante a vitrectomia, o vítreo, a substância gelatinosa que preenche o segmento posterior do olho, é removido junto com a membrana epirretiniana. Para substituir o vítreo removido, um gás especial é utilizado para preencher o olho. Essa cirurgia é geralmente realizada sem internação hospitalar sob anestesia local mais sedação. Durante um mês após a cirurgia é comum uma mancha preta na visão, pois se trata do gás especial usado na cirurgia. Após esse período, o gás é reabsorvido.

Sabe-se que praticamente $100 \%$ dos pacientes desenvolvem catarata a partir do primeiro dia até o quinto ano de seguimento após a cirurgia de vitrectomia. Quando o paciente possui catarata importante, não há dúvida que é preciso retirar-se a catarata durante a vitrectomia. Mesmo porque, sem retirar a catarata, é impossível se enxergar o fundo de olho e a retina. No entanto, quando não há catarata importante, a conduta não é bem estabelecida. Alguns cirurgiões preferem remover o cristalino (nome da lente natural que existe dentro de nosso olho e onde dá a catarata) mesmo sem catarata e realizar a cirurgia da retina (chamada vitrectomia) no mesmo ato operatório (mesmo dia: cirurgia simultânea), enquanto outros preferem apenas realizar a cirurgia da retina, e operar a catarata quando a mesma piorar, meses ou anos após (cirurgia sequencial). Outro dado importante é que, algumas vezes, dependendo do machucado causado pela cirurgia da 
retina (vitrectomia), a cirurgia de catarata realizada meses ou anos depois pode ser mais difícil tecnicamente.

$\mathrm{Na}$ cirurgia de catarata, emprega-se um instrumento microcirúrgico especial cuja ponteira de titânio vibra em frequência ultrassônica, sendo capaz de liquefazer e aspirar a catarata. A função da ponteira é controlada por aparelho, denominado facoemulsificador. Este procedimento é realizado através de pequenas aberturas na córnea, o vidro do nosso olho. Ao término da remoção da catarata, é implantada uma lente intraocular para reabilitar a visão. A cirurgia de catarata é normalmente realizada como um procedimento ambulatorial (sem internação hospitalar) sob anestesia local (anestésico aplicado ao redor do olho) mais sedação.

Caso aceite participar da pesquisa, será sorteado se o Sr. (a) realizará a cirurgia de vitrectomia junto com a cirurgia de catarata ou apenas a vitrectomia no primeiro momento. Neste caso, a cirurgia de catarata será realizada a partir do momento em que esta seja notada pelo médico e esteja causando diminuição da visão ou impedindo a realização dos exames do fundo do olho e assim que o Sr. (a) desejar.

Não há previsão para ressarcimento dos pacientes participantes da pesquisa para cobrir despesas como transporte ou refeição.

Os riscos que envolvem o seu tratamento são: aumento da pressão intraocular (pressão interna do olho), inflamação ocular, infecção ocular, hemorragia dentro do gel vítreo, catarata - lente natural do olho opacificada (suja) nos casos que for realizado apenas a vitrectomia, descolamento de retina, edema de córnea, afacia (impossibilidade de implante de lente intraocular), persistência do problema da membrana epirretiniana ou buraco macular, rotura retiniana, descolamento de coroide. Para resolver as complicações podem ser necessárias medicações específicas e/ou cirurgias adicionais que serão abordadas pelo setor de Oftalmologia do Hospital das Clínicas da Faculdade de Medicina de Ribeirão Preto (HCFMRP).

Os benefícios esperados do tratamento são: restaurar o máximo possível a arquitetura normal da retina, diminuir as queixas como embaçamento da visão e distorção das imagens.

Para que o estudo tenha sucesso, o Sr. (a) deverá comparecer ao HCRPFMRP para consultas oftalmológicas, no primeiro e sétimo dias após a cirurgia e posteriormente com 1 , 3, 6, 9 e 12 meses de pós-operatório, como ocorre de rotina com os pacientes tratados com problemas semelhantes ao seu pelo setor de retina e vítreo do HCRPFMRP. do estudo.

Estão garantidas todas as informações que o Sr. (a) queira, antes durante e depois

A sua participação neste estudo é voluntária, tendo a liberdade de recusar participar. Caso o Sr. (a) aceite participar, poderá retirar seu consentimento a qualquer momento. Este fato não implicará na interrupção de seu atendimento, que está assegurado.

As informações relacionadas ao estudo poderão ser inspecionadas pelos médicos que executam a pesquisa e pelas autoridades legais, no entanto, se qualquer informação for divulgada em relatório ou publicação, isto será feito sob forma codificada, para que a confidencialidade seja mantida.

O Sr. (a) terá a garantia de que qualquer problema decorrente do estudo será tratado no próprio Hospital das Clínicas da Faculdade de Medicina Ribeirão Preto.

Quando os resultados forem publicados, não aparecerá seu nome, e sim um código.

Em qualquer etapa do estudo, você terá acesso aos profissionais responsáveis pela pesquisa para esclarecimento de dúvidas. O principal investigador é o Dr. Karlos Ítalo Souza Viana (CRM-SP 171214), que pode ser encontrado no endereço Avenida Bandeirantes 3900, Ribeirão Preto - São Paulo - Brasil, telefone cel (16)982511000, fixos (16) 3602-2523 ou (16) 3602-2323 e e-mail: karlositalo@gmail.com Se você tiver alguma consideração ou dúvida sobre a ética da pesquisa, entre em contato com o Comitê de Ética em Pesquisa (CEP) do Hospital das Clínicas da Faculdade de medicina de Ribeirão Preto/USP - Campus 
Universitário s/n - Monte Alegre-Ribeirão Preto/SP,Brasil,14048-900 tel: (16) 3602-2228; email:cep@hcrp.usp.br

Fui suficientemente informado a respeito do estudo

Eu discuti as informações acima com o Pesquisador Responsável Karlos Ítalo Souza Viana, sobre a minha decisão em participar nesse estudo. Ficaram claro para mim os objetivos, os procedimentos, os potenciais desconfortos e riscos e as garantias. Concordo voluntariamente em participar deste estudo, assino este termo de consentimento e recebo uma via rubricada pelo pesquisador.

Nome Completo (participante):

Assinatura do participante / representante legal

Data

Nome Completo (pesquisador):

Assinatura do responsável pelo estudo

Data 1

DADOS DE IDENTIFICAÇÃO (OU ETIQUETA INSTITUCIONAL DE IDENTIFICAÇÃO) DO PARTICIPANTE DA PESQUISA OU RESPONSÁVEL

1. NOME:

DOCUMENTO DE IDENTIDADE $\mathrm{N}^{\circ}$ : SEXO: M( ) $F(）$

DATA DE NASCIMENTO:

ENDEREÇO $\mathrm{N}^{\circ}$ APTO

BAIRRO CIDADE

CEP: TELEFONE: DDD ( )

2. LEGAL RESPONSÁVEL

NATUREZA (grau de parentesco, tutor, curador e etc.)

SEXO: M( ) F( )

DATA DE NASCIMENTO:

ENDEREÇO:

$\mathrm{N}^{\circ}$ APTO

BAIRRO CIDADE

CEP: TELEFONE 